\title{
5th National Congress of the Italian Society of Physiotherapy
}

Milan, Italy. 3-4 October 2015

Published: 14 October 2016

S1

Criteria for exercises selection in subjects with low back pain

Alessandro Aina (sandroaina@gmail.com)

Physiotherapist, Dip. MDT, private practice, Milan, Italy

Archives of Physiotherapy 2016, 6(Suppl 1):S1

From the '70s until the '90s, in clinical trials aimed at studying the effects of conservative interventions in people with low back pain, participants were randomly allocated to different treatment groups without a preliminary assessment that went beyond symptoms localization. The initial assumption was that patients exhibiting similar symptoms localization should be considered as a unique group. Consequently, the effects of different interventions were similar and guidelines merely suggested "Stay active".

Since the '80s some physiotherapists began to develop a number of evaluation tests in order to identify specific subgroups among people with low back pain and develop targeted treatments for each subgroup. However, in the early 2000s, the Assessment Diagnosis Treatment Outcome (ASTO) model, developed by K. Spratt [1], stated that each step must be validated before proceeding to the next. This talk will:

1. Illustrate the following assessment and classification approaches: A) Mechanical diagnosis and therapy [2], B) Treatment based classification [3], C) Movement system impairment [4], D) Cognitive functional therapy [5], E) Pathoanatomic based classification [6].

2. Provide criteria for the selection of therapeutic exercises.

3. Highlight the possible overlaps and synergies among different approaches [7].

\section{References}

1. Spratt K, Statistical relevance, in Orthopaedic Knowledge Update: Spine 2, e.a. D.F. Fardon, Editors, Editor. 2002, The American Academy of Orthopaedic Surgeons: Rosemont, Illinois, p. 497-505; in Donelson R. Rapidly reversable low back pain. SelfCare First, LLC, Hanover, New Hampshire, First edition, 2007.

2. McKenzie RA, May S. The lumbar spine: mechanical diagnosis and therapy. 2nd edition. Waikanae, New Zealand: Spinal Publications, 2003.

3. Delitto A, et al. A treatment-based classification approach to low back syndrome: identifying and staging patients for conservative treatment. Phys Ther. 1995;75(6):470-489.

4. Sahrmann S. Diagnosis and treatment of movement impairment syndromes. St. Luis, MO: Mosby, Inc., 2002.

5. O'Sullivan P. Diagnosis and classification of chronic low back pain disorders: maladaptive movement and motor control impairment as underlying mechanism. Man Ther. 2005;10(4):242-255.

6. Petersen $\mathrm{T}$, et al. Diagnostic classification of non-specific low back pain. A new system integrating patho-anatomic and clinical categories. Physiother Theory Pract. 2003;19:213-37.

7. Karayannis NV et al., Movement-based subgrouping in low back pain: synergy and divergence in approaches. Physiotherapy. 2015 Jul 3 [Epub ahead of print].
S2

Recent advances in pathophysiology and treatment of myofascial trigger points

Marco Barbero (marco.barbero@supsi.ch)

Rehabilitation Research Laboratory, Department of Business Economics,

Health and Social Care, University of Applied Sciences and Arts of

Southern Switzerland, SUPSI, Manno, Switzerland

Archives of Physiotherapy 2016, 6(Suppl 1):S2

The original and the most commonly accepted definition of myofascial pain syndrome has been formulated by Simons and Travell in the first volume of The Trigger point Manual edited in 1983 [1]. The authors defined the myofascial pain syndromes as a regional pain characterized by the presence of one or more myofascial trigger points (MTrP). A MTrP is a distinctive clinical characteristic of this painful syndrome and it is defined as a hyperirritable palpable nodule contained in the skeletal muscle fibers. It can produce referred pain, either on digital compression or spontaneously. If stimulated with dry needling or snapping palpation it may exhibit a typical muscle fasciculation or jump sign.

The literature suggests that MTrPs are extremely common and can be considered both a primary cause of a MPS or a secondary pain generator in patients affected by a principal musculoskeletal disorder [2]. Before the mid-1990s, key elements regarding the pathophysiology were unrecognized. Subsequently research studies have made the pathophysiology of myofascial pain syndrome much better understood. Three main hypotheses have been provided: energy crisis theory, muscle spindle concept and the motor endplate hypothesis [3]. Additionally, recently Mense et al. presented an integrated hypothesis which is a work in progress and updated as new evidence emerges [4]. This combines recent electrophysiological and histopathological research findings.

Various methods of MTrP treatment are available but currently no clinical guidelines are available and clinicians are required to balance the available evidence, their clinical experience and the patient's preferences. Treatment approaches can be considered as invasive and non-invasive. Dry needling or intramuscular stimulation, is an invasive technique in which a thin needle is used to penetrate the skin and stimulate the MTrP.

The expected therapeutic effect is to release the taut band and reduce the irritability of the spot tenderness. Together with injections (local anaesthetics, steroids, Botulinum toxin A) these are among the most common treatments for myofascial pain syndrome.

Recently dry needling gained popularity among physiotherapists and three systematic reviews on the efficacy have been completed [5-7]. According to the available systematic reviews dry needling should be considered the first choice treatment but due to the small number of high quality trials additional research requires to be undertaken. Non-invasive treatments include various manual techniques such as ischemic compression or manual stretching, and modalities like ultrasound and low-level laser therapy. No systematic reviews are available for these treatments. However, some trials indicated that manual treatment of MTrPs might reduce the pressure pain threshold of spot tenderness and the VAS score $[8,9]$. 


\section{References}

1. Travell JG and Simons DG. Myofascial pain and dysfunction: the trigger point manual. Baltimore; London: Williams \& Wilkins, 1983.

2. Fricton JR. Clinical care for myofascial pain. Dent Clin North Am. 1991;35:1-28.

3. Simons DG. Clinical and etiological update of myofascial pain from trigger points. J Musculoskel Pain. 1996:4:97-125.

4. Mense S, Simons DG and Russell IJ. Muscle pain : understanding its nature, diagnosis, and treatment. Philadelphia: Lippincott Williams \& Wilkins, 2001

5. Cotchett MP, Landorf KB and Munteanu SE. Effectiveness of dry needling and injections of myofascial trigger points associated with plantar heel pain: a systematic review. J Foot Ankle Res. 2010;3:18.

6. Kietrys DM, Palombaro KM, Azzaretto E, Hubler R, Schaller B, Schlussel JM and Tucker M. Effectiveness of Dry Needling for Upper Quarter

Myofascial Pain: A Systematic Review and Meta-analysis. J Orthop Sports Phys Ther. 2013 Sep;43(9):620-34.

7. Tough EA, White AR, Cummings TM, Richards SH and Campbell JL. Acupuncture and dry needling in the management of myofascial trigger point pain: a systematic review and meta-analysis of randomised controlled trials. Eur J Pain. 2009;13(1):3-10.

8. Llamas-Ramos R, Pecos-Martin D, Gallego-Izquierdo T, Llamas-Ramos I, Plaza-Manzano G, Ortega-Santiago R, Cleland J and Fernandez-de-LasPenas C. Comparison of the short-term outcomes between trigger point dry needling and trigger point manual therapy for the management of chronic mechanical neck pain: a randomized clinical trial. J Orthop Sports Phys Ther. 2014;44(11):852-61.

9. Cagnie B, Dewitte V, Coppieters I, Van Oosterwijck J, Cools A and Danneels L. Effect of ischemic compression on trigger points in the neck and shoulder muscles in office workers: a cohort study. J Manipulative Physiol Ther. 2013;36(8):482-9.

\section{S3}

\section{Rehabilitation of scapular dyskinesia}

Barbara Cagnie (barbara.cagnie@ugent.be)

Department of Rehabilitation Sciences and Physiotherapy, Ghent

University, Ghent, Belgium

Archives of Physiotherapy 2016, 6(Suppl 1):S3

In this lecture, based on her previous work, ${ }^{1,2}$ Dr. Cagnie highlights the critical role of the scapula in providing both mobility and stability of the neck/shoulder region and illustrates a science based clinical reasoning algorithm with practical guidelines for the rehabilitation of scapular dyskinesis.

\section{References}

1. Cagnie B, Struyf F, Castelein B, Cools A, Danneels L, O'leary S. The relevance of scapular dysfunction in neck pain: a brief commentary. J Orthop Sports Phys Ther. 2014;44(6):435-9.

2. Cools AM, Struyf F, De Mey K, Maenhout A, Castelein B, Cagnie B. Rehabilitation of scapular dyskinesis: from the office worker to the elite overhead athlete. Br J Sports Med. 2014 Apr;48(8):692-7.

\section{S4.}

\section{Musculoskeletal rehabilitation in subjects affected by neurological} disorders

Elena Castelli (elecaste83@gmail.com)

San Raffaele Scientific Institute and Vita Salute University, Milan, Italy Archives of Physiotherapy 2016, 6(Suppl 1):S4

Few studies considered the manual therapy techniques applied to patients affected by neurological disorders. It is commonly accepted that manual therapy treatments can address and resolve many muscleskeletal pathologies [1] and it is also well know how these conditions may be aggravated by the presence of impairments of neurological nature (patella-femoral joint pain or low back pain in patients with diagnosis of multiple sclerosis [2], shoulder sub-luxation in patients after stroke [3] etc.) but their treatment modality is still uncharted.

After a scientific literature review, 29 articles including 11 RCT about the use of manual techniques, such as spinal and joint manipulation, soft tissue techniques and osteopathic approaches, in patients affected by neurological diseases, have been selected. Overall, the mentioned studies show a poor clinical efficacy of these treatments; these results may be justified by their poor methodological quality assessed by using the Cochrane Scale.

Despite the above background, the aim of our study is to analyze if a manual therapy approach is effective for improving the respiratory mechanics of patients with diagnosis of amyotrophic lateral sclerosis (ALS). Respiratory issues are a common cause of comorbidities and mortality in patients affected by this disease [4]. The decreased patient's breathing capacity is, in part, due to the progressive motoneurons degeneration. The increase of the chest stiffness, because of adaptation of bone and ligament tissues to a prolonged hypomobility, further worsens this clinical presentation of restrictive nature $[5,6]$. Strongly supported clinical procedures are the non-invasive ventilation (NIV), the mechanic inspiration-expiration techniques, the cough assisted techniques and clearance of the respiratory secretions [7]. Based on our knowledge no articles so far investigated the efficacy of manual techniques applied on the spinal thoracic joints with the aim to reduce the stiffness around this anatomical area with the final goal to improve the breathing capacity. This modality of treatment has already been studied in patients affected by chronic obstructive pulmonary disease [5].

Some preliminary results of a single-center randomized controlled pilot study are presented. At present 18 subjects have been recruited and randomized either in the experimental group or control group. All subjects received 2 daily sessions of conventional physiotherapy; each session lasted for 1 hour. In addition, the subjects of the experimental group were treated with manual techniques for 30 minutes daily for 10 days. Data of breathing capacity, functional vital capacity (FVC) and peak-cough expiratory flow (PCF) were recorded before the first treatment and immediately after the last one. Differences pre-post intervention were analyzed within the same group and between groups.

The two groups were homogeneous at baseline. The statistical analysis conducted showed a statistically significant change in FVC in the experimental group after the first treatment of thoracic mobilization $(p=0,012)$. Moreover, changes in the experimental group were significantly higher $(p=0.01)$ than in the controls. If these data will be confirmed, additional treatment based on mobilization of the thoracic spine maybe useful in the management of respiratory impairments in this population of patients.

\section{References}

1. Bialosky JE, Bishop MD, Price DD, Robinson ME, George SZ. The Mechanisms of Manual Therapy in the Treatment of Musculoskeletal Pain: A Comprehensive Model. Man Ther. 2009 14(5):531-8.

2. Pöllmann W, Feneberg W. Current management of pain associated with multiple sclerosis. CNS Drugs. 2008;22(4):291-324

3. Paci $M$, Nannetti L, Rinaldi L. Glenohumeral subluxation in hemiplegic: an overview. J Rehabil Res Dev. 2005 Jul-Aug;42(4):557-6.

4. Kurian KM, Forbes RB, Colville S, Swingler RJ. Cause of death and clinical grading criteria in a cohort of amyotrophic lateral sclerosis cases undergoing autopsy from the Scottish Motor Neurone Disease Register. J Neurol Neurosurg Psychiatry 2009;80(1):84-7

5. Heneghan NR, Adab P, Balanos GM, Jordan RE. Manual therapy for chronic obstructive airways disease: a systematic review of current evidence. Man Ther. 2012;17(6):507-18.

6. Maclay JD, McAllister DA, Rabinovich R, Haq I, Maxwell S, Hartland S, Connell M, Murchison JT, van Beek E, Gray RD, Mills NL, Macnee W. Systemic elastin degradation in chronic obstructive pulmonary disease. Thorax. 2012;67(7):606-12

7. Kirsten L. G, Noah L. Respiratory therapies for amyotrophic latera sclerosis: a primer. Muscle \& Nerve 2012;46(3):313-331.

S5

Which examination tests suggest the best candidates for manual therapy

Chad Cook (chad.cook@duke.ed)

Division of Physical Therapy, Duke University, NC USA

Archives of Physiotherapy 2016, 6(Suppl 1):S5

It has been assumed that one determines a patient is a candidate for manual therapy during a clinical examination, and that the findings are specific for the demand of a manual therapy intervention. Traditionally, this process (determining candidacy for manual therapy) 
has been associated with conclusions from the physical examination. For example, findings such as positional faults, abnormal movement patterns, and range of motion loss during movement, all identified during the physical examination are suggested triggers for manual therapy use. In reality, this concept has been woefully understudied and may or may not yield value when determining manual therapy candidacy. Three general philosophies have been advocated: 1) Biomechanical assumptions (coupling, stiffness, restrictions, patterns of pain, etc.), 2) Regression based assumptions (modeling and use of clinical prediction rules), and 3) Within and between-session changes (from patient response). Of the three concepts, identifying change (within but mostly, between session) during the clinical physical examination has provided the greatest amount of evidence in support but fails to truly determine if someone could also benefit from an alternative intervention. This platform discusses the present state of literature associating physical examination testing and manual therapy outcomes and discusses the future needs for improved evidence.

\section{References}

1. Thiel HW, Bolton JE. Predictors for immediate and global responses to chiropractic manipulation of the cervical spine. J Manipulative Physiol Ther. 2008;31(3):172-83.

2. Garrison JC, Shanley E, Thigpen C, Hegedus E, Cook C. Between-session changes predict overall perception of improvement but not functional improvement in patients with shoulder impingement syndrome seen for physical therapy: an observational study. Physiother Theory Pract. 2011;27(2):137-45.

3. Hahne AJ, Keating $\mathrm{J}$, Wilson SC. Do within-session changes in pain intensity and range of motion predict between-session changes in patients with low back pain? Aust J Physiother. 2004;50(1):17-23.

4. Tuttle N. Do changes within a manual therapy treatment session predict between-session changes for patients with cervical spine pain? Aust J Physiother 2005;51(1):43-8.

5. Tuttle N, Laasko L, Barrett R. Change in impairments in the first two treatments predicts outcome in impairments, but not in activity limitations, in subacute neck pain: an observational study. Aust J Physiother 2006;52(4):281-5.

6. Tuttle N. Is it reasonable to use an individual patient's progress after treatment as a guide to ongoing clinical reasoning? J Manipulative Physiol Ther. 2009;32(5):396-403.

7. Wright AA, Abbott JH, Baxter D, Cook C. The ability of a sustained withinsession finding of pain reduction during traction to dictate improved outcomes from a manual therapy approach on patients with osteoarthritis of the hip. J Man Manip Ther 2010;18(3):166-72.

8. Saavedra-Hernandez M, Castro-Sánchez AM, Fernández-de-Las-Peñas C, Cleland JA, Ortega-Santiago R, Arroyo-Morales M. Predictors for identifying patients with mechanical neck pain who are likely to achieve shortterm success with manipulative interventions directed at the cervical and thoracic spine. J Manipulative Physiol Ther. 2011;34(3):144-52.

9. Cook C, Lawrence J, Michalak K, Dhiraprasiddhi S, Donaldson M, Petersen $\mathrm{S}$, Learman $\mathrm{K}$. Is there preliminary value to a within- and/or betweensession change for determining short-term outcomes of manual therapy on mechanical neck pain? J Man Manip Ther. 2014;22(4):173-80.

10. Cook C, Showalter C, Kabbaz V, O'Halloron B. Can a within/betweensession change in pain during reassessment predict outcome using a manual therapy intervention in patients with mechanical low back pain? Man Ther. 2012;17(4):325-9.

\section{S6}

Case study: the role of the measurements for the identification of targets and guidance of the treatment

Silvano Ferrari (silvano.ferrari@fastwebnet.it)

Master of Manual Therapy and Musculoskeletal Rehabilitation, Molecular Medicine, Department of Human Anatomy, University of Padova, Padova, Italy Archives of Physiotherapy 2016, 6(Suppl 1):S6

In this report will be discussed the outcome used in the treatment of patients with symptomatic lumbar isthmic spondylolisthesis (SPL) in a case series submitted to be published [1]. The aim of this case series was to show a model of physical therapy treatment targeted to improving pain self-efficacy (PSE) in ten chronic SPL patients and display possible relationships between clinical changes, pain and disability.
PSE is considered a relevant mediator in the relationship between pain and disability in chronic lower back pain (LBP) [2]. The various outcomes employed were questionnaires and physical clinical tests. The questionnaires used were the Oswestry Disability Index (ODI-I) to measure disability [3], the 0/10 Numerical Rating Scale (NRS) to measure pain [4] and the Pain Self Efficacy Questionnaire (PSEQ-I) to measure personal belief about how successfully one can cope with difficult painful situations [5]. The choice of these outcomes has been achieved with the knowledge of their psychometric properties (internal consistency, reproducibility, validity and sensibility in detecting clinical changes after conservative treatment for subacute and chronic LBP) and validity in Italian language.

The physical clinical tests used to detect segmental lumbar instability were the Aberrant Movements test (AMs) (Fig. 1) and the Passive Lumbar Extension test (PLE) (Fig. 2). The Active Straight Leg Raise (ASLR) was performed to assess lumbo-pelvic motor control, and the Supine Bridge Test (SBT) (Fig. 3) was performed to measure lumbar muscles endurance. The choice of these outcomes has been made because these clinical tests have been used and their validity investigated in previous studies in SLP patients [6-7].

Cognitive and behavioural principles were integrated in each individual program and a functional and graded approach was performed to increase the activity level and improve strength, endurance, range of motion, balance, coordination and self-efficacy.

To determine whether the main goals were achieved, we considered as Minimal Clinically Important Difference (MCID) results at least 2 points score reduction for NRS, 10 points score reduction for ODI-I [8] and a score improvement of at least 11 for PSEQ-I [9]. We considered a patient definitely improved when all MCID were attained, partially improved when at least two MCID were attained, and notimproved when only one or no MCID was attained. Concerning instability and endurance clinical tests (secondary goals), we considered a patient definitely improved when all instability tests were negative and SBT reached a score higher than 170 seconds (mean duration in asymptomatic people) [10].

At the end of the treatment, 7 out of 10 patients were considered definitely or partially improved, according to pain, disability and selfefficacy. In any case, PSE was the most improved domain and always related to significant disability reduction. Clinical improvement appeared coherent with instability and endurance test changes ( 9 out of 10 patients improved).

Take home suggestions: the validity and responsiveness of the outcomes must be known. To have objective data reflecting changes that are meaningful for the patient after a clinical intervention, it is basic for physiotherapists when determining the patient's response to treatment and to guide clinical decision-making during the course of treatment.

Consent for publication

The authors have written informed consent from the people in Figs. 1, 2 and 3 , and consent to publish the photographs. The relevant documents can be provided on request.

\section{References}

1. Ferrari S, Vanti C, Costa F, Fornari M. Can Physical Therapy improve Pain Self-Efficacy in symptomatic lumbar isthmic spondylolisthesis? A case series. Disabil Rehabil. (submitted)

2. Foster NE, Thomas E, Bishop A, Dunn KM, Main CJ. Distinctiveness of psychological obstacles to recovery in low back pain patients in primary care. Pain. 2010:148(3):398-406

3. Monticone $M$, Baiardi $P$, Ferrari S, Foti $C$, Mugnai $R$, Pillastrini $P$, Vanti $C$, Zanoli G. Development of the Italian version of the Oswestry Disability Index (ODI-I): A cross-cultural adaptation, reliability, and validity study. Spine. 2009;34(19):2090-5

4. Hjermstad MJ, Fayers PM, Haugen DF, Caraceni A, Hanks GW, Loge JH, Fainsinger R, Aass N, Kaasa S. Studies comparing Numerical Rating Scales, Verbal Rating Scales, and Visual Analogue Scales for assessment of pain intensity in adults: a systematic literature review. J Pain Symptom Manage. 2011;41(6):1073-93.

5. Chiarotto A, Vanti C, Ostelo RW, Ferrari S, Tedesco G, Pillastrini P, Monticone M. The Pain Self-Efficacy Questionnaire: Cross-Cultural Adaptation into Italian and Assessment of Its Measurement Properties. Pain Pract. 2015 Nov;15(8):738-47. 
6. Ferrari S, Vanti C, O'Reilly C. Clinical Presentation and Physiotherapy Treatment in patients with Isthmic Spondylolisthesis. Report on four cases. J Chiropr Med. 2012;11(2)94-103.

7. Ferrari S, Vanti C, Picarreta R, Monticone M. Pain, Disability and diagnostic accuracy of clinical instability and endurance tests in subjects with lumbar spondylolisthesis. J Manipulative Physiol Ther. 2014;37(9):647-659.

8. Ostelo R, Deyo R, Stratford P, Waddell G, Croft P, Von Korff M, Bouter LM de Vet HC. Interpreting change scores for pain and functional status in low back pain. Spine. 2008:33:90-94.

9. Maughan EF, Lewis JS. Outcome measures in chronic low back pain. Eur Spine J. 2010 19:1484-1494.

10. Schellenberg KL, Lang JM, Chan KM, Burnham RS. A clinical tool for office assessment of lumbar spine stabilization endurance: prone and supine bridge maneuvers. Am J Phys Med Rehabil. 2007;86:380-6.

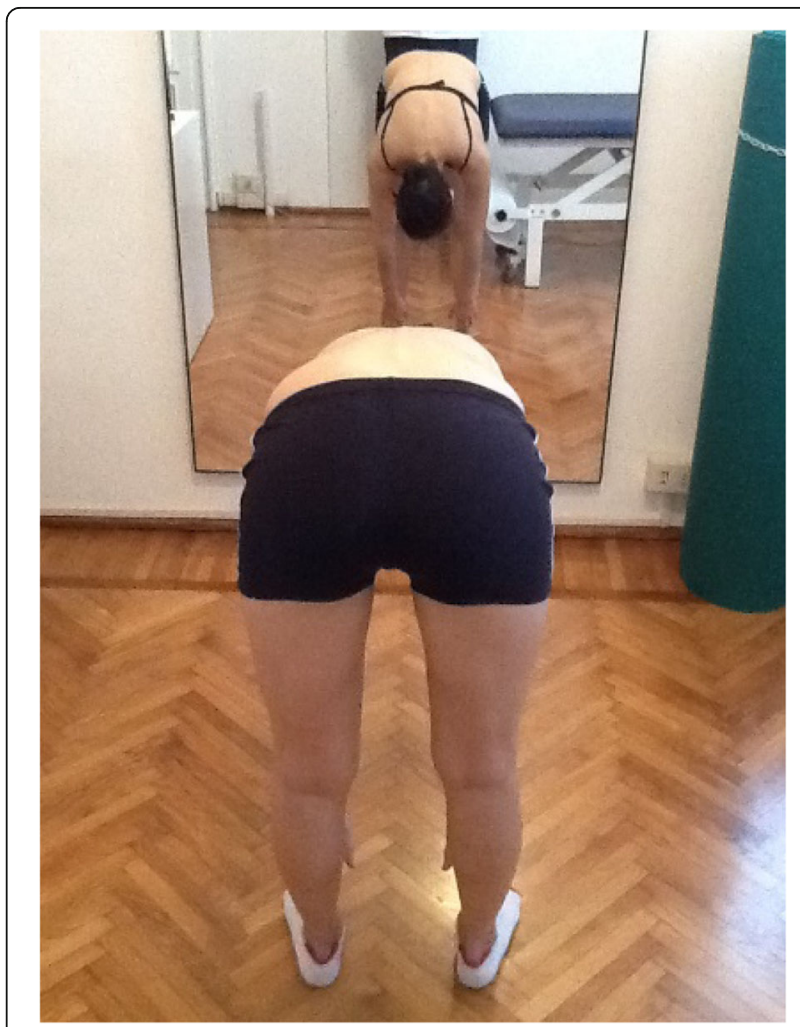

Fig. 1 (abstract S6) Aberrant Movements

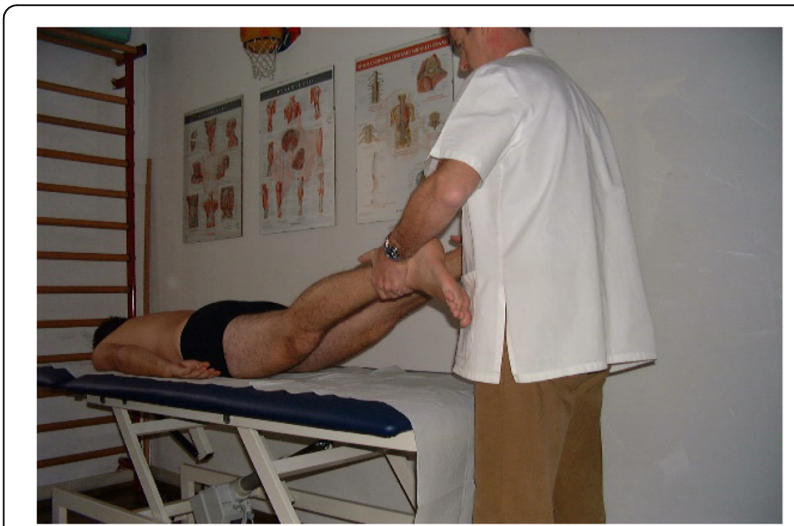

Fig. 2 (abstract S6) Passive Lumbar Extension test

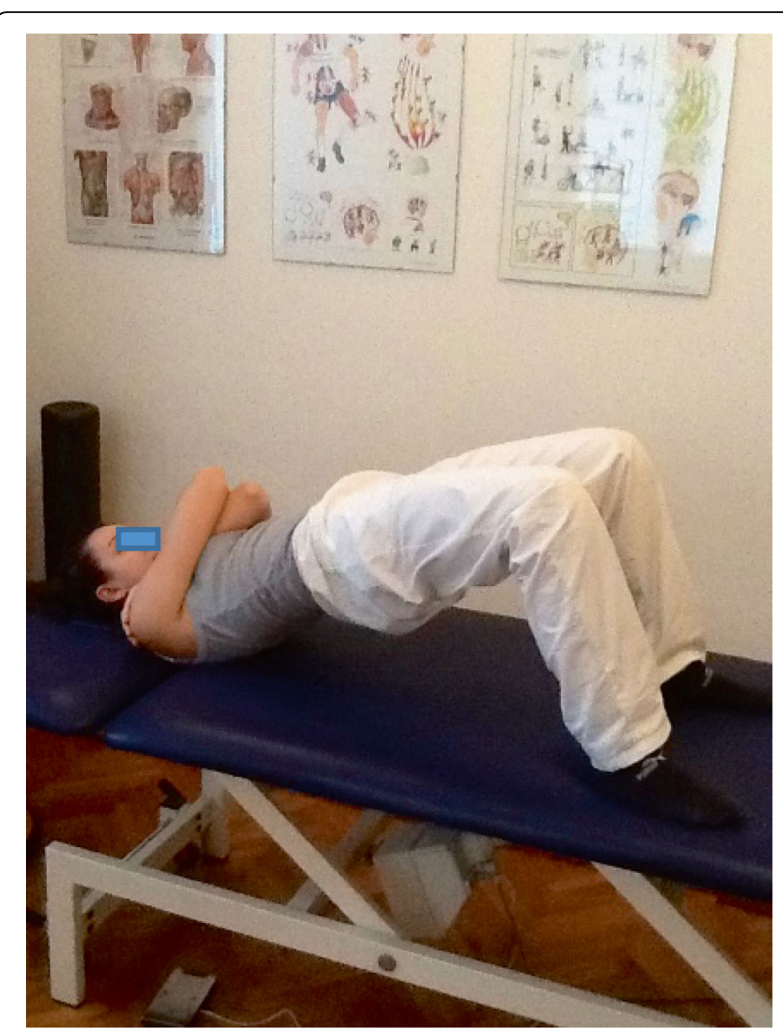

Fig. 3 (abstract S6) Supine Bridge test

S7

Assessment of joint mobility: state of the art

Andrea Foglia, Paolo Bizzarri

Physiotherapists, Orthopaedic Manual Therapists (OMT), Private practitioners, Civitanova Marche

Correspondence: Andrea Foglia (andreafoglia@hrrgroup.org) -

Physiotherapists, Orthopaedic Manual Therapists (OMT), Private practitioners, Civitanova Marche

Archives of Physiotherapy 2016, 6(Suppl 1):S7

More than $90 \%$ of the general population will experience at least a musculoskeletal disorder during their lifetime. These types of joint disorders are often characterized by multiple clinical findings, in particular pain and reduction of joint range of motion (ROM). In such a physical therapy setting where the sole radiological investigations and the medical diagnosis are often not enough to assess the patient's health status, the need to develop new procedures aimed at defining and documenting the patient's health status and his/her clinical course has brought about an increasing interest in this issue. Over the last years the main focus has been on establishing and on validating new tools to assess the joint mobility. Although some of the procedures have had a positive effect on the clinical setting, the proposed assessment tools were often correct from a biomechanical and methodological standpoint, but poorly applicable in the clinical practice. Moreover, such measurements have often proved partial according to an idea based on the biopsycosocial model (International Classification of Functioning, Disability and Health - ICF), where the clinical significance of joint mobility data directly depends on its relation with the person's reduced activity and participation. Therefore, in this setting it is possible to speak of functional range of motion (functional ROM).

This presentation aims at describing our approach to the assessment of the functional ROM, applicable to the clinical setting. This approach is based on the best evidence available in the literature and it is also based on four crucial steps: medical case history, visual inspection/observation, manual mobility testing, self-reported measures. 


\section{References}

1. Zeni JA Jr, Axe MJ, Snyder Mackler L. Clinical predictors of elective total joint replacement in persons with end-stage knee osteoarthritis. BMC Musculoskelet Disord. 2010 May 6;11:86.

2. Lentz TA, Sutton Z, Greenberg S, Bishop MD. Pain-related fear contributes to self-reported disability in patients with foot and ankle pathology. Arch Phys Med Rehabil. 2010 Apr;91(4):557-61.

3. De Smet L. Does restricted wrist motion influence the disability of the upper limb? Acta Orthop Belg. 2007 Aug;73(4):446-50.

4. Post RB, Leferink VJ. Sagittal range of motion after a spinal fracture: does ROM correlate with functional outcome? Eur Spine J. 2004 Oct;13(6):489-94.

5. Ballinger DA, Rintala DH, Hart KA. The relation of shoulder pain and range of motion problems to functional limitations, disability, and perceived health of men with spinal cord injury: a multifaceted longitudinal study. Arch Phys Med Rehabil. 2000 Dec;81(12):1575-81.

6. Wright CJ, Arnold BL, Ross SE, Ketchum J, Ericksen J, Pidcoe P. Clinical examination results in individuals with functional ankle instability and ankle-sprain copers. J Athl Train. 2013 Sep-Oct;48(5):581-9.

7. Wylde V, Lenguerrand E, Brunton L, Dieppe P, Gooberman-Hill R, Mann C, Blom AW. Does measuring the range of motion of the hip and knee add to the assessment of disability in people undergoing joint replacement? Orthop Traumatol Surg Res. 2014 Apr;100(2):183-6.

8. Ruiz FK, Bohl DD, Webb ML, Russo GS, Grauer JN. Oswestry Disability Index is a better indicator of lumbar motion than the Visual Analogue Scale. Spine J. 2014 Sep 1;14(9):1860-5.

9. Dixon D, Johnston M, McQueen M, Court-Brown C. The Disabilities of the Arm, Shoulder and Hand Questionnaire (DASH) can measure the impairment, activity limitations and participation restriction constructs from the International Classification of Functioning, Disability and Health (ICF). BMC Musculoskelet Disord. 2008 Aug 20;9:114.

10. Roe Y, Lundegaard Soberg H, Bautz-Holter E, Ostensjo S. A systematic review of measures of shoulder pain and functioning using the International classification of functioning, disability and health (ICF). BMC Musculoskelet Disor. 2013, 14:73.

\section{S8}

\section{Core stabilization exercises in the treatment of urinary} incontinence

Donatella Giraudo (giraudo.donatella@hsr.it)

San Raffaele Turro Hospital, Milan, Italy

Archives of Physiotherapy 2016, 6(Suppl 1):S8

The functional relationship between the respiratory diaphragm, the abdominal muscles and the pelvic floor is well-established: the latter represents the connective element between the abdominal cavity and the lower limbs, and a correct postural relationship between these two - the abdominal cavity and the thoracic cavity - ensures optimum volume of the "core", optimizing abdominal-pelvic function.

Control of the contraction of the pelvic floor, which if attained automatically on the increase of intraabdominal pressure occurs prior to the contraction of the abdominal wall muscles, is a mechanism preventing the onset of stress urinary incontinence and prolapse. Together with the stabilizing action provided by the transverse abdominal muscle, the pelvic floor and the diaphragm, the posterior muscles of the spine also contribute to stabilization of the "core", thus counteracting possible destabilization caused by dysfunction.

Many actions which involve the pelvic floor (defecation, urination, pregnancy and childbirth) pose a hazard due to the increase in intraabdominal pressure, which must be countered with an appropriate breathing pattern and rhythm; simultaneously, the moderate contraction of the abdominal wall directs expiratory pressure towards the glottis and not towards the pelvic floor. On the increase of intraabdominal pressure, contraction of the pelvic floor allows the correct position of the ureterovesical junction to be maintained and, together with the counterthrust provided by the intact fascial system, the development of forces which contribute to the increase in urethral pressure.

The contraction of the pelvic floor, in turn, affects the contraction of the abdominal muscles. The role played by the transverse abdominal muscle is greater if the spine is extended, while the role of the external abdominal oblique muscle is greater when the spine is bent. These close relationships between the walls of the abdominal cavity explain the relationships observed between stress urinary incontinence, faecal incontinence, lumbago and changes in respiratory rate. The sacroiliac joint (SIJ) dysfunction also interferes with the stability system of the trunk. Urinary urge incontinence has been reported in this condition, and resolved when the SIJ pain was relieved.

\section{References}

1. Portillo F, Grelot L, Milano S, et al. Brainstem neurons with projecting axons to both phrenic and abdominal motor nuclei: a double fluorescent labeling study in the cat. Neurosci Lett. 1994;173:50-4.

2. De Troyer A. Mechanical role of the abdominal muscles in relation to posture. Respir Physiol. 1983;53:341-53.

3. Constantinou C, Govan D. Contribution and timing of transmitted and generated pressure components in the female urethra. In: 'Female Incontinence', 1981, Allan R. Liss Inc., New York.

4. Neumann P, Gill V. Pelvic floor and abdominal muscle interaction: EMG activity and intra-abdominal pressure. Int Urogynecol Pelvic Floor Dysfunct. 2002;13:125-32.

5. Sapsford R, Hodges P. Contraction of the pelvic floor muscles during abdominal maneuvers. Arch Phys Med Rehabil. 2001;82(8):1081-8.

6. Junginger B, Baessler L, Sapsford R. Effect of abdominal and pelvic floor tasks on muscle activity, abdominal pressure and bladder neck. Int Urogynecol J. 2010;21(1):69-77.

7. Smith M, Russell A, Hodges P. Do incontinence, breathing difficulties, and gastrointestinal symptoms increase the risk of future back pain? J Pain. 2009;10(8):876-86

8. Hodges $P$, Richardson C. Inefficient muscular stabilization of the lumbar spine associated with low back pain. Spine (Phila Pa 1976). 1996;21:2640-50.

9. Eisenstein S, Engelbrecht D, El Masry W. Low back pain and urinary incontinence. Spine (Phila Pa 1976). 1994;19:1148-52

10. O'Sullivan P, Beales D, Avery A. Normalisation of aberrant motor patterns in subjects with sacroiliac joint pain following a motor relearning intervention: a multiple subject case study investigating the ASLR test. Fourth Interdisciplinary World Congress on Low Back and Pelvic Pain, Montreal, 2001.

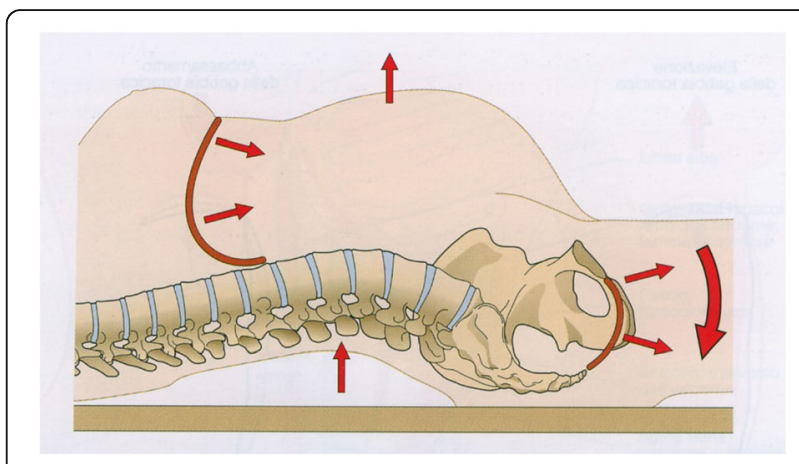

Fig. 4 (abstract S8) Relationship between respiratory diaphragm, abdominal wall, pelvic floor muscles and rachis in incorrect expiratory pattern with incompetence of abdominal wall

S9

Preventing surgical subacromial decompression through rotator cuff rehabilitation

Chris Littlewood (c.littlewood@sheffield.ac.uk)

University of Sheffield, Sheffield, UK

Archives of Physiotherapy 2016, 6(Suppl 1):\$9

Shoulder pain is one of the most common musculoskeletal symptoms and subacromial impingement syndrome and its various synonyms including rotator cuff tendinopathy, subacromial pain etc. are widely regarded as the most common cause. 
There are a range of treatment options available, both conservative and surgical. In recent years the number of subacromial decompressions, a widely used surgical treatment approach for this condition, has risen exponentially. But why is this?

Conservative treatment approaches, particularly exercise, are widely regarded as effective interventions for this type of mechanical shoulder pain. Recent studies have shown that such conservative approaches are comparable to surgical interventions. Also, patients on a surgical waiting list who undertake a structured exercise programme might respond sufficiently to elect not to have the operation. So, it seems that if all patients are exposed to a structured exercise programme prior to being considered for surgery then a good proportion will not require such invasive intervention. But, if conservative treatment is at least as good as operative treatment then why are we even bothering to consider surgery at all considering that it is a more invasive, risky and expensive procedure than conservative care?

Such a question can only be addressed by posing another question; if conservative treatment 'fails', what then?

This talk will cover the research in relation to the effectiveness of different treatment approaches for subacromial impingement syndrome (mechanical shoulder pain without movement restriction) before considering the principles that physiotherapists should follow when designing rehabilitation programmes for their patients with the aim of maximising clinical outcome and reducing the need for surgery.

\section{S10}

\section{Methodological aspects of Clinical Prediction Rules in the} rehabilitation of Low Back Pain

Paolo Pillastrini (paolo.pillastrini@unibo.it)

Department of Biomedical and Neuromotor Sciences, University of Bologna, Bologna, Italy

Archives of Physiotherapy 2016, 6(Suppl 1):S10

Clinical Prediction Rule (CPR) is a tool to assist the process of classification and improve clinical decision making, using the evidence to determine which patients will more easily benefit from a specific treatment strategy. Depending on the model proposed by McGinn, development and evaluation of CPR is done through a process divided into three phases: Derivation of CPR, Validation of CPR, CPR Impact Assessment on the clinical behavior.

There are diagnostic and therapeutic CPR.

Diagnostic CPRS

Robin Haskins, in his scientific research titled "Diagnostic clinical prediction rules for specific subtypes of low back pain: A systematic review", presented a review of the main diagnostic CPR published. The search found that 13 diagnostic CPRS for LBP have been derived. One that assists in the identification of lumbar spinal stenosis, and 2 which assist in the screening of inflammatory back pain have undergone validation. No impact analysis studies were identified. Most diagnostic CPRS for LBP are in their initial development phase and cannot be recommended for use in clinical practice at this time. Therapeutic CPRS

The therapeutic CPRS in LBP have been defined for the first time in 2007 by Julie Fritz, when she presented a Clinical Commentary in which, from the classification of Crime of 2005, she sought to better define the 4 subgroups, describing for each of them the state of the art with respect to the effectiveness of the therapeutic procedures adopted.

CPR 1- Group Manipulation - No symptoms below the knee; onset of recent ( $<16$ days); low score to FABQ-W (Fear-Avoidance Beliefs Questionnaire-Work Subscale) $(<19)$; hypomobility lumbar spine (evaluated with the Spring test); ROM of internal rotation of the hip greater than $35^{\circ}$ in at least one hip joint.

CPR 2 - Group stabilization - The most important variables were: age, straight-leg raise, prone instability test, aberrant motions, lumbar hypermobility, and fear-avoidance beliefs. Basically, they found: age younger than 40; average SLR> $91^{\circ}$; aberrant trunk movement present; prone instability test positive.

CPR 3 - Group specific exercises - They were rated according to McKenzie's approach, who identified as more appropriate intervention one in which repetitive movements in a specific direction have the effect of reducing pain and symptoms. The most important symptom is considered the centralization of pain. The group is made up of specific exercises: Group Extension (symptoms more distal buttock; symptoms that centralize extension lumbar; symptoms periferalization during lumbar bending; directional preference: extension); Group Flexion [age not younger ( $>50$ years); directional preference: bending; positive imaging for lumbar stenosis]; Group Lateral Shift (visible deviation of the shoulders than the pelvis in the frontal plane; directional preference: shifting motions of the pelvis in the frontal plane).

CPR 4 - Group Traction - Signs and symptoms of compression to the nerve root; no movement which centralizes the symptoms.

Based on all the above considerations, it can be helpful to develop an algorithm with some therapeutic indications to help guide the clinician in the process of decision-making in LBP.

\section{References}

1. Currier LL, Froehlich PJ, Carow SD, McAndrew RK, Cliborne AV, Boyles RE, Mansfield LT, Wainner RS. Development of a clinical prediction rule to identify patients with knee pain and clinical evidence of knee osteoarthritis who demonstrate a favorable short-term response to hip mobilization. Phys Ther. 2007 Sep;87(9):1106-19.

2. Delitto A, Erhard RE, Bowling RW. A treatment-based classification approach to low back syndrome: identifying and staging patients for conservative treatment. Phys Ther. 1995 Jun;75(6):470-85.

3. Fritz JM, Cleland JA, Childs JD. Subgrouping patients with low back pain: evolution of a classification approach to physical therapy. J Orthop Sports Phys Ther. 2007 Jun;37(6):290-302. Review. Erratum in: J Orthop Sports Phys Ther. 2007 Dec;37(12):769.

4. Haskins R, Osmotherly PG, Rivett DA. Diagnostic clinical prediction rules for specific subtypes of low back pain: a systematic review. J Orthop Sports Phys Ther. 2015 Feb;45(2):61-76, A1-4

5. McGinn TG, Guyatt GH, Wyer PC, Naylor CD, Stiell IG, Richardson WS Users' guides to the medical literature: XXII: how to use articles about clinical decision rules. Evidence-Based Medicine Working Group JAMA. 2000 Jul 5;284(1):79-84.

6. Sutlive TG, Lopez HP, Schnitker DE, Yawn SE, Halle RJ, Mansfield LT, Boyles RE, Childs JD. Development of a clinical prediction rule for diagnosing hip osteoarthritis in individuals with unilateral hip pain. J Orthop Sports Phys Ther. 2008 Sep;38(9):542-50.

7. Vicenzino B, Smith D, Cleland J, Bisset L. Development of a clinical prediction rule to identify initial responders to mobilisation with movement and exercise for lateral epicondylalgia. Man Ther. 2009 Oct;14(5):550-4.

8. Wainner RS, Fritz JM, Irrgang JJ, Delitto A, Allison S, Boninger ML. Development of a clinical prediction rule for the diagnosis of carpal tunnel syndrome. Arch Phys Med Rehabil. 2005 Apr;86(4):609-18.

S11

Interpretability of outcome measures in musculoskeletal rehabilitation

Daniele Piscitelli (danypisci@yahoo.it)

Ph.D. Candidate in Neuroscience, Department of Translational Medicine and Surgery, University of Milano-Bicocca, Milano, Italy

Archives of Physiotherapy 2016, 6(Suppl 1):S11

A health outcome measure has been described as a measure of health change, at a defined time, as a result of one or more health care processes [1]. In order to identify relevant problems directly from patients, rehabilitation clinicians and researchers need to assess patient-reported outcomes that may not be directly measurable; for example, disability, quality of life, satisfaction, or pain intensity. The International Classification of Functioning, Disability and Health (ICF) framework catalogues these features, consequently the assessment can be performed at different levels including body functions and structures, activities and participation. The majority of outcome related to activity limitations and participation restrictions are often measured indirectly by their manifestations and are referred to as "latent variables", "latent traits" or "constructs" [2]. Therefore, we need to transform the manifestations of these "latent" variables into 
numbers using questionnaire or scale. Such patient-reported outcomes (PRO) can be taken as measurements, and the assessment of the psychometric properties of these instruments is crucial. Clinicians need to be aware of the characteristics of outcome measures to select the appropriate one and interpret correctly the results. In the psychometric field has been proposed two main test theories [1]: the classical test theory (CTT) and item response theory (IRT). Recently, an international Delphi study has proposed a Consensusbased Standards for the selection of health Measurement Instruments (COSMIN) [3] aimed at providing a taxonomy of psychometric properties, pointing out the measurement properties of PRO instruments assessed by CTT and IRT methods. COSMIN distinguished three domains: reliability, validity, and responsiveness. Reliability had three measurement properties: internal consistency, reliability, and measurement error. Validity had three measurement properties: content validity, criterion validity and construct validity. The last domain included only one property, the responsiveness.

The interpretability was not taken into account as a measurement property, but it was considered an important characteristic of a measurement instrument. It was defined as "the degree to which one can assign qualitative meaning to an instrument's quantitative scores or change in scores" [4]. The meaning of the results must be interpreted carefully. Indeed, the predominant types of outcomes measure are ordinal scale. In PRO tools, by definition, the intervals between categories are separated by unknown quantities, and conclusions may, therefore, be misleading; e.g., the calculation of minimal (clinically) important differences is compromised by the lack of interval scaling [5]. IRT models such Rasch analysis (RA) [6] allow a transformation of the ordinal score into a linear, interval scores because with Rasch transformation the location of items, as well as patients, are presented on the same scale [7].

A proper knowledge of the above-citied measurement properties is a prerequisite for use tool in clinical practice and research in order to prevent inappropriate conclusion and to improve clinical decision making process [8].

\section{References}

1. Streiner DL, Norman GR. Health measurement scales : a practical guide to their development and use (4th ed.). Oxford; New York: Oxford University Press, 2008.

2. Tesio L. Measuring behaviours and perceptions: Rasch analysis as a tool for rehabilitation research. J Rehabil Med. 2003; 35(3):105-115.

3. Mokkink LB, Terwee CB, Patrick DL, Alonso J, Stratford PW, Knol DL, et al. The COSMIN study reached international consensus on taxonomy, terminology, and definitions of measurement properties for healthrelated patient-reported outcomes. J Clin Epidemiol. 2010; 63(7):737-745.

4. Terwee $C B$, Bot SD, de Boer MR, van der Windt DA, Knol DL, Dekker J, et al. Quality criteria were proposed for measurement properties of health status questionnaires. J Clin Epidemiol. 2007; 60(1):34-42.

5. Doganay Erdogan B, Leung YY, Pohl C, Tennant A, Conaghan PG Minimal Clinically Important Difference as Applied in Rheumatology: An OMERACT Rasch Working Group Systematic Review and Critique. J Rheumatol. 2016 Jan;43(1):194-202.

6. Tennant A, Conaghan PG. The Rasch measurement model in rheumatology: what is it and why use it? When should it be applied, and what should one look for in a Rasch paper? Arthritis Rheum. 2007; 57(8):1358-1362.

7. Meroni R, Piscitelli D, Bonetti F, Zambaldi M, Cerri CG, Guccione AA. et al. Rasch Analysis of the Italian version of Pain Catastrophizing Scale (PCS-I). J Back Musculoskelet Rehabil. 2015 Dec 2;28(4):661-73.

8. Black N. Patient reported outcome measures could help transform healthcare. BMJ. 2013 Jan 28; 346, f167.

\section{$\mathrm{S} 12$}

Conservative treatment of the misalignment of the spine: state of the art and perspectives

Michele Romano (michele.romano@isico.it)

ISICO, Istituto Scientifico Italiano Colonna Vertebrale, Milan, Italy

Archives of Physiotherapy 2016, 6(Suppl 1):S12

The biggest problem in the treatment of a patient with idiopathic scoliosis is the impossibility of working directly on the cause of the problem, which remains unknown. Each type of surgical, orthotic or exercise-based treatment must act exclusively upon the effects of the disease and thus minimize them.

Focusing the reasoning on the conservative treatment approaches, the first concept to convey is that, until today, the only reliable strategies are the brace and the specific exercises. The use of alternative treatment approaches such as dental bite, heel lift, electrical stimulation, manual approach [1] or food tips have never been shown able to modify the natural history of the disease.

Typically, all over the world, excluding Europe, the most accepted therapeutic approach for the treatment of a vertebral misalignment was the surgery and the conservative treatment has almost always been considered if not harmful, at least useless. This is due to the scarcity of experimental trials that had been published until then. In the recent years the situation changed allowing the development of two Cochrane Reviews: one consacreted on Scoliosis and Brace [2] and the second one on Scoliosis and Specific Exercises [3]. It has just been released an update of The Cochrane Review on braces with the conclusions absolutely in favour of the effectiveness of this tool, contrary to what is always said by the SRS (Scoliosis Research Society), the American association of spine surgeons specialized in spine surgery for scoliosis disease. A decisive blow to the absolute conviction of the surgeons had already been inflicted by the publication of the article "Effects of Bracing with Idiopathic Scoliosis in Adolescents", [4] a RCT of 2013, led by the SRS that compared the results of two groups of patients: one group treated with brace and control group, to test the effectiveness of the brace to lower the risk of surgery. The first follow up, absolutely in favour of the brace, has prompted the ethics committee to modify the research, stopping the randomization of patients based on the effectiveness of one comparative protocol.

Another review on Scoliosis and Specific Exercises has been published. The conclusion was that the evidence for the effectiveness of the exercises as a treatment are too weak. As for the Cochrane Review concerning the brace, it is also expected an update of this paper. Considering the items that will be introduced in the new version, the conclusions will definitely increase the demonstrable effectiveness of this approach for the treatment of scoliosis. Worldwide, the methods for scoliosis treatment based on specific exercises that have proven effectiveness, with the publication of some articles are very few and are little known in Italy, with the exception of the SEAS. One of the most interesting treatment strategies for the future consists in the integration of self-correction in the activities of daily life, to train an effective contrast to the vicious circle of Stokes [5], representing the linked correlation between the progressive worsening of the curves and the vertebrae deformation.

\section{References}

1. Romano M, Negrini S. Manual therapy as a conservative treatment for adolescent idiopathic scoliosis: a systematic review. Scoliosis. 2008 Jan $22 ; 3: 2$.

2. Negrini S, Minozzi S, Bettany-Saltikov J, Chockalingam N, Grivas TB, Kotwicki T, Maruyama T, Romano M, Zaina F. Braces for idiopathic scoliosis in adolescents. Cochrane Database Syst Rev. 2015 Jun 18; 6.

3. Romano M, Minozzi S, Bettany-Saltikov J, Zaina F, Chockalingam N, Kotwicki T, Maier-Hennes A, Negrini S Exercises for adolescent idiopathic scoliosis. Cochrane Database Syst Rev. 2012 Aug 15;8

4. Dolan LA, Wright JG, Weinstein SL. Effects of bracing in adolescents with idiopathic scoliosis. Engl J Med. 2014 Feb 13;370(7):681.

5. Stokes IA. Mechanical modulation of spinal growth and progression of adolescent scoliosis. Stud Health Technol Inform. 2008;135:75-83.

\section{S13}

Balance training in subjects with musculoskeletal disorders

Andrea Tettamanti (tettamanti.andrea@hsr.it)

Laboratory of Analysis and Rehabilitation of Motor Function,

Neuroscience Division, San Raffaele Hospital, Milan, Italy

Archives of Physiotherapy 2016, 6(Suppl 1):S13

Balance and proprioceptive deficits are present in most of the subjects with neurological diseases and in many older people. The effect of balance training in these subjects is quite well established [1-3]. 
Although they are few considered, balance deficits are present also in many subjects with musculoskeletal diseases. A lesion of the knee or ankle could lead to a balance deficit, and the effects of balance training is a reduction in the recurrence of ankle sprains in chronic ankle instability, a reduction in giving way episodes in $\mathrm{ACL}$ injured people, a reduction of risk of falling in elderly people, and a reduced incidence of knee and ankle injuries [4]. Less evident is that also in subjects with low back pain (LBP) or neck pain balance deficit is present.

In recent years it has been documented that individuals with acute and chronic LBP show changes in trunk muscles activity (transversus abdominis and multifidus particularly). A consistent finding is a delayed activation of trunk muscles during both unpredictable and predictable trunk perturbations. Trunk balance deficits and muscle activation impairments could also originate from poor position sense, which has been reported to be present in individuals with CLBP [5]. Also in people with neck pain the coordination of head movements, the coordination of the movement of the vertebrae of the cervical spine, and postural balance were shown to be impaired [6]. Considering the prevalence of these two conditions, the number of people suffering of balance deficits secondary to musculoskeletal disorder could be relevant.

Despite the documented balance deficits, rehabilitative protocols for improving muscle activation in subjects with LBP are primarily focused on feedforward mechanisms, using exercises that emphasize the maintaining of static postures (i.e. squat exercises, curl up, side and front support). These kinds of exercises, including trunk muscle strengthening exercises, are included in protocols using the concept of core stabilization training. Nevertheless, a recent systematic review stated that they are not superior to other active exercises in the long term [7]. In subjects with neck pain exercises for improving position sense and muscle activations rely principally on neck coordination and repositioning exercises [8].

Only few studies investigate the role of balance exercises in restoring sensorimotor function and alleviate symptoms in subjects with back or neck pain. The efficacy of balance training in individuals with CLBP and neck pain was studied in two recent trials $[4,5]$. These kinds of exercises are different from the classical exercises of core stability for low back pain or exercises of neck coordination. Balance exercises are focused on the improvement of feedback mechanics of motor control, while classical core training or neck coordination exercises are mainly focused on feedforward muscular activations. These studies on balance training support the idea that this kind of training is effective and can be practiced easily. In subjects with neck pain it can effectively improve cervical sensorimotor function and decrease neck pain intensity and in subjects with LBP it reduces disability and improves quality of life.

\section{References}

1. Gunn H, Markevics S, Haas B, Marsden J, Freeman J. Systematic Review: The Effectiveness of Interventions to Reduce Falls and Improve Balance in Adults With Multiple Sclerosis. Arch Phys Med Rehabil. 2015 Oct;96(10):1898-912.

2. Veerbeek JM, van Wegen $E$, van Peppen $R$, van der Wees PJ, Hendriks E, Rietberg M, Kwakkel G. What Is the Evidence for Physical Therapy Poststroke? A Systematic Review and Meta-Analysis. Quinn TJ, ed. PLoS One. 2014;9(2):e87987.

3. Mansfield A, Wong JS, Bryce J, Knorr S, Patterson KK. Does perturbationbased balance training prevent falls? Systematic review and meta-analysis of preliminary randomized controlled trials. Phys Ther. 2015 May;95(5):700-9.

4. Beinert $K$, Taube $W$. The effect of balance training on cervical sensorimotor function and neck pain. J Mot Behav. 2013;45(3):271-8.

5. Gatti R, Faccendini S, Tettamanti A, Barbero M, Balestri A, Calori G. Efficacy of trunk balance exercises for individuals with chronic low back pain: a randomized clinical trial. J Orthop Sports Phys Ther. 2011 Aug:41(8):542-52.

6. Childs JD, Cleland JA, Elliott JM, Teyhen DS, Wainner RS, Whitman JM, Sopky BJ, Godges JJ, Flynn TW; American Physical Therapy Association. Neck pain: Clinical practice guidelines linked to the International Classification of Functioning, Disability, and Health from the Orthopedic Section of the American Physical Therapy Association. J Orthop Sports Phys Ther. 2008 Sep;38(9):A1-A34.
7. Smith BE, Littlewood C, May S. An update of stabilisation exercises for low back pain: a systematic review with meta-analysis. BMC Musculoskelet Disord. 2014 Dec 9;15:416.

8. Jull G, Falla D, Treleaven J, Hodges P, Vicenzino B. Retraining cervical joint position sense: the effect of two exercise regimes. J Orthop Res. 2007 Mar;25(3):404-12.

S14

Dosage of manual therapy: principles for clinical practice

Carla Vanti (carla.vanti@unibo.it)

Department of Biomedical and Neuromotor Sciences, University of

Bologna, Bologna, Italy

Archives of Physiotherapy 2016, 6(Suppl 1):S14

The dosage of manual therapy techniques refers to the optimal therapeutic dose (e.g. the amount of treatment that may produce a therapeutic effect) and the optimal interval between doses (e.g. the sessions' scheduling). About each session, the main parameters involved in the dosage are: the starting position, the force/pressure exerted, the rhythm and speed, the type of technique, the Range of Motion (ROM), the stadium of healing, the number of repetitions, and the total duration of the session.

A non-specific/neutral/painless position is a common choice to apply antalgic techniques, whereas a specific/end of range position is applied to perform the techniques aiming to improve the ROM. The amount of force/pressure exerted depends on the type of technique, the treated area, the type of pathology/dysfunction, and the morphological type of patient and therapist. However, the force used by physical therapists relates not only to patient, but also to physical therapist characteristics (academic qualification, sex, weight and height). Nevertheless, it was demonstrated that clinicians can successfully deliver prescribed traction forces while treating patients. Concerning the rhythm/speed, a high rhythm is used to stimulate the $\beta$-receptors and improve the movement of fluids, whilst a slow rhythm is preferred to provoke a tissue deformation. It was shown that HVLA manipulation induces an initial mechanical, non-opioid hypoalgesia (superior to placebo and control) and that passive painless techniques induce the H-reflex inhibition. The sympathetic nervous system activation is also related to the type of technique (e.g. HVLA vs mobilization).

Concerning the Grades of Movement, manual therapy literature suggests to use intermittent Grade I and II to manage pain and induce relaxation, and Grade III, IV and V to treat hypomobility. However, the frequency and amplitude of the oscillation forces in grades I and IV are poorly reproducible. Moreover, the higher the grade of mobilization, the greater the force applied by physical therapists.

About the total number of sessions, data from clinical trials are extremely variable. When a patient is in acute phase, normally a treatment from daily to three times a week is suggested; in subacute phase from twice to three times a week, and in chronic phase from once to twice a week. The sessions scheduling also depends on the amount of home exercises prescribed and the compliance of the patient. Home exercises are commonly indicated from one to five-six times a day.

Psychosocial factors should also be considered in the choice of the amount of manual therapy delivered. Physical therapists can experience feelings of tension between the advice and treatment they feel is best for their patient and the patient's own beliefs and attitudes. Improving communication skills may help decrease feelings of conflict, enhance working relationships, and encourage a more consistent approach.

According to a shared decision-making approach, clinicians and patients communicate with each other with the best available evidence when they have to make decisions. Then, patients are supported to decide on the characteristics and consequences of the various options.

\section{References}

1. Chiradejnant A, Latimer J, Maher CG. Forces applied during manual therapy to patients with low back pain. J Manipulative Physiol Ther. 2002;25(6):362-9. 
2. Gudavalli MR, Vining RD, Salsbury SA, Corber LG, Long CR, Patwardhan AG, Goertz CM. Clinician proficiency in delivering manual treatment for neck pain within specified force ranges. Spine J. 2015;15(4):570-6.

3. Haas M, Vavrek D, Peterson D, Polissar N, Neradilek MB.Dose-response and efficacy of spinal manipulation for care of chronic low back pain: a randomized controlled trial. Spine J. 2014 Jul 1;14(7):1106-16.

4. Jeffrey JE, Foster NE. A qualitative investigation of physical therapists experiences and feelings of managing patients with nonspecific low back pain. Phys Ther. 2012;92(2):266-78.

5. Jull G, Moore A. What is a Suitable Dosage of Physical Therapy Treatment? Man Ther. 2002;7(4):181-2.

6. Lee M, Moseley A, Refshauge K. Effect of feedback on learning a vertebral joint mobilization skill. Phys Ther. 1990;70(2):97-102.

7. Pentelka L, Hebron C, Shapleski R, Goldshtein I.The effect of increasing sets (within one treatment session) and different set durations (between treatment sessions) of lumbar spine posteroanterior mobilisations on pressure pain thresholds. Man Ther. 2012;17(6):526-30.

8. Sandman L. et al. Adherence, shared decision-making and patient autonomy. Med Health Care Philos. 2012;15(2):115-27.

9. Threlkeld AJ. The effects of manual therapy on connective tissue. Physiotherapy. 1992; 72(12): 893-902.

10. Williams JM, Cuesta-Vargas A. Quantification of prone thoracic manipulation using inertial sensor-derived accelerations. J Manipulative Physiol Ther. 2014;37(4):230-5.

\section{S15}

Are there speed limits in post-surgery lower limb rehabilitation?

Stefano Vercelli (stefano.vercelli@fsm.it)

Unit of Occupational Rehabilitation and Ergonomics, Salvatore Maugeri

Foundation, IRCCS, Veruno (NO), Italy

Archives of Physiotherapy 2016, 6(Suppl 1):S15

Exactly ten years ago, Kevin Wilk wrote an editorial, wherein he questioned the possibility of identifying speed limits in rehabilitation [1]. In that issue of JOSPT, the accelerated philosophy was applied to a famous Italian soccer player, who returned to official first division soccer games within (only) 90 days after anterior cruciate ligament reconstruction [2]. Donald Shelbourne commented this exceptional success by encouraging all surgeons and physical therapists to find their surgical procedure and rehabilitation protocol limits [3]. However, this encouragement does not seem to have been put into practice by most physical therapists yet. Therefore, in 2015, the APTA felt the need to launch a campaign against the bad practice of prescribing under dosed strength training programs. In essence, it was advised against the use of physical agents except when necessary, as well as the use of continuous passive motion machines for the postoperative management of patients following uncomplicated total knee replacement [4].

The type of physiotherapy exercise interventions after major surgery of lower limb (such as total hip or knee arthroplasty, THA and TKA) has often been based on treatment tradition or time-progression, and not on firm scientific evidence, basic exercise physiology principles, or both [5]. Patients are not all equal, so it is imperative the need to shift the focus from the time-based protocols toward an individualized and evaluation-based approach. Recent meta-analyses on the effectiveness of physiotherapy exercise after THA and TKA generally conclude that physiotherapy exercise either does not work or is it very effective. ${ }^{5}$ In line with the recent claims from APTA [4], the reason for this may be that the rehabilitation was of too little intensity or offered at the wrong time, too late after surgery [5].

Recently, Bandholm and Kehlet [5] set four simple rules to follow in clinical practice and in future studies within physiotherapy exercise after THA and TKA. First, the timing should be right. This means that intervention should start before the deficits are at the greatest, if the goal is a fast recovery. Second, the ingredients should be right and based on documented deficits. Functional rehabilitation must be supplemented by muscle strengthening (with the right dose) and range of motion recovery. Tradition and fear of symptoms exacerbation have typically precluded progressive strength training early after surgery, and lifestyle restriction are commonly applied after THA to prevent dislocation. However, both these precautions have been strongly questioned [6,7], and the strongest predictors of persistent pain after TKA are more related to catastrophizing, mental health, or preoperative knee pain than exercise intensity. Third, the ingredients should not be too many, preferring the few exercises that will have the greatest chance of transfer from strength gain to improved functional performance. Fourth, the exercises should be well described, including - whenever it is possible - the indication of the relative load/repetition maximum.

Are we ready to try this at home?

\section{References}

1. Wilk KE. Are there speed limits in rehabilitation? J Orthop Sports Phys Ther. 2005;35:50-51.

2. Roi GS, Creta D, Nanni G, Marcacci M, Zaffagnini S, Snyder-Mackler L. Return to official italian first division soccer games within 90 days after anterior cruciate reconstruction: a case report. J Orthop Sports Phys Ther. 2005;35:52-61.

3. Shelbourne D. Invited commentary. J Orthop Sports Phys Ther 2005;35:61-62

4. Internet site: www.choosingwisely.org [accessed September 15, 2015].

5. Bandholm T, Kehlet $H$. Physiotherapy exercise after fast-track total hip and knee arthroplasty: time for reconsideration? Arch Phys Med Rehabil. 2012;93:1292-1294.

6. Jacobsen TL, Husted $H$, Kehlet $H$, Bandholm T. Progressive strength training (10 RM) commenced immediately after fast-track total knee arthroplasty: is it feasible? Disabil Rehabil. 2012;34:1034-1040.

7. van der Weegen W, Kornuijt A, Das D. Do lifestyle restriction and precautions prevent dislocation after total hip arthroplasty? A systematic review and meta-analysis of the literature. Clin Rehabil. 2015, Mar 31 [Epub ahead of print].

S16

Classification of predominant neuropathic, nociceptive or central sensation pain

Lennard Voogt (l.p.voogt@hr.nl)

Rotterdam University of Applied Sciences, Rotterdam, The Netherlands Archives of Physiotherapy 2016, 6(Suppl 1):S16

Over the last decade we have witnessed impressive progress in the understanding of neurophysiologic mechanisms underlying chronic musculoskeletal pain. What we have learned from this scientific research is that pain should be seen as the outcome of very complex interactions between biological, psychological and sociological processes and that the brain plays a central role in the integration and processing of a variety of inputs into the creation of a concrete conscious experience of pain. One characteristic of this processing is that inputs into the brain can be modulated in several ways, which means that the relation between tissue damage and pain experience is certainly not linear per se. Besides this, we have learned that it is of primary importance that caregivers in the field of chronic musculoskeletal pain have a thorough understanding of the neurophysiology of pain and that they take these insights into account while they inform, advice and treat their patients. This is even more important when we consider the fact that about $20 \%$ of the human population is now suffering from some form of chronic pain and that our treatment-effects are moderate at best.

Some scholars in the field of musculoskeletal pain point to the importance of a connection between pain-mechanisms and interventions in order to improve treatment effects in the near future. Current research shows that we can distinguish between different pain mechanisms and that it is valid to make distinctions between nociceptive, neuropathic and 'centralised' pain. Knowledge of the different physiological mechanisms underlying these three different forms of pain is important from a clinical perspective because it makes it possible to think more effectively about the relation between pain-physiology and our (physical therapy) interventions. It seems logical to suppose that nociceptive pain-forms require different treatment strategies than neuropathic or 'centralised' pain-forms. To do so it is important for clinicians to make valid interpretations regarding the pain-mechanisms driving the pain of their patients. 
Although the pain laboratory is not the same as the clinical encounter, we think that it is indeed possible to translate physiological knowledge of pain-mechanisms to the clinical encounter and that proper interpretations of signs and symptoms of patients with chronic musculoskeletal pain can be made. For this purpose we proposed a clinical algorithm with which clinicians can make substantiated distinctions between predominant nociceptive, neuropathic or 'centralised' pain in their patients. The algorithm is based on both scientific research and the clinical experience of specialists in the field of (chronic) musculoskeletal pain. During the lecture the algorithm will be presented and discussed in light of patients with low back pain. The way in which the algorithm should be used and decisions should be made is the main objective of the lecture.

\section{References}

1. Nijs J, Apeldoorn A, Hallegraef H, Clark J, Smeets R, Malfliet A, Girbés EL, De Kooning M, Ickmans K. Low back pain: guidelines for the clinical classification of predominant neuropathic, nociceptive, or central sensitisation pain. Pain Physician. 2015; 18:E333-E346.

2. Nijs J, Torres-Cueco R, Van Wilgen CP, Girbés EL, Struyf F, Roussel N, Van Oosterwijck J, Daenen L, Kuppens K, Vanderweeën L, Hermans L, Beckwée D, Voogt L, Clark J, Moloney N, Meeuws M. Applying modern pain neuroscience in clinical practice: criteria for the classification of central sensitization pain. Pain Physician. 2014; 18:447-457.

\section{P1}

A wearable proprioceptive stabilizer (Equistasi ${ }^{\circledR}$ ) for rehabilitation of balance disorders in multiple sclerosis patients: preliminary results of a randomized, double-blind, versus placebo controlled study

Aceto Maria', Spina Emanuele', Paone Paolo², Silvestre Francesco', Carotenuto Antonio', Cerillo llaria', Orefice Giuseppe ${ }^{1}$

'Department of Neuroscience, Reproductive Sciences and Dentistry, Federico II University, Napoli, Italy: ${ }^{2}$ Statistician, Pacal Consulting Sas, Milan, Italy

Correspondence: Aceto Maria (maria.aceto@unina.it) - Department of Neuroscience, Reproductive Sciences and Dentistry, Federico II University, Napoli, Italy

Archives of Physiotherapy 2016, 6(Suppl 1):P1

\section{Background}

Recent studies have stated that focal mechanical vibration could be an effective tool in the treatment of some neurological disorders. We performed a pilot study to test the feasibility and effectiveness of a balance training program in association with a wearable proprioceptive stabilizer (Equistasi ${ }^{\circledR}$ ) that emits focal mechanical vibrations in patients with multiple sclerosis (MS).

Methods

Twenty patients with balance and gait disorders affected by clinically defined MS were randomly divided into two groups wearing an active or inactive device. All patients received a 3 weeks program of balance training. Assessments were performed at baseline, after the rehabilitation period ( $\mathrm{T} 1$ ), and 3 weeks after (T2) using posturographic measures, dynamic gait index, clinical scales for balance and fatigue.

Results

Both groups were matched for age, sex, EDSS and disease duration. There were no significant differences between-groups in the area of the center of pressure with both opened or closed eyes. Equistasi group showed an increased first right step length at $\mathrm{T} 1 \quad(+18 \%$, $p<0.02)$ and T2 $(p<0.04)$ and an increased first left step lenght at T1 $(+17 \%$. $\mathrm{p}=0.05)$ compared to T0 with an increased average step at $\mathrm{T} 1$ $(+9 \%, \mathrm{p}<0.03)$ and $\mathrm{T} 2$.

We also found a decrease in time of both right and left double support at $\mathrm{T} 1(-27 \%, \mathrm{p}<0.03 ;-36 \%, \mathrm{p}<0.01$, respectively) and an improvement in the Functional Reach Test $(+19 \% . \quad \mathrm{p}<0.02)$, Berg
Balance Scale score $(+6 \%, p<0.01)$ and Fatigue Severity Scale score $(-14 \%, p<0.03)$ at T1. Placebo group showed only an increase of the time of right double support at $\mathrm{T} 1(+46 \%, \mathrm{p}=0.05)$, while no significant results were found for all the other measures.

Conclusions

This study showed that people with MS treated with Equistasi ${ }^{\oplus}$, achieved improvements in balance disorders, especially when assessed through Gait Analysis, compared to placebo. This pilot trial shows that a physiotherapy program for training balance in association with focal mechanical vibration might be an helpful rehabilitative support in improving patients' balance.

\section{References}

1. Volpe D, Giantin MG, Fasano A. A Wearable Proprioceptive Stabilizer (Equistasi) for Rehabilitation of Postural Instability in Parkinson's Disease: A Phase II Randomized Double-Blind, Double- Dummy, Controlled Study. Plos One. 2014 Nov 17;9(11):e112065.

2. Brunetti $\mathrm{O}$, Botti FM, Roscini $\mathrm{M}$ et al. Focal vibration of quadriceps muscle enhances leg power and decreases knee joint laxity in female volleyball players. J Sports Med Phys Fitness. 2012 Dec;52(6):596-605.

3. Martin CL, Phillips BA, Kilpatrick TJ, et al. Gait and balance impairment in early multiple sclerosis in the absence of clinical disability. Mult Scler. 2006 Oct;12(5):620-8.

4. Pearson OR, Busse ME, Van Deursen RWM, Wiles CM. Quantification of walking mobility in neurological disorders. OJM. 2004 Aug;97(8):463-475.

5. Katusic A, Alimovic S, Mejaski-Bosnjak V. The effect of vibration therapy on spasticity and motor function in children with cerebral palsy: a randomized controlled trial. NeuroRehabilitation. 2013;32(1):1-8.

P2

Effect of repeated neck retraction movements on strength and EMG activity of the upper limbs, range of motion and cervical posture

Bassi Raffaele ${ }^{1}$, Fiorito Serena ${ }^{2}$, Aina Alessandro ${ }^{3}$

${ }^{1}$ Vita-Salute San Raffaele University, Milan, Italy; ${ }^{2}$ NEMO Clinical Centre,

Niguarda Hospital, Milan, Italy; ${ }^{3}$ Physiotherapist, Dip. MDT, private practice, Milan, Italy

Correspondence: Bassi Raffaele (raffaele.bassi.1@gmail.com) - VitaSalute San Raffaele University, Milan, Italy

Archives of Physiotherapy 2016, 6(Suppl 1):P2

Background and aim

Neck pain is a common clinical condition in result of different factors including changes in cervical posture [1] and mobility [2]. The McKenzie method of Mechanical Diagnosis and Therapy (MDT) deals also with neck disorders. Repeated cervical movements are the main diagnostic and therapeutic strategy used in MDT [3]. The most used is the neck retraction movement, which involves pulling the head and neck posteriorly into a position in which the head is aligned on the thorax, while maintaining the look ahead [4] (Fig. 5). In scientific literature, neck retraction is poorly investigated even if it has been described as an effective method to treat symptoms, achieve pain centralization [5], improve ROM and correct head posture. To date, no articles have analyzed the effect of repeated retraction on strength performance and few have dealt with related EMG activity of the upper limbs muscles. The aim of this study is to investigate the effect of 30 repeated neck retractions on upper limbs strength performance, posture and cervical spine mobility in healthy subjects.

Materials and methods

50 healthy subjects were recruited and randomly assigned to two groups: CTRL (control), INT (intervention). 25 subjects (CTRL) performed in sitting position 3 series of 10 flexion-extension cervical movements, while 25 subjects (INT), in the same position, completed 3 series of 10 neck retractions. Each subject was assessed 
both at baseline (T0) and at the end of repeated movements (T1) in terms of cervical range of motion, rest posture of the head, upper limbs' strength and EMG activity. As regards to force assessment, palmar and pinch strength was evaluated using Jamar and Pinch dynamometers, isometric strength in shoulder abduction and elbow flexion-extension using Biodex dynamometer. During isometric contraction measured by Biodex, EMG activation of Deltoid, Biceps and Triceps Brachii was recorded. All evaluations were performed bilaterally.

Results

Preliminary results from 16 subjects ( 8 CTRL, 8 INT) showed a significant improvement in the intervention group in cervical range of motion, strength (left elbow extension) and EMG activation of right deltoid.

\section{Discussion and conclusion}

Further analysis is needed to verify in depth this phenomenon, before elaborating any hypothesis regarding the underlying mechanisms.

\section{Consent for publication}

The authors have written informed consent from the person in Fig. 5 , and consent to publish the photograph. The relevant documents can be provided on request.

\section{References}

1. Donelson, R. Grant, W. Kamps, C. Richman, P. Cervical and referred pain response to repeated end-range testing: A prospective, randomized trial. Twelfth Annual Meeting of the North American Spine Society, New York, New York October 22-25, 1997.

2. Bovim, G. Schrader, H. Sand, T. Neck pain in general population. Spine. 1994; 19:1307-1309.

3. McKenzie, R. The cervical and thoracic spine: mechanical diagnosis and therapy. 1st ed. Spinal Publication, New Zealand Ltd; 1990.

4. Pearson, ND. Walmsley. RP. Trial into the effects of repeated neck retractions in normal subjects. Spine. 1995 Jun 1;20(11):1245-50; discussion 1251

5. May, S. Aina, A. Centralization Phenomenon and Directional Preference: a Systematic review. Man Ther. 2012;17:497-506.

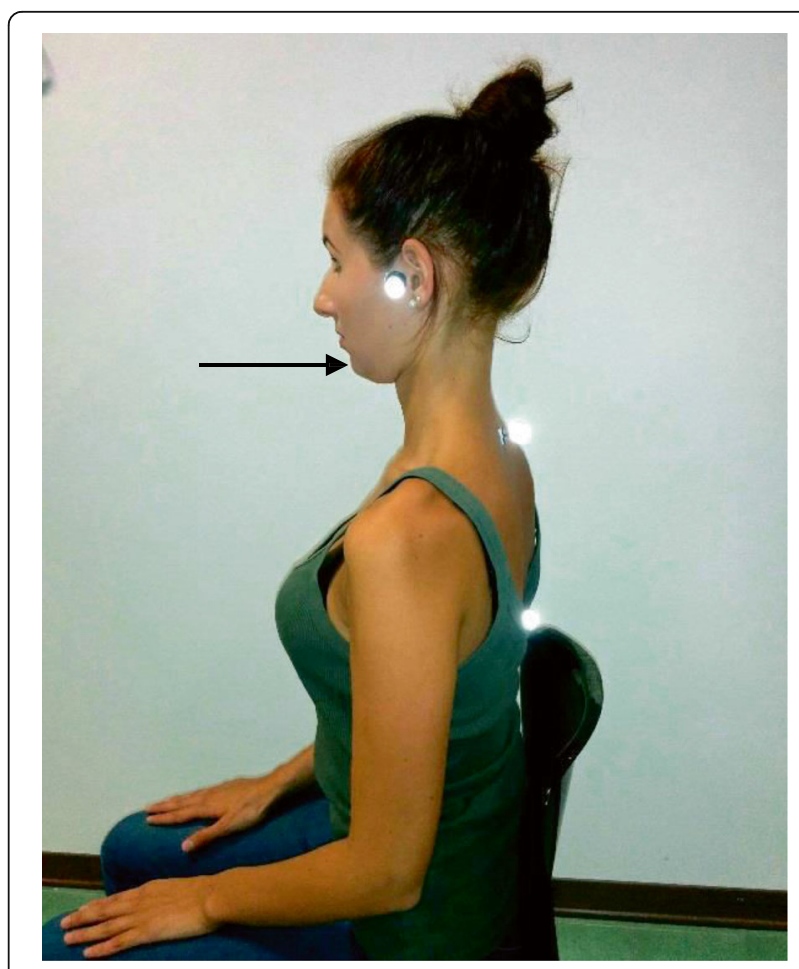

Fig. 5 (abstract P2) Neck retraction movement
P3

Hamstring injuries: clinical assessment or image evaluation?

Bonfanti M., Pasquetti M.

Private practice, Milan, Italy

Correspondence: Pasquetti M. (marapasqui@gmail.com) - Private practice, Milan, Italy

Archives of Physiotherapy 2016, 6(Suppl 1):P3

\section{Background}

Hamstring injuries are the single most common injury in professional football and have a high incidence and recurrence rate. The diagnosis has traditionally relied both on clinical measures and on the use of diagnostic imaging. A few studies have suggested the use of specific clinical tests. Physicians evaluating hamstring strains are increasingly turning to magnetic resonance imaging (MRI) to support the clinical diagnosis. However, little information is available to assess how MRI compares with the clinical evaluation in the classification of the injuries.

\section{Objective}

To summarize the current evidence about the diagnostic accuracy and the clinical utility of clinical tests for hamstring injuries in comparison to the use of MRI.

Materials and methods

We searched the MEDLINE and Embase databases (along with the grey literature) for studies aimed at assessing the validity of clinical tests and imaging techniques to diagnose hamstring injuries. Cohort, case-control and cross-sectional studies enrolling people with hamstring or posterior thigh pain were included, provided that they 1) used MRI or US to diagnose the condition, 2) applied at least 1 clinical test to evaluate the hamstring pathology. and 3) compared the results of the clinical assessment and the MRI/ US diagnosis.

Results

37 potential articles were retrieved, of which 7 articles met the inclusion criteria.

Actually, MRI seems to be the most applied instrument of evaluation but several studies have demonstrated that it is not able to identify muscle injuries of minor entity.

Discussion

MRI can be helpful in verifying the diagnosis of a hamstring injury and to prognosticate layoff time but clinical evaluation is still the most relevant diagnostic instrument. There is still a lack of specificity in the clinical tests developed to diagnose hamstring injuries.

\section{Conclusion}

Clinical assessment with specific tests is essential in the diagnosis of hamstring injuries, especially in minor entity injuries in order to discriminate from other pathologies. However, further high-quality studies are needed before these tests can be used as independent diagnostic tools.

\section{References}

1. Ahmad CS, Redler LH, Ciccotti MG, Maffulli N, Longo UG, Bradley J. Evaluation and Management of Hamstring Injuries. Am J Sports Med. 2013 41:2933-2947.

2. Freckleton G, Cook J, Pizzari T. The predictive validity of a single leg bridge test for hamstring injuries in Australian Rules Football Players. Br J Sports Med. 2014;48:713-717.

3. Heiderscheit BC, Sherry MA, Silder A, Chumanov ES, Thelen DG. Hamstring Strain Injuries: Recommendations for Diagnosis, Rehabilitation and Injury Prevention. J Orthop Sports Phys Ther. 2010 Feb;40(2):67-81.

4. Reiman MP, Loudon JK, Goode AP. Diagnostic accuracy of clinical tests for assessment of hamstring injury: a systematic review. J Orthop Sports Phys Ther. 2013 Apr;43(4):223-31.

5. Schneider-Kolsky ME, Hoving JL, Warren P, Connell DA. A Comparison Between Clinical Assessment and Magnetic Resonance Imaging of Acute Hamstring Injuries. Am J Sports Med. 2006 Jun;34(6):1008-1015. 
6. Sherry M. Evaluation and Treatment of Hamstring Related Injuries. Sports Health. 2012 4(2):107-114.

P4

Effectiveness of the physical therapy treatment on pelvic floor muscles in pelvic girdle pain. A literature review

Bortolami Arianna ${ }^{1}$, Pillastrini Paolo ${ }^{2}$, Vanti Carla ${ }^{2}$

${ }^{1}$ Private practice, Padova, Italy; ${ }^{2}$ Department of Biomedical and

Neuromotor Sciences, University of Bologna, Bologna, Italy

Correspondence: Bortolami Arianna (arianna.bortolami@gmail.com) -

Private practice, Padova, Italy

Archives of Physiotherapy 2016, 6(Suppl 1):P4

\section{Backgroud and aim}

Pelvic girdle pain (PGP) occurs mainly during pregnancy and in the first year after childbirth. Effectiveness of the physical therapy used for this condition is still widely discussed in the literature. The aim of this study is to investigate the effectiveness of the physical therapy for pelvic floor muscles in PGP.

Material and methods

PubMed, PeDro, The Cochrane Collaboration, CINHAL, and Scopus databases were searched using the terms pelvic floor, pelvic girdle, pubic symphysis, sacroiliac joint, pregnancy, and post pregnancy. No time limit or language was given. Additional records were searched through reference lists from guidelines and reviews.

Results

Only two randomized controlled trials (RCT) were found from the search. The first one involved 257 pregnant healthy women, before gestation week 20th. The experimental group received supervised group exercises, including pelvic floor muscles training, whereas the control group received standard care by midwife and gynaecologist. No significant difference in prevalence of low back pain or PGP was shown between groups. The second RCT involved 88 women with persistent PGP who were recruited 3 months after delivery. The treatment group was instructed to perform stabilizing exercises, including pelvic floor muscles training; the control group received information about PGP through a phone call. Pelvic floor muscles were evaluated before and after the treatment, by nerve conduction study (NCS). The program of stabilizing exercises was not more effective in improving consequences of persistent postpartum PGP than the clinically natural course. Pelvic floor muscles activity was not improved, unlike other muscles.

Discussion

These articles raise important questions about the usefulness of pelvic floor exercises both for the prevention of PGP during pregnancy and the treatment of persistent PGP after childbirth. The lack of improvement of pelvic floor muscles after the performance of stabilization exercises makes questionable the effectiveness of this program, also when it is addressed to the pelvic floor. The very small number of high-quality clinical trials suggests that further research is needed.

\section{Conclusions}

Pelvic floor physical therapy has not proved more effective than common obstetric care to prevent PGP during pregnancy, nor to treat persistent PGP after childbirth.

\section{Acknowledgement}

The authors would like to acknowledge the GSTM (Gruppo di Studio della Terapia Manuale e Riabilitazione Muscoloscheletrica) that provided support for this study.

\section{References}

1. Eggen MH1, Stuge B, Mowinckel $P$, Jensen KS, Hagen KB Can supervised group exercises including ergonomic advice reduce the prevalence and severity of low back pain and pelvic girdle pain in pregnancy? A randomized controlled trial. Phys Ther. 2012 Jun;92(6):781-90.

2. Gutke A1, Sjödahl J, Oberg B. Specific muscle stabilizing as home exercises for persistent pelvic girdle pain after pregnancy: a randomized, controlled clinical trial. J Rehabil Med. 2010 Nov;42(10):929-35
3. Stuge B1, Sætre K, Brækkenl $H$. The association between pelvic floor muscle function and pelvic girdle pain-a matched case control 3D ultrasoundstudy. Man Ther. 2012 Apr;17(2):150-6.

4. Stuge B1, Mørkved S, Dahl HH, Vøllestad N. Epub 2005 Dec 28. Abdominal and pelvic floor muscle function in women with and without long lasting pelvic girdle pain. Man Ther. 2006 Nov;11(4):287-96

5. Fitzgerald CM1, Mallinson T. The association between pelvic girdle pain and pelvic floor muscle function in pregnancy. Int Urogynecol J. 2012 Jul;23(7):893-98

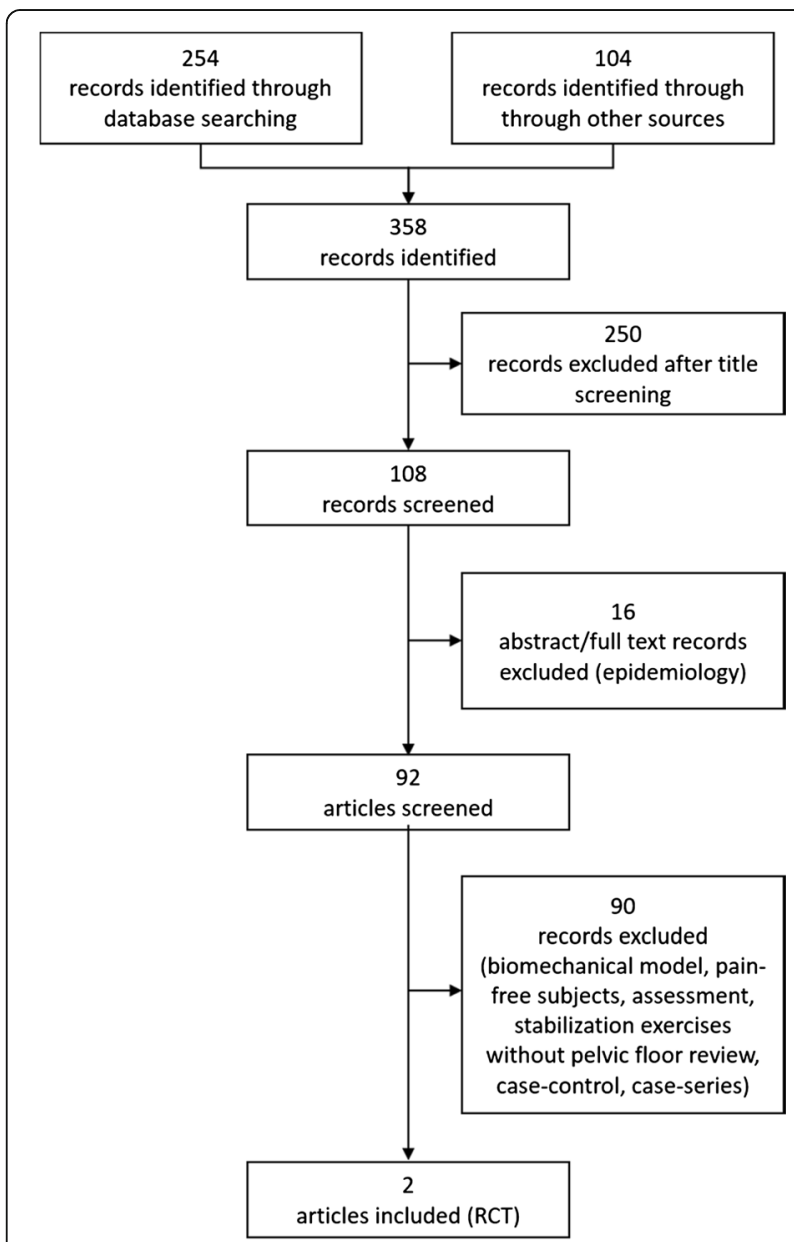

Fig. 6 (abstract P4) Flow diagram showing the different phases of studies selection

P5 Scapulo-humeral muscles electromiographic activity during the elevation movement of the upper limb in subjects with rotator cuff lesion

Brioschi $D^{1}$, Vitali $M^{2}$, Pedretti $A^{1}$, Fraschini $G^{2}$, Tettamanti $A^{3}$

${ }^{1}$ Vita-Salute San Raffaele University, Milan, Italy; ${ }^{2}$ Orthopedic Department, San Raffaele Hospital, Milan, Italy; ${ }^{3}$ Laboratory of Movement Analysis, Division of Neuroscience, San Raffaele Scientific Institute, Milan, Italy

Correspondence: Brioschi D (d.brioschi@studenti.unisr.it) - Vita-Salute San Raffaele University, Milan, Italy Archives of Physiotherapy 2016, 6(Suppl 1):P5 


\section{Background and aim}

Abnormal scapulo-humeral rhythm has been identified in patients with diagnosis of rotator cuff lesion [1-4]: they establish compensatory mechanisms that consist of a different pattern and timing of muscle activation compared to healthy subjects [5]. Some muscles aren't much investigated in literature due to the complexity in the analysis of their activation with traditional electromyography (sEMG). The purpose of this study is to determine possible differences in function of the gleno-humeral muscles in patients with rotator cuff injury, using sEMG.

Material and methods

25 patients with rotator cuff injury and indication for surgical cuff repair from San Raffaele Hospital, and 30 healthy subjects, were recruited. sEMG activity of anterior deltoid (DA), trapezius (TRSuperior, TRMiddle, TRInferior), latissimus dorsi (LD), levator scapulae (ES), rhomboids (RO) and infraspinatus (INF) was recorded during the humerus elevation on the scapular plane from $0^{\circ}$ to $120^{\circ}$ at $30 \% \mathrm{sec}$ angular velocity (Fig. 7). The movement was performed before and after three maximal isometric contractions and a fatigue test in which the subject had to maintain the isometric contraction at $50 \%$ of his maximal torque for 30 seconds. Thanks to a customized software (EVA11-B10NIX) we were able to filter and analyze the signal (timing of activation and many signal features) using Wavelet-Denoise and Independent- ComponentAnalysis, in order to reduce the noise and the cross-talk between muscles, reaching muscles as RO and ES.

Results

TRI had a lower signal frequency content in pathological subjects at baseline $(p=0.05)$; LD showed an earlier onset timing related to DA $(p=0.033)$ and a superior signal frequency content in pathological subjects at baseline $(p=0.033)$; RO had a variation between the groups in the change of onset timing related to DA after effort $(p=0.05)$.

Discussion and conclusion

In pathological subjects TRI was already fatigued at baseline; LD was sooner activated probably to replace the cuff muscles activity; RO showed a variation in the change of onset timing related to DA after the effort, so the pathological subjects switched them later compared to the healthy subjects. The differences in the pathological subjects group could lead to hypomobility of the scapula with decreased upward rotation and increased adduction, conditions that could cause the alteration of the scapulo-humeral rhythm.

\section{Consent for publication}

The authors have written informed consent from the person in Fig. 7 and consent to publish the photograph. The relevant documents can be provided on request.

\section{References}

1. Karduna AR, McClure PW, Michener LA, Sennett B. Dynamic Measurements of Three-Dimensional Scapular Kinematics: A Validation Study. J Biomech Engineer. 2001; 123: 184-90.

2. Ludewig PM, Cook TM, Nawoczenski DA. Three-dimensional scapular orientation and muscle activity at selected positions of humeral elevation. J Orthop Sports Phys Ther. 1996; 24 (2): 57-65.

3. Matsuki K, Matsuki KO, Yamaguchi S, Ochiai N, Sasho T, Sugaya H, Toyone T, Wada Y, Takahashi K, Banks SA. Dynamic in vivo glenohumeral kinematics during scapular plane abduction in healthy shoulders. J Orthop Sports Phys Ther. 2012; 42 (2): 96-104.

4. Ludewig PM, Reynolds JF. The Association of Scapular Kinematics and glenohumeral Joint Pathologies. J Orthop Sports Phys Ther. 2009; 39: 90-104.

5. Cools AM, Witvrouw EE, Declercq GA, Danneels LA, Cambier DC. Scapular muscle recruitment patterns: Trapezius muscle latency with and without impingement symptoms. Am J Sports Med. 2003; 31 (4) $542-9$

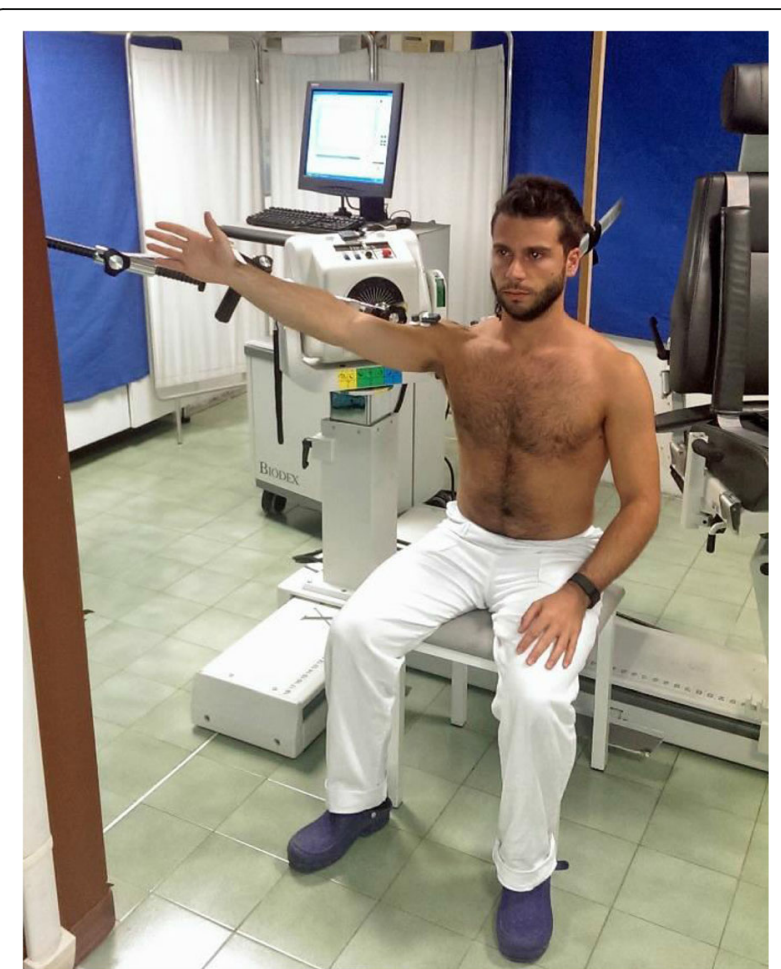

Fig. 7 (abstract P5) The elevation was performed following the passive movement of the lever of an isokinetic dynamometer (Biodex ${ }^{\oplus}$ System 4 pro) that moved with the correct speed and direction

P6 Mechanical low back pain: secular trend and intervention topics of randomized controlled trials

Castellini $G^{1}$, Gianola $S^{2,3}$, Bonovas $S^{4}$, Banfi $G^{5,6}$, Moja $L^{2,4}$

${ }^{1}$ University of Milan, Milan, Italy; ${ }^{2}$ Unit of Clinical Epidemiology, IRCCS Galeazzi Orthopedic Institute, Milan, Italy; ${ }^{3}$ Center of Biostatistics for Clinical Epidemiology, Department of Health Sciences, University of Milano-Bicocca, Monza, Italy; ${ }^{4}$ Department of Biomedical Sciences for Health, University of Milan, Milan, Italy; ${ }^{5}$ Scientific Directorate, IRCCS Galeazzi Orthopedic Institute, Milan, Italy; ${ }^{6}$ Vita - Salute San Raffaele University, Milan, Italy

Correspondence: Castellini G (gre.caste@gmail.com) - University of Milan, Milan, Italy

Archives of Physiotherapy 2016, 6(Suppl 1):P6

\section{Background}

The number of randomized controlled trials (RCTs) that are published each year is increasing across all medical specialties. Rehabilitation does not appear to be an exception [1]. Mechanical low back pain (MLBP) is considered one of the most common causes of disability and work absenteeism [2, 3]: although several interventions are used to treat MLBP, rehabilitation plays a central role.

Objective

To evaluate the amount of published RCTs focusing on MLBP rehabilitation, the secular trend, and the distribution of different intervention topics studied. 


\section{Methods}

We selected all Cochrane systematic reviews focusing on rehabilitation therapies for MLBP. We extracted all included RCTs. Two independent reviewers screened and analyzed the information regarding intervention topics.

Results

After duplicate's removal, a total of 196 RCTs were included. The number of RCTs increased consistently over the decades: 2 trials (1\%) in 1961-1970, $10(5 \%)$ in 1971-1980, 41 (21\%) in 1981-1990, 68 (35\%) in 1991-2000, and 75 (38\%) in 2001-2010. The topic of interest for the majority of RCTs was exercise therapy $(n=115 ; 29 \%)$, followed by spinal manipulation therapies ( $n=60 ; 15 \%$ ) (Fig. 8).

Discussion

Although the amount of research relevant to rehabilitation practice has exponentially increased during the last decades (from 1,925 trials in 1990 to 5,301 in 2000, and 15,293 in 2011) [1], our findings demonstrate that only a small proportion of these trials were related to the study of MLBP. There exists a discrepancy between the prevalence of this disorder and research efforts invested to reduce its burden.

Conclusion

The amount of RCTs focusing on MLBP has risen over the years, with exercise therapy representing the topic of highest research interest.

\section{References}

1. Costa LO, Maher CG, Lopes AD, de Noronha MA, Costa LC: Transparent reporting of studies relevant to physical therapy practice. Rev Bras Fisioter. 2011, 15:267-271.

2. Maniadakis N, Gray A: The economic burden of back pain in the UK. Pain. 2000, 84:95-103.

3. Hoy D, March L, Brooks P, Blyth F, Woolf A, Bain C, Williams G, Smith E, Vos T, Barendregt J, et al.: The global burden of low back pain: estimates from the Global Burden of Disease 2010 study. Ann Rheum Dis. 2014, 73:968-974.

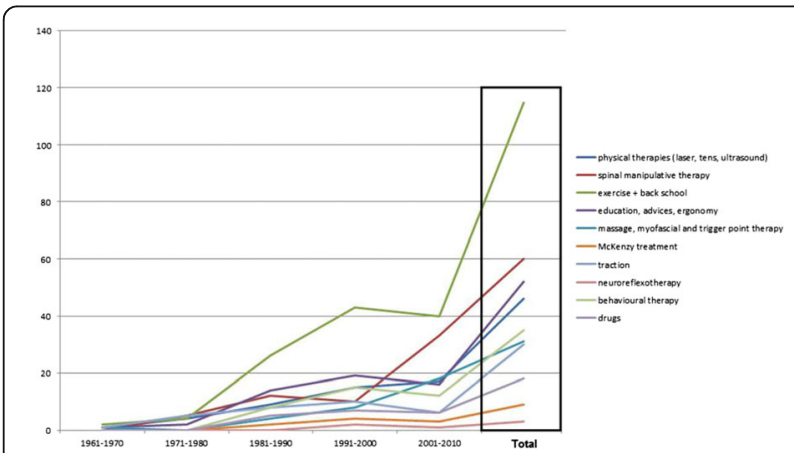

Fig. 8 (abstract P6) Topics of MLBP rehabilitation interventions in published RCTs: a trend over time

P7

Quality of reporting in rehabilitation interventions for low back pain: a review of published randomised controlled trials Greta Castellini', Silvia Gianola ${ }^{2,3}$, Pamela Frigerio ${ }^{4}$, Michela Agostini ${ }^{5}$, Rosa Bolotta ${ }^{6}$, Davide Corbetta ${ }^{7}$, Monica Gasparini ${ }^{1}$, Paolo Gozzer ${ }^{8}$, Erica Guariento ${ }^{9}$, Linda $\mathrm{Li}^{10}{ }^{1}$, Valentina Pecoraro ${ }^{2}$, Valeria Sirtori ${ }^{7}$, Andrea Turolla ${ }^{5}$, Andreano $A^{3}$, Lorenzo Moja $a^{2,11}$

${ }^{1}$ University of Milan, Milan, Italy; ${ }^{2}$ Clinical Epidemiology Unit, I.R.C.C.S.

Galeazzi Orthopedic Institute, Milan, Italy; ${ }^{3}$ Center of Biostatistics for Clinical Epidemiology, Department of Health Sciences, University of MilanoBicocca, Monza, Italy; ${ }^{4}$ Spinal Cord Unit, Niguarda Ca' Granda Hospital, Milan, Italy; ${ }^{5}$ Laboratory of Kinematics and Robotics. I.R.C.C.S. Fondazione Ospedale San Camillo, Venezia, Italy; ' ${ }^{6}$ Service of Physiotherapy, National Institute of Injury Insurance, Milan, Italy; ${ }^{7}$ Rehabilitation Department, San Raffaele Hospital, Milan, Italy; ${ }^{8}$ APSS Tn, Villa Igea, Trento, Italy; ${ }^{9}$ La Quiete casa di cura S.r.l, Varese, Italy; ${ }^{10}$ Department of Physical Therapy, University of British Columbia, Vancouver, British Columbia, Canada; ${ }^{11}$ Department of Biomedical Sciences for Health, University of Milan, Milan, Italy Correspondence: Greta Castellini (gre.caste@gmail.com) - University of Milan, Milan, Italy
Archives of Physiotherapy 2016, 6(Suppl 1):P7

In this oral communication the authors describe the results of a systematic review aimed at assessing the quality of reporting of rehabilitation intervention for mechanical low back pain, that has been published as a full-text article after the 5th S.I.F. Congress [1]. Based on the description of the intervention in 185 RCTs included in the review, the authors concluded that less than one fifth of RCTs reported the necessary information that would allow the intervention to be replicated in clinical practice.

\section{References}

1. Gianola S, Castellini G, Agostini M, Bolotta R, Corbetta D, Frigerio P, Gasparini M, Gozzer P, Guariento E, Li LC, Pecoraro V, Sirtori V, Turolla A, Andreano A, Moja L. Reporting of Rehabilitation Intervention for Low Back Pain in Randomized Controlled Trials: Is the Treatment Fully Replicable? Spine (Phila Pa 1976) 2016 Mar;41(5):412-8.

P8

Power analysis and sample size reporting in rehabilitation of low back pain: review of randomized controlled trials included in Cochrane systematic review

Castellini $\mathrm{G}^{1}$, Gianola $\mathrm{S}^{2,3}$, Bonovas $\mathrm{S}^{4}$, Moja $\mathrm{L}^{1,2,4}$

${ }^{1}$ University of Milan, Milan, Italy; ${ }^{2}$ Unit of Clinical Epidemiology, IRCCS Galeazzi Orthopedic Institute, Milan, Italy; ${ }^{3}$ Center of Biostatistics for Clinical Epidemiology, Department of Health Sciences, University of Milano- Bicocca, Monza, Italy; ${ }^{4}$ Department of Biomedical Sciences for Health, University of Milan, Milan, Italy

Correspondence: Castellini G (gre.caste@gmail.com) - University of Milan, Milan, Italy

Archives of Physiotherapy 2016, 6(Suppl 1):P8

\section{Background}

Well-designed and properly executed Randomized Controlled Trials (RCTs) provide the most reliable evidence on the efficacy of health care interventions [1]. Selection of an appropriate sample size is a key step in the early process of research design to detect a meaningful clinical effect of an intervention. Although in the rehabilitation field the number of RCTs has been increasing [2], most of the studies are based on clinical observation with small sample sizes and reporting is still inadequate [3].

Objective

To assess the reporting of sample size calculation in RCTs on rehabilitation interventions for mechanical low back pain (MLBP).

Methods

RCTs included in Cochrane systematic reviews (SRs), published up to February 2015 and focusing on MLBP rehabilitation interventions, were reviewed. Two independent investigators extracted data on sample size calculation through ad hoc checklist, based on recommendations of the CONSORT statement 2010, identifying six key items. Our2 primary outcome was the proportion of RCTs that reported sample size calculation in the Methods section; secondary outcome was the completeness of power analysis reporting. We also examined for improvements over time.

Results

Of the 222 eligible RCTs (range year of publication min-max was 1968-2013) included in 14 SRs, sample size calculation was reported in $80(36.04 \%)$ RCTs. Of those, only 13 RCTs $(16,25 \%)$ provided a complete description reporting all the six elements required. About half reported 4 or more items (median $=4$, IQR $3-5$ ). The most frequently reported parameters were type II error $(91.25 \%, n=73)$, the assumption for treatment effect to be detected $(86.25 \%, n=69)$ and the type I error $(85 \%, n=68)$. From 1968 to 2013 there was an increase in the completeness of reporting of sample size calculation however, trend of reporting has been superior than not reporting only since 2005 (Fig. 9). 


\section{Conclusions}

In the rehabilitation field, authors have improved the quality of reporting since CONSORT statement's publication. However, determination and transparent reporting of sample size and power analysis are still inadequate, influencing the quality and accuracy of research.

\section{References}

1. Calvert M, Blazeby J, Altman DG, Revicki DA, Moher D, Brundage MD. Reporting of patient-reported outcomes in randomized trials: the CONSORT PRO extension. JAMA. 2013, 309:814-822.

2. Castellini G. GS, Banfi G., Bonovas S., Moja L.: Mechanical low back pain: secular trend and intervention topics of randomized controlled trials. Physiother Can. 2015, In press.

3. Abdul Latif L, Daud Amadera JE, Pimentel D, Pimentel T, Fregni F: Sample size calculation in physical medicine and rehabilitation: a systematic review of reporting, characteristics, and results in randomized controlled trials. Arch Phys Med Rehabil. 2011, 92:306-315.

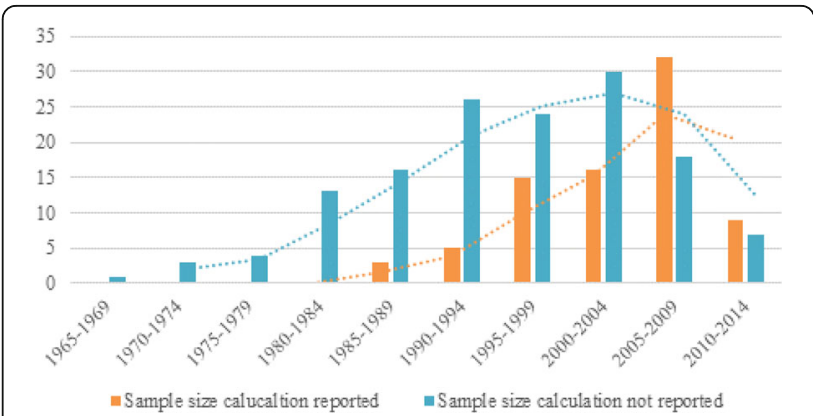

Fig. 9 (abstract P8) Trend of reporting of sample size calculation over time

\section{P9}

A core outcome set for clinical trials in non-specific low back pain Alessandro Chiarotto, Caroline B. Terwee, Maarten Boers, Raymond W. Ostelo

$\mathrm{EMGO}^{+}$Institute for Health and Care Research, VU University and VU University Medical Center, Amsterdam, The Netherlands

Correspondence: Alessandro Chiarotto (ottoale.physio@gmail.com) $\mathrm{EMGO}^{+}$Institute for Health and Care Research, VU University and VU University Medical Center, Amsterdam, The Netherlands Archives of Physiotherapy 2016, 6(Suppl 1):P9

In this abstract the authors illustrate the results of an international and multidisciplinary Delphy survey aimed at updating the current recommendations about the domains to be included in a core outcome set for clinical trials in non-specific low back pain. The study has been published as a full-text article before the 5th SIF Congress (1). Four out of 41 domains presented in the initial list of potential core domains were included in the updated core set: physical functioning, pain intensity, health-related quality of life and number of deaths.

\section{References}

1. Chiarotto A, Deyo RA, Terwee CB et al. Core outcome domains for clinical trials in non-specific low back pain. Eur Spine J. 2015;24(6):1127-42.

\section{Acknowledgements}

On behalf of the international steering committee for the development of a core outcome set for low back pain.

The authors of this study would like to acknowledge the Wetenschappelijk College Fysiotherapie (WCF) of the Royal Dutch Society for Physical Therapy (KNGF) that funded this study.
P10

Roland \& Morris Disability Questionnaire and Oswestry Disability Index: which has better measurement properties? A systematic review and meta-analysis

Alessandro Chiarotto ${ }^{1}$, Lara J. Maxwell ${ }^{2}$, Caroline B. Terwee ${ }^{1}$, George A. Wells, Peter Tugwell ${ }^{2}$, Raymond W. Ostelo ${ }^{1}$

${ }^{1} \mathrm{EMGO}^{+}$Institute for Health and Care Research, VU University and VU University Medical Center, Amsterdam, the Netherlands; ${ }^{2}$ Ottawa

Hospital Research Institute, University of Ottawa, Ottawa, Canada Correspondence: Alessandro Chiarotto (ottoale.physio@gmail.com) $\mathrm{EMGO}^{+}$Institute for Health and Care Research, VU University and VU University Medical Center, Amsterdam, the Netherlands Archives of Physiotherapy 2016, 6(Suppl 1):P10

In this abstract the authors report the results of a systematic review aimed at comparing the measurement properties of two questionnaires that are largely used to assess physical functioning in patients with non-specific low back pain, i.e. the Roland \& Morris Disability Questionnaire and the Oswestry Disability Questionnaire. This review has been published as a full-text article after the 5th SIF Congress. ${ }^{1}$ Based on the 11 studies included, the authors concluded that none of the two instruments has proved to be superior to the other so far, but future studies should focus on directly comparing content and structural validity of these questionnaires, as this has not yet been done.

\section{Acknowledgement}

The authors of this study would like to acknowledge the Wetenschappelijk College Fysiotherapie (WCF) of the Royal Dutch Society for Physical Therapy (KNGF) that funded this study.

\section{References}

1. Chiarotto A, Maxwell LJ, Terwee CB, Wells GA, Tugwell P, Ostelo RW. Roland-Morris Disability Questionnaire and Oswestry Disability Index: Which Has Better Measurement Properties for Measuring Physical Functioning in Nonspecific Low Back Pain? A Systematic Review and MetaAnalysis. Phys Ther. 2016 Apr 14. [Epub ahead of print]

P11

Prevalence of myofascial trigger points in spinal pain disorders: systematic review and meta-analysis

Alessandro Chiarotto ${ }^{1}$, Ron Clijsen ${ }^{2}$, Cesar Fernandez-de-las-Penas ${ }^{3}$, Marco Barbero ${ }^{2}$

'Department of Health Sciences, VU University, Amsterdam, the Netherlands; ${ }^{2}$ Department of Business, Health and Social Care, University of Applied Sciences and Arts of Southern Switzerland (SUPSI), Manno, Switzerland; ${ }^{3}$ Department of Physical Therapy, Occupational Therapy, Rehabilitation and Physical Medicine, Universidad Rey Juan Carlos, Madrid, Spain

Correspondence: Alessandro Chiarotto (ottoale.physio@gmail.com) Department of Health Sciences, VU University, Amsterdam, the Netherlands

Archives of Physiotherapy 2016, 6(Suppl 1):P11

In this oral communication the authors describe the results of a systematic review on the prevalence of Myofascial trigger points (MTrPs) in subjects with spinal pain disorders, that has been published as a full-text article after the 5th S.I.F. Congress [1]. Based on the twelve cross-sectional studies included in the review, active MTrPs were found to be present in all assessed muscles of subjects with back pain. However, the authors concluded that the prevalence estimates should be taken cautiously and further high-quality studies with larger samples are still needed in this field.

\section{Acknowledgement}

The authors of this study would like to acknowledge the Thim van der Laan foundation that provided funding for this study.

\section{References}

1. Chiarotto A, Clijsen R, Fernandez-de-Las-Penas C, Barbero M. Prevalence of Myofascial Trigger Points in Spinal Disorders: A Systematic Review and Meta-Analysis. Arch Phys Med Rehabil. 2016 Feb;97(2):316-37. 
P12

Post-surgical scar rating scales in physiotherapy: a systematic

\section{review}

Ciceri Matteo ${ }^{1}$, Rossetti Sara ${ }^{2}$, Vercelli Stefano ${ }^{3}$

${ }^{1}$ School of Physiotherapy, University of Insubria, Varese, Italy; ${ }^{2}$ School

of Physiotherapy, University of Piemonte Orientale, Novara, Italy;

${ }^{3}$ Unit of Occupational Rehabilitation and Ergonomics, Salvatore

Maugeri Foundation - IRCCS, Veruno (NO), Italy

Correspondence: Ciceri Matteo (cicecm@hotmail.it) - School of

Physiotherapy, University of Insubria, Varese, Italy

Archives of Physiotherapy 2016, 6(Suppl 1):P12

\section{Background and objectives}

Pathologic scars can induce patients to pursue treatment due to symptoms, functional restrictions, or poor aesthetics $[1,2]$. Physical and psychological aspects can have both a significant impact on the patient's well-being and quality of life (QoL), although it remains debatable which specific scar features should be included in a scale to ensure a complete evaluation in rehabilitation [3]. In the last five years new scales have been created and others have been supplemented with data regarding their clinimetric properties. Aim of this study was to review the most used and clinimetrically sound outcome measures currently available for post-surgical scar assessment in rehabilitation. This will assist clinicians and researchers in choosing the more appropriate and suitable scar rating scale for their specific needs.

\section{Methods}

A systematic review of the Medline and Embase databases was performed up to July, 2015. All published peer-reviewed studies referring to the development, validation or clinical use of scales or questionnaires in patients with post-surgical scars were screened. Of 922 articles initially identified, 48 full-text articles were retrieved for assessment. Of these, 16 met inclusion criteria for data collection. Data were collected pertaining to instrument item domains, validity, reliability, and Rasch analysis.

Results

Eight outcome measures were identified. Scales examined with their clinimetric properties based on classical test theory are shown in Table 1.

\section{Discussion}

When choosing a scar rating scale, clinicians and researchers must consider which aspects are most relevant to their practice or research design, and thus which -and how many differenttools best fit their needs. From a strictly clinimetric point of view the Patient and Observer Scar Assessment Scale (POSAS) and Patient-Reported Impact of Scars Measure (PRISM) may be preferred over others scales, even if further validation is needed to test their responsiveness, interpret score changes for clinical studies, and adapt them for use in different languages and cultural contexts.

\section{Conclusions}

There is currently no gold standard to be used in rehabilitation for assessing post-surgical scars, although the POSAS -used to measure scar quality and symptoms- and PRISM -used to measure QoL in patints with scar- emerged as the most robust scales.

\section{References}

1. Vercelli S, Ferriero G, Sartorio F, Stissi V, Franchignoni F. How to assess postsurgical scars: A review of outcome measures. Disabil Rehabil. 2009;31:2055-2063.

2. Ferriero G, Vercelli S, Salgovic L, Sartorio F, Franchignoni F. Is adherent scar always nonpliable? Plast Reconstr Surg. 2011;127:2518-2519

3. van der Wal MBA, Verhaegen PDHM, Middelkoop E, van Zuijlen PPM. A clinimetric overview of scar assessment scales. J Burn Care Res. 2012:33:e79-e87.
Table 1 (abstract P12) Psychometric properties of scar rating scales based on classical test theory

\begin{tabular}{|c|c|c|c|c|c|c|}
\hline Authors (year) & Scar Types & $\begin{array}{l}\text { Sample } \\
\text { Size (n) }\end{array}$ & Scale & $\begin{array}{l}\text { Internal } \\
\text { Consistency } \\
\text { (Cronbach } \\
\text { alpha) }\end{array}$ & $\begin{array}{l}\text { Convergent } \\
\text { Validity }\end{array}$ & Reliability \\
\hline $\begin{array}{l}\text { Beausang et al. } \\
\text { (1998) }\end{array}$ & $\begin{array}{l}\text { Excisioned } \\
\text { scars }\end{array}$ & 69 & MSS & / & $\begin{array}{l}\text { Correlation with } \\
\text { histology } \\
(p<0.001)\end{array}$ & $\begin{array}{l}\text { Intra-observer: } \\
\text { variation } \\
\text { between } 8 \% \text { and } \\
15 \% \\
\text { Inter-observer } \\
\text { (Spearman): } \\
0.87 \text { (range } \\
0.83-0.89 \text { ) }\end{array}$ \\
\hline $\begin{array}{l}\text { van de Kar et al. } \\
\text { (2005) }\end{array}$ & $\begin{array}{l}\text { Linear surgical } \\
\text { scars }\end{array}$ & 100 & $\begin{array}{l}\text { POSAS } \\
(v .2 .0)\end{array}$ & $\begin{array}{l}0.86 \text { [OSAS]; } \\
0.90 \text { [PSAS] }\end{array}$ & / & $\begin{array}{l}\text { Inter-observer } \\
\text { (ICC): } 0.88 \\
\text { (95\%Cl } 0.84-0.91) \\
\text { [OSAS]; } \\
\text { Test-retest (ICC): } \\
0.94 \text { ( } 95 \% \text { Cl } \\
0.91-0.96) \\
\text { [PSAS] }\end{array}$ \\
\hline $\begin{array}{l}\text { Truong et al. } \\
\text { (2005) }\end{array}$ & $\begin{array}{l}\text { Linear scars } \\
\text { from breast } \\
\text { and axillary } \\
\text { surgery }\end{array}$ & 106 & vSS & 0.79 & $\begin{array}{l}\text { Agreement with } \\
\text { patient rating of } \\
\text { scar pliability } \\
(p=0.01) \text { and } \\
\text { color }(p=0.001) ; \\
\text { no correlation } \\
\text { with patients' } \\
\text { satisfaction } \\
(p=0.12)\end{array}$ & $\begin{array}{l}\text { Inter-observer } \\
\text { (ICC): } 0.64 \text { (95\%Cl } \\
0.51-0.74)\end{array}$ \\
\hline Bock et al. (2006) & $\begin{array}{l}\text { Keloids, } \\
\text { hypertrophic } \\
\text { scars }\end{array}$ & 100 & $\begin{array}{l}\text { Bock } \\
\text { Qol }\end{array}$ & $\begin{array}{l}\text { Psychological } \\
\text { scale: } 0.86-0.88 \text {; } \\
\text { Physical scale: } \\
0.77-0.78\end{array}$ & $\begin{array}{l}\text { Correlation } \\
\text { between } \\
\text { Psychological } \\
\text { and Physical } \\
\text { scales (Pearson): } \\
0.20-0.22\end{array}$ & $\begin{array}{l}\text { Test-retest } \\
\text { (Pearson): } \\
\text { Psychological } \\
\text { scale: } 0.96 ; \\
\text { Physical scale: } \\
0.94\end{array}$ \\
\hline $\begin{array}{l}\text { Singer et al. } \\
(2007)\end{array}$ & $\begin{array}{l}\text { Scars from } \\
\text { surgical } \\
\text { incisions and } \\
\text { traumatic } \\
\text { lacerations }\end{array}$ & 50 & SBSES & / & $\begin{array}{l}\text { Correlation with } \\
\text { VAS for } \\
\text { cosmetic } \\
\text { appearance } \\
\text { (Spearman): } \\
0.75-0.92\end{array}$ & $\begin{array}{l}\text { Inter-obsenver } \\
\text { (Spearman): } 0.73- \\
0.85\end{array}$ \\
\hline \multirow[t]{2}{*}{$\begin{array}{l}\text { Truong et al. } \\
\text { (2007) }\end{array}$} & $\begin{array}{l}\text { Linear scars } \\
\text { from breast } \\
\text { surgery }\end{array}$ & 31 & vSS & 0.71 & $\begin{array}{l}\text { Correlation with } \\
\text { OSAS }(p<0.001) \text {; } \\
\text { no correlation } \\
\text { with PSAS } \\
(p=0.18)\end{array}$ & $\begin{array}{l}\text { Inter-observer } \\
\text { (ICC): } 0.54 \text { (95\%CI } \\
0.33-0.73)\end{array}$ \\
\hline & & & $\begin{array}{l}\text { POSAS } \\
\text { (v1.0) }\end{array}$ & $\begin{array}{l}0.74 \text { [OSAS]; } \\
0.77 \text { [PSAS] }\end{array}$ & $\begin{array}{l}\text { OSAS: } \\
\text { correlations } \\
\text { with VSS } \\
(p<0.001) \text { and } \\
\text { with PSAS } \\
(p=0.04)\end{array}$ & $\begin{array}{l}\text { Inter-observer } \\
\text { (ICC): 0.33 (95\%CI } \\
0.11-0.56) \text { [OSAS] }\end{array}$ \\
\hline Balci et al. (2009) & $\begin{array}{l}\text { Keloids, } \\
\text { hypertrophic } \\
\text { scars }\end{array}$ & 48 & DLQ & 0.78 & / & / \\
\hline $\begin{array}{l}\text { Deslauriers et al. } \\
\text { (2009) }\end{array}$ & $\begin{array}{l}\text { Scars from } \\
\text { orthopaedic } \\
\text { surgery }\end{array}$ & 53 & $\begin{array}{l}\text { PSAS- } \\
\mathrm{Fr}\end{array}$ & 0.98 & / & $\begin{array}{l}\text { Test-retest (ICC): } \\
0.96 \text { (range 0.78- } \\
0.96 \text { ) }\end{array}$ \\
\hline $\begin{array}{l}\text { Durani et al. } \\
\text { (2009) }\end{array}$ & $\begin{array}{l}\text { Scars from } \\
\text { cardiothoracic } \\
\text { and varicose } \\
\text { vein surgery, } \\
\text { nevi excision, } \\
\text { scar revision }\end{array}$ & 372 & PSAQ & $\begin{array}{l}\text { All subscales: } \\
0.73-0.94\end{array}$ & $\begin{array}{l}\text { Correlations } \\
\text { with: clinician } \\
\text { VAS ( } p<0.01 \text { ) } \\
\text { except for } \\
\text { Satisfaction with } \\
\text { symptoms } \\
\text { subscale; patient } \\
\text { VAS ( } p<0.01) \text {; } \\
\text { MSS ( } p<0.01 \text { ) } \\
\text { except for } \\
\text { Satisfaction with } \\
\text { symptoms } \\
\text { subscale }\end{array}$ & $\begin{array}{l}\text { Test-retest (ICC): } \\
\text { Cardiothoracic } \\
\text { and vein groups } \\
0.71-0.86 ; \text { Nevi } \\
\text { excision group } \\
0.48-0.86 ; \text { Scar } \\
\text { revision group } \\
0.37-0.74\end{array}$ \\
\hline $\begin{array}{l}\text { Brown et al. } \\
\text { (2010) }\end{array}$ & $\begin{array}{l}\text { Normal, } \\
\text { depressed, } \\
\text { stretched, and } \\
\text { raised scars }\end{array}$ & 103 & PRISM & $\begin{array}{l}\text { QoL: 0.92-0.93; } \\
\text { Symptoms: } \\
0.84-0.85\end{array}$ & $\begin{array}{l}\text { Correlations } \\
\text { between QoL } \\
\text { and HADS, QoL } \\
\text { and GWBI (all } \\
\text { p<0.01); } \\
\text { between } \\
\text { Symptoms and } \\
\text { HADS ( } p<0.05 \text { ), } \\
\text { and Symptoms } \\
\text { and GWBI } \\
(p<0.01)\end{array}$ & $\begin{array}{l}\text { Test-retest (ICC): } \\
\text { QoL: } 0.89 ; \\
\text { Symptoms: } 0.83\end{array}$ \\
\hline $\begin{array}{l}\text { Ferriero et al. } \\
(2010)\end{array}$ & $\begin{array}{l}\text { Adherent } \\
\text { post-surgical } \\
\text { scars }\end{array}$ & 25 & vSS & I & $\begin{array}{l}\text { Correlation with } \\
\text { Adheremeter } \\
\text { severity index } \\
(p<0.05)\end{array}$ & / \\
\hline $\begin{array}{l}\text { Nicholas et al. } \\
\text { (2012) }\end{array}$ & Keloid scars & 41 & VSS & 0.65 & $\begin{array}{l}\text { Correlation with } \\
\text { OSAS }(p<0.01) \\
\text { No correlation with } \\
\text { PSAS }(p=0.29)\end{array}$ & $\begin{array}{l}\text { Inter-observer } \\
\text { (ICC): } 0.38 \text { (95\%Cl } \\
0.19-0.57)\end{array}$ \\
\hline
\end{tabular}


Table 1 (abstract P12) Psychometric properties of scar rating scales based on classical test theory (Continued)

\begin{tabular}{|c|c|c|c|c|c|c|}
\hline & & & $\begin{array}{l}\text { POSAS } \\
(v .2 .0)\end{array}$ & $\begin{array}{l}0.86 \text { [OSAS]; } \\
0.82 \text { [PSAS] }\end{array}$ & $\begin{array}{l}\text { OSAS: } \\
\text { correlation with } \\
\text { VSS }(p<0.01) \text {; } \\
\text { no correlation } \\
\text { with PSAS } \\
(p=0.34)\end{array}$ & $\begin{array}{l}\text { Inter-observer } \\
\text { (ICC): } 0.66 \text { (95\%CC } \\
0.51-0.79) \text { [OSAS] }\end{array}$ \\
\hline $\begin{array}{l}\text { Economopoulos } \\
\text { et al. (2012) }\end{array}$ & $\begin{array}{l}\text { Scars from } \\
\text { thyroid and } \\
\text { parathyroid } \\
\text { surgery }\end{array}$ & 696 & PSAQ & $\begin{array}{l}\text { Appearance: } \\
0.79 ; \\
\text { Consciousness: } \\
0.85\end{array}$ & I & $\begin{array}{l}\text { Test-retest (ICC; } \\
\text { sample size: } 70): \\
\text { Appearance } 0.79 \\
(95 \% \text { Cl } 0.69- \\
0.87) ; \\
\text { Consciousness } \\
0.81 \text { (95\%Cl } \\
0.71-0.88)\end{array}$ \\
\hline Choi et al. (2014) & $\begin{array}{l}\text { Linear, linear } \\
\text { bulging, } \\
\text { hypertrophic, } \\
\text { adhesive } \\
\text { scars }\end{array}$ & 97 & DLQI & / & $\begin{array}{l}\text { Correlation with } \\
\text { symptoms } \\
(p<0.05) \text {, but } \\
\text { not with VSS } \\
\text { ( } p=0.769) \text {, type } \\
\text { of scar } \\
(p=0.724) \text {, time } \\
\text { elapsed after } \\
\text { surgery } \\
(p=0.812)\end{array}$ & I \\
\hline
\end{tabular}

Legend: VSS Vancouver Scar Scale, DLQI Dermatology Life Quality Index, MSS Manchester Scar Scale, POSAS Patient and Observer Scar

Assessment Scale, Bock QoL Bock Quality of Life questionnaire, SBSES Stony Brook Scar Evaluation Scale, PRISM Patient-Reported Impact of Scars Measure, PSAQ Patient Scar Assessment Questionnaire, HADS Hospital Anxiety and Depression Scale, GWBI General Well-Being Index, VAS Visual Analogue Scale, ICC Intraclass Correlation Coefficient

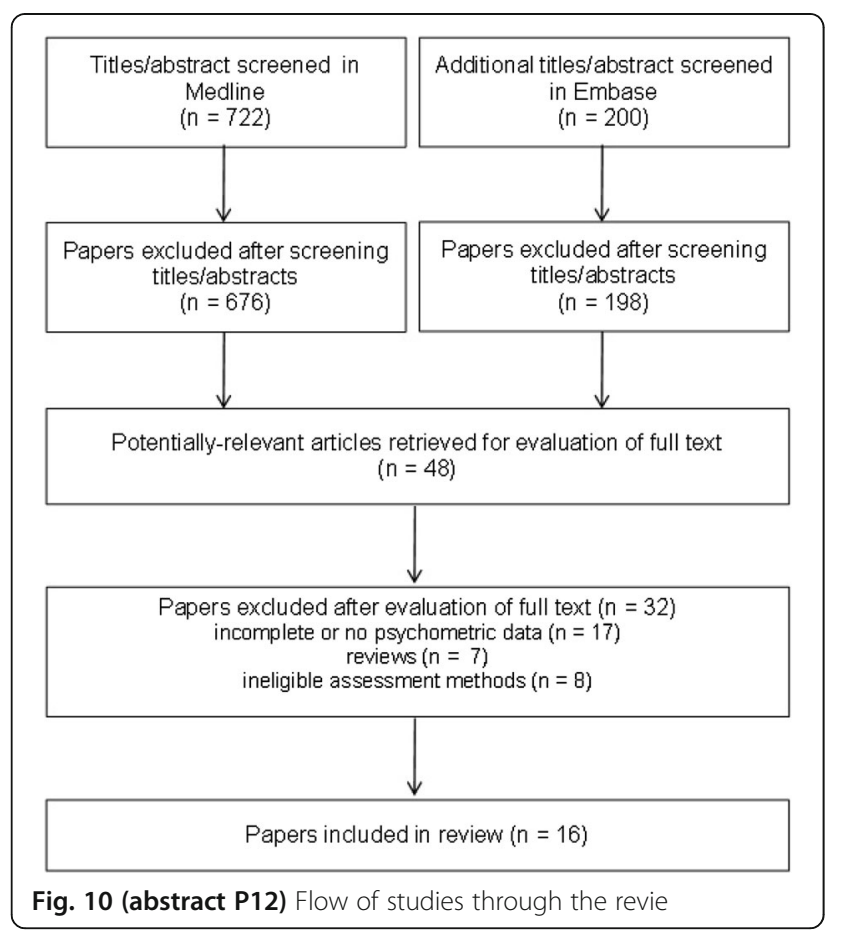

P13

Does a pre-surgery Action Observation training impact on the functional recovery after hip and knee replacement? A randomized controlled trial

Cislaghi $M^{1}$, Penone $G^{1}$, Marinelli $G^{2}$, Rezzan $G^{2}$, Melegati $G^{3}$, Gatti $R^{4}$

${ }^{1}$ Vita-Salute San Raffaele University, Milan, Italy; ${ }^{2}$ Vita-Salute San Raffaele

University, Milan, Italy; ${ }^{3}$ Rehabilitation I Unit, Center for Sports

Rehabilitation, IRCCS Galeazzi Orthopaedic Institute, Milan, Italy;

${ }^{4}$ Laboratory of Analysis and Rehabilitation of Motor Function,

Neuroscience Division, San Raffaele Hospital, Milan, Italy

Correspondence: Cislaghi M (m.cislaghi@studenti.unisr.it) - Vita-Salute

San Raffaele University, Milan, Italy

Archives of Physiotherapy 2016, 6(Suppl 1):P13

\section{Background and aim}

Several studies have shown that Action Observation (AO) $[1,2]$ is effective in neurologic diseases but its effects in musculoskeletal conditions has been poorly investigated [3]. In particular, no study examined so far the efficacy of the AO training delivered before ortophaedic surgery. This study was aimed at verifying if a pre-surgery AO training has effects on functional recovery after hip and knee replacement. Preliminary data collected in a small sample of patients have been presented at the World Confederation for Physical Therapy Congress 2015 [4].

Materials and methods

Eighty subjects were recruited from those who were waiting for primary hip or knee replacement surgery at the Galeazzi Orthopaedic Institute of Milan. They were randomized into 2 groups: AO+B (action observation + educational brochure) and $\mathrm{B}$ (educational brochure). The subjects of the experimental group $(A O+B)$ from the day of the pre-recovery until the day before surgery watched daily a video (18 minutes) showing strengthening exercises and functional activities proposed during the postoperative rehabilitation. Participants in both groups were also given a booklet containing the same information of the video. After the surgery both groups performed the same physiotherapy intervention. The participants were evaluated by a blind physical therapist before (7-40 days) surgery (T0), at discharge after 10-20 days of inpatient rehabilitation (T1), and at approximately 40 days post-surgery (T2). Assessment included 6MWT, 10MWT, VAS and SF-36. Specific tests, including the OHS, the KOOS and the active ROM of knee, were also applied in subgroups (hip and knee surgery) of participants.

Results

The analysis of the first 31 participants with non-parametric tests showed no significant difference between the groups. However, in the $\mathrm{AO}+\mathrm{B}$ group the improvement in $10 \mathrm{MWT}$ and $6 \mathrm{MWT}$ was significantly associated to the days of video observation (10MWT: $r=-0.64$, $p=0.01 ; 6 \mathrm{MWT}: \mathrm{r}=0.48, \mathrm{p}=0.07$ )

Discussion and conclusion

The correlation between the days of video administration and the improvement of gait might indicate that the preoperative AO training has effects on the functional recovery following hip and knee replacement surgery only when lasting over a sufficiently long period.

\section{References}

1. Buccino G, Solodkin A, L. Small S. Functions of the Mirror neuron System: implication for neurorehabilitation. Cog Behav Neurol. 2006; 19: 55-63.

2. Fadiga L, Fogassi L, Pavesi G, Rizzolatti G. Motor facilitation during Action Observation: a magnetic stimulation study. J Neurophysiol 19.95; 73(6): 2608-11.

3. Bellelli G, Buccino G, Bernardini B, Padovani A, Trabucchi M. Action observation treatment improves recovery of postsurgical orthopedic patients: evidence for a top-down effect? Arch Phys Med Rehabil. 2010; 91: 1489-94.

4 Rezzan G, Marinelli G, Margato F, Melegati G, Tettamanti A, Gatti R. Efficacy of action observation pre-operative training in functional recovery after hip and knee prosthesis. Physiotherapy 2015; 11(Suppl 1):e1502-3. 
P14

The use of Kinesio Taping in the treatment of hematomas: can we distinguish fancy from the effects?

Colombo Claudio ${ }^{1}$, Tolosa Francesca ${ }^{2}$, Andrea Moriondo ${ }^{3}$, Vercelli Stefano 4

${ }^{1}$ Private Practice, Verbania, Italy; ${ }^{2}$ Private Practice, Oleggio (NO), Italy;

${ }^{3}$ Department of Surgical and Morphological Sciences, University of Insubria, Varese, Italy; ${ }^{4}$ Unit of Occupational Rehabilitation and Ergonomics, Salvatore Maugeri Foundation - IRCCS, Veruno (NO), Italy Correspondence: Colombo Claudio (colombo.claudio92@gmail.com) Private Practice, Verbania, Italy

Archives of Physiotherapy 2016, 6(Suppl 1):P14

\section{Background and objective}

Kinesio Taping (KT) has been proposed to improve circulation and superficial hematomas [1]. One of the key working mechanisms involves the formation of convolutions on the patient's skin. Nevertheless, no advantages of using KT to generate convolutions have been recently observed in patients with low back pain [2], and their role in the treatment of hematomas has never been tested before. Aim of this study was to analyze the effects of KT, applied with and without the formation of convolutions, on color intensity of superficial hematomas.

Material and methods

This study had a cross-sectional design. The KT was applied for $24 \mathrm{~h}$ on 13 patients with a post-surgical superficial hematoma. Three tails were randomly applied with different degrees of strain, expecting to obtain respectively the correct formation of convolutions, some convolutions, and no convolution. The independent variables were the 3 strain levels, while the dependent variable was the color intensity of skin. The color intensity was measured on digital images captured with a standardized system, and it was processed with the method of polar coordinates CIE $L^{*} a^{*} b^{*}[3,4]$.

Results

Applying KT to hematomas did not significantly change $(p>0.05)$ the color intensity in the central area under the tape. There was a significant treatment effect $(p<0.05)$ under the edges of the tape, independently from the formation of convolutions ( $p>0.05)$.

\section{Discussion}

The experimental hypothesis of this study was based on remarkable skin color changes observed in patients treated with KT. Our results were not related with the formation of convolutions, and significant changes were observed only along the edges of the tape. This could be related to the pressure gradient created between the KT edges and the adjacent area. The conflict between statistical results and clinical experiences was resolved by taking into consideration a well-known visual perceptive effect called Cornsweet effect [5].

Conclusions

The effects of KT on hematomas are not likely to be influenced by the formation of convolutions. Moreover, the relationship between the local reduction of color intensity and the actual healing of subcutaneous tissues remains to be confirmed. Future studies will serve to deepen the rationale of the KT working mechanisms.

\section{References}

1. Kase K, Wallis J, Kase T. Clinical Therapeutic Applications of the Kinesio Taping Method. Tokyo, Japan: Ken Ikai Co Ltd; 2003.

2. Parreira Pdo C, Costa Lda C, Takahashi R, Junior LC, Junior MA, Silva TM, Costa LO. Kinesio Taping to generate skin convolutions is not better than sham taping for people with chronic non-specific low back pain: a randomised trial. J Physiother. 2014;60(2):90-6.

3. Kaartinen IS, Välisuo PO, Alander JT, Kuokkanen HO. Objective scar assessment-A new method using standardized digital imaging and spectral modelling. Burns. 2011;37:74-81.

4. Hallam MJ, McNaught K, Thomas AN, Nduka C. A practical and objective approach to scar colour assessment. J Plast Reconstr Aesthet Surg. 2013;66(10):e271-6.

5. Cornsweet TN. Visual perception. New York, NY: Academic Press, 1970.
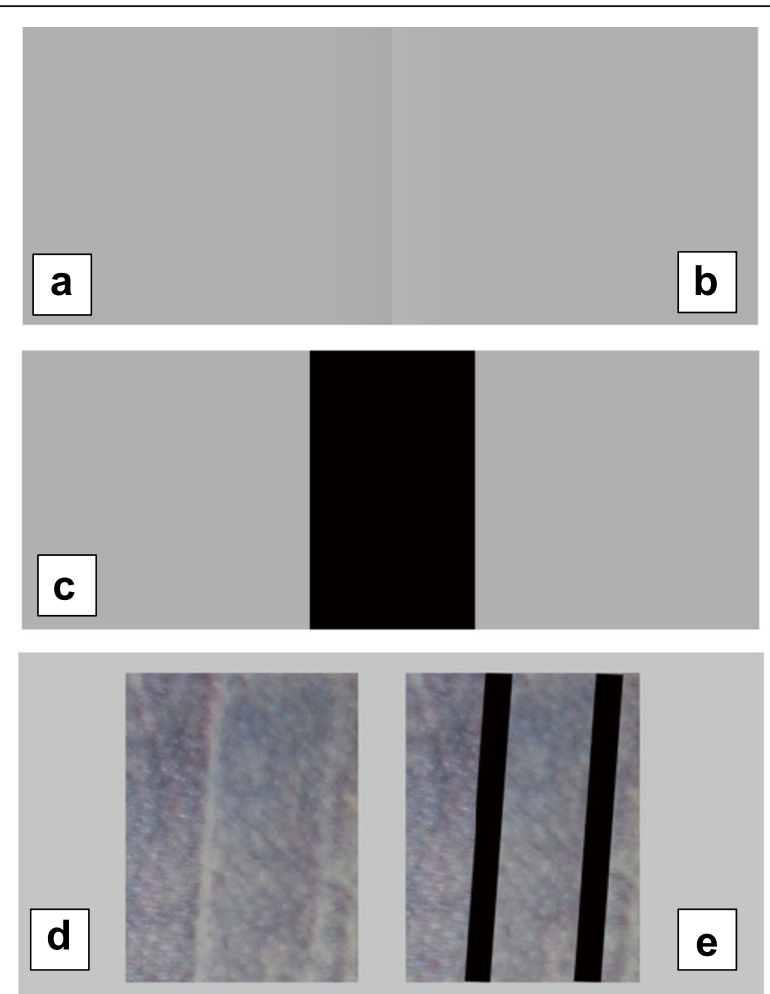

Fig. 11 (abstract 14) Graphical representation of the Cornsweet effect $^{5}$ : the two areas in the upper image have the same hue and brightness, but are perceived by the human eye as two different shades of gray -a darker (a) and a lighter one (b)- due to the presence of the central 'ridge', which consists of two rows of pixels of different shades of gray. When the central ridge is hidden by a black band (c) this effect is no longer evident. Observing the lower image from a patient's skin, on the left (d) one perceives the area under KT tail as lighter than the surrounding skin. This perceived difference in chromatic intensity is reduced when the areas near the margins are hidden (e)

P15

Who is able to perform explicit motor imagery after stroke?

Stefano Doronzio', Matteo $\mathrm{Paci}^{2}$

${ }^{1}$ Private practice, Prato, Italy; ${ }^{2}$ Unit of Functional Rehabilitation,

Department of Continuing Care, Azienda USL 4, Prato, Italy

Correspondence: Stefano Doronzio (doronziostefano@gmail.com) -

Private practice, Prato, Italy

Archives of Physiotherapy 2016, 6(Suppl 1):P15

\section{Introduction}

Motor imagery can be defined as the imagining of actions without their execution [1]. The selection of patients is a key factor for implement motor imagery into clinical practice. This study is aimed to identify which type of demographic and clinical characteristics are associated with an impaired ability to perform explicit motor imagery in patients with hemiplegia following stroke.

Methods

A sample of patients were recruited and assessed with the KVIQ-10 [2], composed of visual (V) and kinesthetic (K) subscales and mental chronometry for each item of the scale, in order to evaluate participants' motor imagery vividness. Demographic and clinical features (age, gender, type of stroke, side of lesion, time from stroke and stroke clinical subtype), including physical impairments assessments (Fugl-Meyer Scale and modified Ashworth scale) were also recorded and put in a multiple regressions analysis to select variables significantly associated with: (1) the total score of the KVIQ visual imagery section; (2) the total score of the KVIQ motor imagery section; (3) the 
total chronometry of the visual section; (4) the total chronometry of the Kinesthetic section. Further stepwise multiple regressions with separate values for limb (upper and lower limbs) were performed. Results

Forty-two right-handed persons with stroke (age $=68.4 \pm 13.3$ years with duration of symptoms $13.3 \pm 43.1$ months) were able to comply with the KVIQ-10. Regression models show that time from stroke is able to predict mental chronometry of the KVIQ-10 K and V subscores (adjusted $\mathrm{R}^{2}=$ .081 and .077 , respectively), $\mathrm{K}$ upper limb mental chronometry (adjusted $\mathrm{R}^{2}=.063$ ), $\mathrm{K}$ and $\mathrm{V}$ lower limb mental chronometry (adjusted $\mathrm{R}^{2}=.079$ and .076 , respectively). All the other variables were not included in the models. Discussion

This study shows that time from stroke is the unique independent predictor for mental chronometry. However, since it explains only a small part of the variability, more variables should be investigated in larger samples. Our results suggest that patients ability to perform MI may decrease with time after stroke.

\section{References}

1. Malouin F, Richards CL, Durand A.Slowing of motor imagery after a right hemispheric stroke. Stroke Res Treat. 2012:297217.

2. Malouin F, Richards $\mathrm{CL}$, Jackson PL, Lafleur MF, Durand A, Doyon J. The Kinesthetic and Visual Imagery Questionnaire (KVIQ) for assessing motor imagery in persons with physical disabilities: a reliability and construct validity study. J Neurol Phys Ther. 2007;31: 20-29.

Table 2 (abstract P15) Patients' demographic and clinical characteristics

\begin{tabular}{lll}
\hline Age (years), mean \pm SD & & $68.4 \pm 13.3$ \\
Gender (males) number (\%) & & $26(61.9 \%)$ \\
Time from stroke (months), mean \pm SD & & $13.3 \pm 43.1$ \\
Type of stroke (ischaemic), number (\%) & & $30(71.4 \%)$ \\
Side of hemiplegia (right), number (\%) & & $16(38.1 \%)$ \\
OCSP Classification, number (\%) & TACS & $16(38.1 \%)$ \\
& PACS & $11(26.2 \%)$ \\
& POCS & $6(14.3 \%)$ \\
SPMSQ score, mean \pm SD & LACS & $9(21.4 \%)$ \\
Neglect, number (\%) & & $1.1 \pm 1.3$ \\
Aphasia, number (\%) & & $3(7.1 \%)$ \\
MAS score, mean \pm SD & & $4(9.5 \%)$ \\
Fugl-Meyer Pain, mean \pm SD & Total score & $6.1 \pm 7.0$ \\
Fugl-Meyer Motricity, mean \pm SD & Upper Limb & $3.3 \pm 4.0$ \\
& Lower limb & $18.4 \pm 1.7$
\end{tabular}

OCSP Oxfordshire Community Stroke Project classification, TACS total anterior circulation syndrome, PACS partial anterior circulation syndrome, LACS lacunar syndrome, POCS posterior circulation syndrome, SPMSQ Short Portable Mental Status Questionnaire, MAS modified Ashworth scale, ROM range of motion
P16 Responsiveness of the Bridge tests in Symptomatic Lumbar Spondylolisthesis

Silvano Ferrari ${ }^{1}$, Carla Vanti ${ }^{2}$, Marco Monticone ${ }^{3}$

${ }^{1}$ Master of Manual Therapy and Musculoskeletal Rehabilitation, University of Padova, Padova, Italy; ${ }^{2}$ Department of Biomedical and Neuromotor Sciences, University of Bologna, Bologna, Italy; ${ }^{3}$ Physical Medicine and Rehabilitation Unit, Salvatore Maugeri Foundation, IRCCS, Lissone (Monza Brianza), Italy

Correspondence: Silvano Ferrari (silvano.ferrari@fastwebnet.it) - Master of Manual Therapy and Musculoskeletal Rehabilitation, University of Padova, Padova, Italy

Archives of Physiotherapy 2016, 6(Suppl 1):P16

\section{Background and objective}

Bridging maneuvers, also called Bridge tests (BTs), were proposed to detect abdominal and spinal muscles stabilization endurance. They were also used to train lumbar muscles in patients with low back pain (LBP). To date no study was made on the responsiveness of BTs in subjects with LBP and Spondylolisthesis (SPL) submitted to a physical therapy program. The aim of this study was to examine the ability of BTs to be responsive in detecting clinical changes after conservative treatments in subjects with symptomatic lumbar spondylolisthesis.

\section{Materials and methods}

This prospective cohort observational study involved two Outpatient Physical Therapy Clinics. 120 adults with symptomatic SPL were included. Patients received physical therapy treatments targeted to the symptomatic SPL including the performance of supervised exercises and the teaching of home exercises program to improve the lumbar stability. Two expert Orthopaedic Physical Therapists collected the measurements and administered the treatments. At the beginning and immediately after the treatment, the participants completed a booklet containing the Oswestry Disability Index-Italian version (ODI-I), a Numerical Rating Scale (NRS), and performed the Supine Bridge Test (SBT) and the Prone Bridge Test (PBT). The global perception of effectiveness was measured with a 7-point Likert scale (GPE).

Results

The mean post-treatment change of PBT was $18.2(14.5 ; 21.9)$ and the effect size $-0.62(P<0.001)$; the SBT results were $43.9(35.1 ; 52.8)$ and $-0.75(P<0.001)$, respectively. All other outcome measures (NRS and ODI-I) showed statistically significant improvements after the period of treatment (Table 3).

Discussion

Our results showed a relevant effect of the treatment on the BTs scores. The changes in BTs scores appeared also significantly related to the amount of perceived improvement and were coherent with the changes in the other outcome measures (NRS and ODI-I). Most part of patients in our sample referred a much better or better condition on GPE, so we cannot comment about the responsiveness of BTs in subjects who did not change or worsened their state.

Conclusions

Bridge maneuvers proved to be responsive and may be suggested to detect clinical changes after conservative treatment in subjects with symptomatic SPL.

\section{References}

1. Ferrari S, Vanti C, O'Reilly C. Clinical presentation and physiotherapy treatment of 4 patients with low back pain and isthmic spondylolisthesis. J Chiropr Med. 2012;11(2):94-103.

2. Ferrari S, Vanti C, Piccarreta R, Monticone M. Pain, Disability, and Diagnostic Accuracy of Clinical Instability and Endurance Tests in Subjects With Lumbar Spondylolisthesis. J Manipulative Physiol Ther. 2014; 37(9):647-59.

3. Ferrari S, Manni T, Bonetti F, Villafañe $J H$, Vanti C. A literature review of clinical tests for lumbar instability in low back pain: validity and applicability in clinical practice. Chiropr Man Ther. 2015 Apr 8;23:14.

4. Monticone $M$, Baiardi $P$, Vanti C, Ferrari S, Pillastrini P, Mugnai R, Foti C. Responsiveness of the Oswestry Disability Index and the Roland Morris Disability Questionnaire in Italian subjects with sub-acute and chronic low back pain. Eur Spine J. 2012;21(1):122-129.

5. Schellenberg KL, Lang JM, Chan KM, Burnham RS. A clinical tool for office assessment of lumbar spine stabilization endurance: prone and supine bridge maneuvers. Am J Phys Med Rehabil. 2007;86(5):380-386. 
Table 3 (abstract P16) Instruments scores before and after treatment (data expressed as mean \pm SD)

\begin{tabular}{llllll}
\hline & Pre-treatment & Post-treatment & $\begin{array}{l}\text { Mean change } \\
(95 \%(\mathrm{Cl})\end{array}$ & Effect size & $P$ value \\
\hline ODI-I & $22.5 \pm 13.0$ & $10.7 \pm 9.5$ & $-11.8,(-13.6--9.9)$ & 1.04 & $<0.001$ \\
NRS & $43.9 \pm 23.0$ & $15.8 \pm 17.4$ & $-28.1,(-31.9 ;-24.3)$ & 1.38 & $<0.001$ \\
PBT & $23.5 \pm 26.4$ & $41.7 \pm 32.3$ & $18.2,(14.5 ; 21.9)$ & -0.62 & $<0.001$ \\
SBT & $76.4 \pm 60.1$ & $120.4 \pm 57.3$ & $43.9,(35.1 ; 52.8)$ & -0.75 & $<0.001$ \\
\hline
\end{tabular}

ODI-I Oswestry Disability Index, Italian version, NRS Numerical Rating Scale, $C I$ Confidence interval, PBT Prone Bridge Test, SBT Supine Bridge Test

\section{3 patients evaluated for spinal pain}

528 did not have

lumbar Spondylolisthesis

\section{5 subjects with symptomatic lumbar} Spondylolisthesis remained

5 subjects were excluded:

-1 had inflammatory spinal disease

-2 had peripheral neuropathy

-2 had previous spinal surgery

\section{0 subjects participated to the study: - 72 women \\ - 48 men}

Fig. 12 (abstract P16) Flow chart

P17

The relationship between number of sessions and clinical results in lumbar symptomatic spondylolisthesis

Silvano Ferrari ${ }^{1}$, Carla Vanti ${ }^{2}$, Marco Monticone ${ }^{3}$

${ }^{1}$ Master of Manual Therapy and Musculoskeletal Rehabilitation, University of Padova, Padova, Italy; ${ }^{2}$ Department of Biomedical and Neuromotor Sciences, University of Bologna, Bologna, Italy; ${ }^{3}$ Physical Medicine and Rehabilitation

Unit, Salvatore Maugeri Foundation, IRCCS, Lissone (Monza Brianza), Italy

Correspondence: Silvano Ferrari (silvano.ferrari@fastwebnet.it) - Master of Manual Therapy and Musculoskeletal Rehabilitation, University of Padova, Padova, Italy

Archives of Physiotherapy 2016, 6(Suppl 1):P17

\section{Background and objective}

The relationship between the number of sessions and the therapeutic effect has not been adequately investigated either in non-specific LBP or in symptomatic lumbar spondylolisthesis (SPL). The aim of this study was to evaluate the effectiveness of 5-8 vs 9-12 sessions of physical therapy treatments on the reduction of symptoms on Grade I symptomatic lumbar SPL. Materials and methods

A retrospective cohort study of 64 consecutive patients admitted for physical therapy with symptomatic lumbar grade I SPL was conducted. All participants were retrospectively assigned to one of two groups, receiving either 5-8 or 9-12 sessions (experimental or control group, respectively) of physical therapy treatments. Outcome measures were the Numeric Rating Scale for pain (NRS), the Italian version of the Oswestry Disability Index (ODI-I) for disability, the Prone Bridge Test (PBT) and the Supine Bridge Test (SBT) for muscular endurance. The number of therapeutic sessions required to achieve similar clinical and functional outcomes was recorded and compared between groups.

Results

Experimental group performed significantly less treatments than control group (6.1 \pm 0.8 vs $9.8 \pm 1.9, \mathrm{P}<0.001)$. However, both groups had similar outcomes in NRS and ODI-I (all, $\mathrm{p}<0.02$ ), and a significant effect of time interaction existed for PBT and SBT immediately after the intervention (all, $p<0.001$ ),

Discussion

This study showed that the performance of supervised graded exercises with education in a home exercise program in fewer treatment sessions is as effective as control group in more sessions, indicating that SPL may be responsive to a series of 5-8 treatment sessions delivered over a period of 6-8 weeks. Comparison of the clinical outcomes between groups revealed a similar attainment of physical performance level at discharge, measured with lumbar endurance (SBT and PBT). Similar rates of pain and disability were also found at the end of treatment.

Conclusions

In the treatment of symptoms on grade I SPL, 5-8 sessions of physical therapy are as effective as 9-12 sessions. Our study adds some information to assist physical therapists in clinical decision making on the number of expected treatment sessions for people presenting for treatment of SPL.

\section{References}

1. Ferrari S, Vanti C, O'Reilly C. Clinical presentation and physiotherapy treatment of 4 patients with low back pain and isthmic spondylolisthesis. J Chiropr Med. 2012;11(2):94-103.

2. Ferrari S, Vanti C, Piccarreta R, Monticone M. Pain, Disability, and Diagnostic Accuracy of Clinical Instability and Endurance Tests in Subjects With Lumbar Spondylolisthesis. J Manipulative Physiol Ther. 2014; 37(9):647-59.

3. Ferrari $S$, Manni $T$, Bonetti $F$, Villafañe $J H$, Vanti C. A literature review of clinical tests for lumbar instability in low back pain: validity and applicability in clinical practice. Chiropr Man Ther. 2015:8:23:14

4. Garet M, Reiman MP, Mathers J, Sylvain J. Nonoperative treatment in lumbar spondylolysis and spondylolisthesis: a systematic review. Sports Health. 2013; 5:225-32

5. McNeely ML, Torrance G, Magee DJ. A systematic review of physical therapy for spondylolysis and SPL. Man Ther. 2003;8: 80-91

Table 4 (abstract P17) Mean (SD) for each outcome at all study visits in each group, mean difference (SD) within groups, and mean difference (95\% Cl) between groups

\begin{tabular}{|c|c|c|c|c|c|c|c|}
\hline & \multicolumn{2}{|c|}{ Pre-treatment } & \multicolumn{2}{|c|}{ Post-treatment } & \multicolumn{2}{|c|}{$\begin{array}{l}\text { Within groups } \\
\text { difference }\end{array}$} & \multirow{2}{*}{$\begin{array}{l}\text { Between groups } \\
\text { difference } \\
\text { Exp minus Cntr }\end{array}$} \\
\hline & $\begin{array}{l}\operatorname{Exp} \\
(n=31)\end{array}$ & $\begin{array}{l}\text { Cntr } \\
(n=33)\end{array}$ & $\begin{array}{l}\operatorname{Exp} \\
(n=31)\end{array}$ & $\begin{array}{l}\text { Cntr } \\
(n=33)\end{array}$ & Exp & Cntr & \\
\hline NRS & $\begin{array}{l}49.3 \\
(24.6)\end{array}$ & $\begin{array}{l}47.4 \\
(21.2)\end{array}$ & $\begin{array}{l}17.4 \\
(20.3)\end{array}$ & $\begin{array}{l}16.3 \\
(18.2)\end{array}$ & & & $\begin{array}{l}-1.2(-11.3 \text { to } \\
8.9)\end{array}$ \\
\hline ODI-I & $\begin{array}{l}26.3 \\
(14.3)\end{array}$ & $\begin{array}{l}20.2 \\
(13.3)\end{array}$ & $\begin{array}{l}12.6 \\
(8.0)\end{array}$ & & & $\begin{array}{l}7.6^{*} \\
(3.7)\end{array}$ & $\begin{array}{l}-0.02(-6.4 \text { to } \\
6.4)\end{array}$ \\
\hline PBT & $\begin{array}{l}28.1 \\
(32.7)\end{array}$ & $\begin{array}{l}21.1 \\
(15.5)\end{array}$ & $\begin{array}{l}48.0 \\
(36.9)\end{array}$ & $\begin{array}{l}42.0 \\
(31.6)\end{array}$ & $\begin{array}{l}19.9^{*} \\
(4.5)\end{array}$ & $\begin{array}{l}20.9^{*} \\
(4.4)\end{array}$ & $\begin{array}{l}-6.0(-23.3 \text { to } \\
11.3)\end{array}$ \\
\hline SBT & $\begin{array}{l}101.0 \\
(66.4)\end{array}$ & $\begin{array}{l}78.0 \\
(52.0)\end{array}$ & $\begin{array}{l}133.2 \\
(59.3)\end{array}$ & $\begin{array}{l}130.1 \\
(46.6)\end{array}$ & $\begin{array}{l}32.2^{*} \\
(8.5)\end{array}$ & $\begin{array}{l}52.1^{*} \\
(8.5)\end{array}$ & $\begin{array}{l}-3.1(-30.7 \text { to } \\
24.5)\end{array}$ \\
\hline
\end{tabular}

NRS Numerical Rating Scale, ODI-I Oswestry Disability Index, Italian version, $P B T$ Prone Bridge Test, SBT Supine Bridge Test

a Post minus Pre; ${ }^{*} \mathrm{p}<0.05$ 


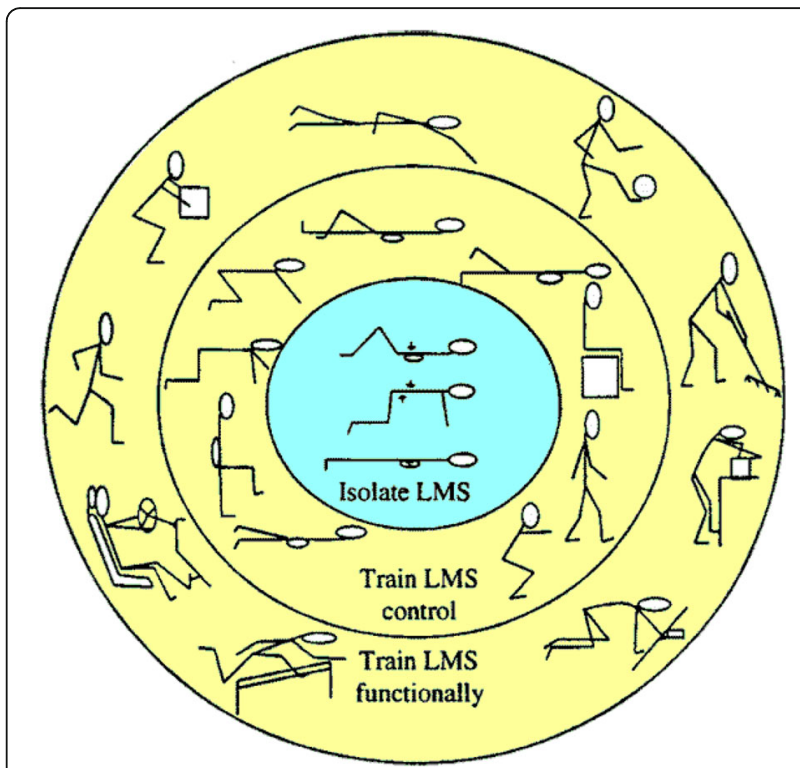

Fig. 13 (abstract P17) A model of stabilization exercises according to O'Sullivan approach (modified from: O' Sullivan P, Lumbar segmental instability: clinical presentation and specific stabilizing exercises management)

P18

Conservative treatments for upper extremity tendinopathies in occupational medicine: narrative review

Garzonio Fabiola', Zanetta Anna ${ }^{2}$, Bargeri Serena ${ }^{3}$, Cerone Giorgia ${ }^{4}$, Sartorio Francesco ${ }^{5}$

${ }^{1}$ Physiotherapist, private practice, Somma Lombarda, Varese, Italy; ${ }^{2}$ Physiotherapist, private practice, Nebbiuno, Novara, Italy;

${ }^{3}$ Physiotherapist, private practice, Borgomanero, Novara, Italy; ${ }^{4}$ School of Physiotherapy, University of Piemonte Orientale, Novara, Italy; ${ }^{5}$ Servizio di Fisiatria Occupazionale ed Ergonomia, Fondazione Salvatore Maugeri - IRCCS, Veruno (NO), Italy

Correspondence: Garzonio Fabiola (fabiolagarzonio@gmail.com) Physiotherapist, private practice, Somma Lombarda, Varese, Italy Archives of Physiotherapy 2016, 6(Suppl 1):P18

\section{Background and objective}

Lately, upper limbs tendinopathies (ULTs) experienced a dramatic increase among workers. Conservative treatments are the primary choice to relieve symptoms. However, scientific evidence about their effectiveness is debated. This paper aims to present a literature review about conservative interventions effects in work-related ULTs.

\section{Material and methods}

Literature searches were conducted using Medline and Embase (both January 2000 - May 2015), considering English, Italian and French papers. We included studies concerning conservative treatments for work-related ULTs in adults. We excluded trials about surgery.

Results

We included 152 studies, later separated in 15 categories: combined and individual interventions (Fig. 14).

\section{Discussion and conclusions}

Many authors have provided theoretical framework (i.e.: Protection, Rest, Ice, Compression, Elevation, Medicaments, Modalities - PRICEMM; Protection, Optimal Loading, Ice, Compression, Elevation POLICE; Education, Unloading, Reloading, Prevention - EdUReP) to assist physiotherapists in ULTs managing [1,2]. To help tendon healing, it's important to reduce absolute Resting time starting the rehabilitation promptly, base concepts of Optimal Loading/Reloading. Tendinopathies rehabilitation programs have emphasized appropriate, functional progression with concentric/eccentric work and job specific training. Significant improvements in pain and function have been shown in rotator cuff tendinopathy and lateral epicondylalgia. Combined Medicaments and Modalities are generally accepted to approach ULTs [3]. Histologically, inflammatory cells absence in tendinopathies has explained nonsteroidal anti-inflammatory drugs and corticosteroids inadequacy. Consequently, it's been proved their lacking evidence in long therm. Limited evidence supported ultrasound and laser in rotator cuff tendinopathy and moderate evidence in lateral epycondilalgia ${ }^{4}$. Extracorporeal shock wave therapy promising findings need to be interpreted cautiously, because of lacking scientific support. No included paper considered TECAR therapy effectiveness in ULTs. Manual therapies (i.e. Deep Friction Massage - DFM, Augmented Soft-Tissue Mobilization - ASTM) have shown encouraging case reports but lack of RCT on humans. Low-quality evidence is available for DFM, especially if compared with eccentric load plus stretching in lateral epicondylalgia. ASTM's increased shoulder active motion, and in lateral epicondylalgia it has revealed antalgic effect and improved strenght grip ${ }^{5}$. For ULTs conservative management ergonomic strategies, workers education and awareness about risk factors are essential to prevent tendinopathies onset (Fig. 15).

\section{References}

1. Bleakley CM, Glasgow P, MacAuley DC. PRICE needs updating, should we call the POLICE? Br J Sports Med. 2012; 46:220-1.

2. Davenport TE, Kulig K, Matharu Y, Blanco CE. The EdUReP model for nonsurgical management of tendinopathy. Phys Ther. 2005; 85:1093-103.

3. Verhagen AP, Bierma-Zeinstra SMA, Burdorf A, Stynes SM, de Vet HCW, Koes BW. Conservative interventions for treating work-related complaints of the arm, neck or shoulder in adults. Cochrane Database Syst Rev. 2013,(12).

4. Desmeules F, Boudreault J, Roy JS, Dionne C, Frémont P, MacDermid JC. The efficacy of therapeutic ultrasound for rotator cuff tendinopathy: A systematic review and meta-analysis. Phys Ther Sport. 2015.

5. Blanchette MA, Normand MC. Augmented soft tissue mobilization vs natural history in the treatment of lateral epicondylitis: a pilot study. J Manipulative Physiol Ther. 2011; 34(2):123-30.

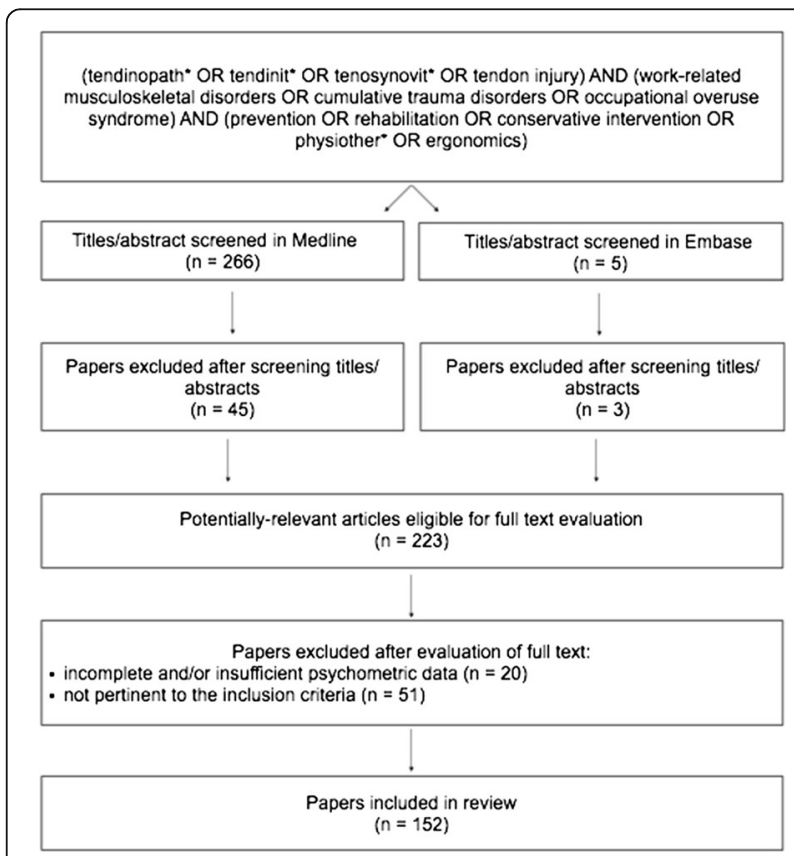

Fig. 14 (abstract P18) Papers research and selection 


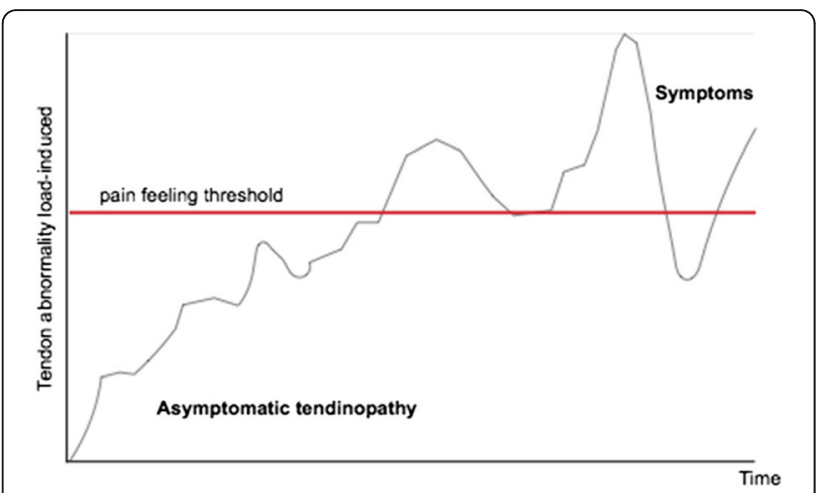

Fig. 15 (abstract P18) "Iceberg" tendinopathies. Relation between overuse - time and tendinopathies underhand onset

P19

The time-related effect of roller-massager on extensibility of the hamstring muscles

Filippo Ghirlanda, Alessandro Schneebeli, Corrado Cescon and Marco Barbero

Rehabilitation Research Laboratory, Department of Business Economics, Health and Social Care, University of Applied Sciences and Arts of Southern Switzerland, SUPSI, Manno, Switzerland

Correspondence: Filippo Ghirlanda (filippo.ghirlanda@supsi.ch) Rehabilitation Research Laboratory, Department of Business Economics, Health and Social Care, University of Applied Sciences and Arts of Southern Switzerland, SUPSI, Manno, Switzerland Archives of Physiotherapy 2016, 6(Suppl 1):P19

\section{Background and aim}

Static stretching is one of the most common methods used to improve range of motion and increase muscle extensibility. However, it has been show that sustained static stretching could affect strength and performance [1]. Recently new devices such as rollermassager have been introduced in alternative to stretching. There is an increasing number of studies that shows a significant increase in range of motion after rhythmic compression with roller-massager $[2,3]$. A large variability in the duration of the intervention was used in different studies (from 5 to 60 seconds). Therefore, the aim of this study was to evaluate the time-related effect of roller-massager on extensibility of the hamstring muscles.

\section{Materials and methods}

Ten healthy subjects were recruited. Subjects were asked to participate in eight sessions of roller-massager with different duration. The duration of roller-massager was randomized and ranged from 5 to 180 s. Subjects perform a Sit-and-Reach test (Modified Sit-and-Reach box, Baseline Evaluation Instruments, USA) before and immediately after the intervention. Hamstrings massage was performed with a rollermassager by Theraband ${ }^{\circledast}$ (The Hygenic Corporation, Akron, USA) with the subjects lying prone on an examination table. Table was connected to an ergometer that allow to maintain a constant compression of $13 \mathrm{~kg}$. Rhythmic compression was performed at $120 \mathrm{bpm}$ as shown in previous studies [2,3]. Difference between pre and post Sit-and-Reach test was computed for each session.

Results

The mean value for extensibility increase in hamstring muscles for $5,10,30,60,90,120,180$ s was respectively 1.99 ( \pm 1.30 SD), 2.76 ( $\pm 1.73 \mathrm{SD}), 4.38( \pm 2.47 \mathrm{SD}), 3.99$ ( $\pm 2.15 \mathrm{SD}), 5.01$ ( $\pm 2.23 \mathrm{SD})$, $4.08( \pm 1.13 \mathrm{SD}), 4.17( \pm 1.41 \mathrm{SD}) \mathrm{cm}$. The results are reported in the Box-Plots (Fig. 16).

Discussion and conclusion

Results showed an increase of the hamstring muscles extensibility after an intervention with roller-massager. The peak of hamstring muscles extensibility was reached about 30-90s. It is important to acknowledge that the sample size used in this study is small and future studies with bigger sample may describe more accurately the relationship between the duration of the roller-massager intervention and the hamstring muscles extensibility.

\section{References}

1. Decoster LC, Cleland J, Altieri C, Russell P. The effects of hamstrings stretching on range of motion: a systematic literature review. J Orthop Sports Phys Ther. 2005; Volume 35: 6: 377-387.

2. Halperin I, Aboodarda SJ, Button DC, Andersen LL, Behm DG. Roller massager improves Range of Motion of plantar flexor muscles without subsequent decreases in force parameters. Int J Sports Phys Ther. 2014; 9 (1): 92-102.

3. Sullivan KM, Silvey BJ, Button DC, Behm DG. Roller- Massager application to the hamstrings increases sit and rech reange of motion within five to ten seconds without performance impairments. Int J Sports Phys Ther. 2009; 8 (3): 228-236

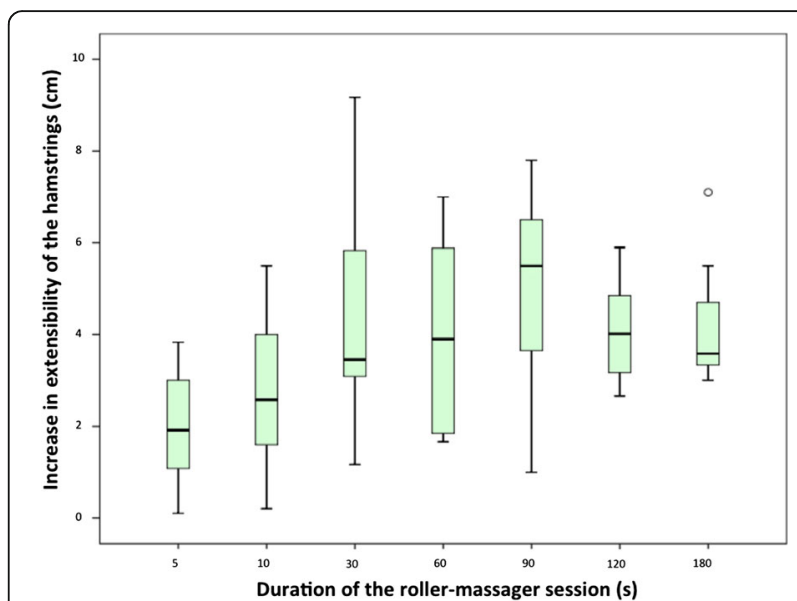

Fig. 16 (abstract P19) Range of motion increase with different durations of the Roller-Massager intervention

P20

Effect of two different exercise programs on pain, disability and quality of life in people with subacute and chronic nonspecific neck pain

Gioia $\mathrm{G}^{1}$, Faccendini $\mathrm{S}^{2}$, Aina $\mathrm{A}^{3}$, Tettamanti $\mathrm{A}^{4}$

${ }^{1}$ Physiotherapy Degree student, Vita-Salute San Raffaele University, Milan, Italy; ${ }^{2}$ Physical Therapy Department, San Raffaele Hospital, Milan, Italy;

${ }^{3}$ Private practice, MDT, Milan, Italy; ${ }^{4}$ Laboratory of Movement Analysis, Division of Neuroscience, San Raffaele Scientific Institute, Milan, Italy

Correspondence: Gioia G (g.gioia93@gmail.com) - Physiotherapy

Degree student, Vita-Salute San Raffaele University, Milan, Italy

Archives of Physiotherapy 2016, 6(Suppl 1):P20

\section{Background and aim}

Neck pain is one of the most common musculoskeletal disorders in the world [1]. Exercise therapy is one of the various treatment approaches [2]. At San Raffaele Hospital has been created a program of rehabilitation where small groups of patients learn exercises for neck pain. The aim of this study is to compare the efficacy of two different exercise programs on pain, disability and quality of life in people with sub-acute and chronic nonspecific neck pain.

Materials and methods

Randomized, controlled and blinded study. Sixteen subjects were divided into Experimental Group (EG) and Control Group (CG). EG (N=8) did an exercise program based on neck retraction and extension. CG $(\mathrm{N}=8)$ did an exercise program based on general mobilization of neck. Both groups did 15 minutes of aerobic and elastic resistance training. Primary outcomes were pain (measured with VAS), disability (measured with Neck Disability Index, NDI), and quality of life (measured with 
SF12, physical - SF12P - and mental - SF12-M - section). Secondary outcomes were fear avoidance beliefs (measured with FABQ [3]), headache, dizziness, and drug consumption. Data were collected at baseline (T0), at the end of the program (T1: after 3-5 weeks of training, 2-3 times per week, for a total of 10 treatments), and follow up was performed one month after the end of the program (T2).

Results

Non-parametric statistic was used. The two groups were homogeneous at baseline. In the EG the within-group analysis (considering the three times of measure together) showed a significant improvement in NDI $(p=0.013)$ and SF12-MCS $(p=0.030)$. A statistically significant improvements was found in NDI (T0-T2, $\mathrm{p}=0.028), \mathrm{SF} 12-\mathrm{M}$ (T0-T2 and T1-T2, $\mathrm{p}=0.046), \mathrm{SF} 12-\mathrm{P}(\mathrm{T} 0-\mathrm{T} 2, \mathrm{p}=0.046)$. In the CG, only VAS T0$\mathrm{T} 1$ variation was statistically significant $(p=0.028)$. In the betweengroups analysis, NDI (T1-T2, $\mathrm{p}=0.052), \mathrm{SF} 12-\mathrm{M}(\mathrm{T} 1-\mathrm{T} 2, \mathrm{p}=0.052)$ and SF12-P (T0-T2, $\mathrm{p}=0.020)$ were significantly improved in SG compared to CG (Table 5). There were no significant changes in secondary outcomes.

\section{Discussion and conclusion}

An exercise program based on neck retraction and extension seems to reduce disability and to have positive effects on QoL, especially in follow-up assessments (long term results), whereas a program based on general mobilization of neck have benefits in pain only during at short term. The experimental treatment seems to be better than general mobilization in reducing disability and improving QoL, but further investigations are needed.

\section{References}

1. Hoy D, March L, Woolf A, et al. The global burden of neck pain: estimates from the Global Burden of Disease 2010 study. Ann Rheum Dis. 2014 Jan; 73:1309-1315.

2. Gross A, Kay TM, Paquin JP, Blanchette S, Lalonde P, Christie T, Dupont G, Graham N, Burnie SJ, Gelley G, Goldsmith CH, Forget M, Hoving JL, Brønfort G, Santaguida PL. Cervical Overview Group. Exercises for mechanical neck disorders. Cochrane Database Syst Rev. 2015 Jan 28;1:CD004250

3. Lee K, Chiu T, Lam T. Psychometric properties of the Fear-Avoidance Beliefs Questionnaire in patients with neck pain. Clin Rehabil. 2006; 20: 909-920.

Table 5 (abstract P20) Between Group analysis post-follow up (T1-T2)

\begin{tabular}{llll}
\hline & EXPERIMENTAL GROUP & CONTROL GROUP & $p^{*}$ \\
\hline VAS & $-1.95(-3.25-0.70)$ & $-1.00(-2.70-0.00)$ & 0.662 \\
NDI & $3.00(0.00-15.00)$ & $-2.00(-11.00-2.00)$ & 0.052 \\
SF12 - PCS & $2.85(-5.00-5.00)$ & $3.30(-1.00-13.00)$ & 0.792 \\
SF12 - MCS & $-13.70(-21.90-5.10)$ & $-0.90(-1.40-7.10)$ & 0.052 \\
\hline
\end{tabular}

*Mann-Whitney test

P21

A bridge between clinical practice and research: how health professionals can study literature and learn on the job Granzotto $\mathrm{G}^{1}$, Coppola L'ㄹ. Gava I $^{3}$, Frassinelli $\mathrm{M}^{4}$, Gattinoni $F^{1}$

${ }^{1}$ Dipartimento di Riabilitazione, Azienda ULSS 7 Pieve di Soligo, Italy; ${ }^{2}$ Ospedale S. Antonio, Azienda ULLS 16, Padova, Italy; ${ }^{3}$ Ospedale Civile Conegliano, Azienda ULSS 7 Pieve di Soligo, Italy; ${ }^{4}$ Azienda ULSS 7 Pieve di Soligo, Italy

Correspondence: Coppola L (coppolalucia@tiscali.it) - Ospedale S.

Antonio, Azienda ULLS 16, Padova, Italy

Archives of Physiotherapy 2016, 6(Suppl 1):P21

\section{Background and purpose}

Evidence based medicine (EBM) and research utilisation are promoted as ways for clients to receive the best level of care. However, physical therapists and physicians sometimes don't know the most recent literature. So, in the educational field, professionals often give patients outdated booklets. In the Rehabilitation Department in ULSS 7, Veneto, three instruction booklets have been available as giveaway for the patients. They addressed self-treatment, exercises and gave an educational counselling: exercises of neck school, physical therapy after anterior cruciate ligament reconstruction and shoulder arthroplasty. They were written 4 years ago and they were not up-to-date. So, it's been common practice among the practitioners to add hand written notes to personalize each rehabilitation plan based on oral knowledge. In this way, educational interventions could be "experience based practice" and not based on ultimate high quality research evidences. A learning project was created with the goal of implementing literature in best practice, updating the available booklets.

Material and methods

A course (ECM n. 3103) was planned, structured in five 3-hour-long modules and 4 hours for individual study, for a total of 19 hours. The first lesson aimed at updating on the database research method. The participants were divided into 3 groups. Each group had to define a search and find articles corresponding to a specific question. The members of the group had to analyze the bibliography and draft a revision of the booklet according to EBM. The study was done during working time, i.e. it was a learning-on-thejob project.

Results and conclusion

All the 58 physical therapists and medical physicians (100\%) completed the course. A total of 63 articles were analysed from online databases (Medline, PEDro, Cochrane). Three booklets were considered and revised. During the meetings, all professionals (in small groups) studied the literature, even if somebody of them didn't know English languages or research methods. A refresher course can help and improve a clinical practice, and can support the process of updating instruction booklets. Giving to professionals in the field time to study EBM proved to be a good method for the implementation of EBM.

\section{References}

1. Coppola L, Masiero S, Putoto G, Imparare a cambiare. II Fisioterapista, 14 (6), 2008 pp.1-7.

2. Formazione sul campo (Fsc) e criteri per l'assegnazione di crediti ECM alle attività di Fsc approvato dalla Commissione Nazionale per la Formazione Continua il 13 Gennaio 2010

3. Knowles MS. Quando I'adulto impara, Franco Angeli, Milano 1999.

4. Lyons $\mathrm{C}$, Brown T, Tseng MH. Evidence-based practice and research utilisation: perceived research knowledge, attitudes, practices and barriers among Australian paediatric occupational therapists. Aust Occup Ther J. 2011 Jun;58(3):178-86.

5. Manuale operativo per l'accreditamento di attività di Formazione sul campo per organizzatori di formazione, Regione del Veneto, Centro Regionale di Riferimento per l'Educazione Continua in Medicina Veneto, Luglio 2013.

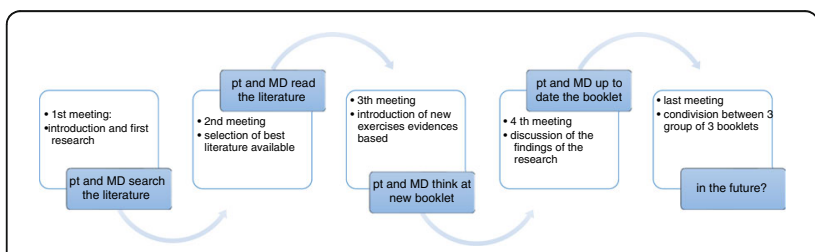

Fig. 17 (abstract P21) The learning-of-the-job- project: meetings and individual study 
P22

Walking capacity improves after neuromotor physiotherapy in stroke patients

Lorenzo Guidotti ${ }^{1}$, Marco Postiglione ${ }^{2}$, Bruna Lombardi ${ }^{3}$, Matteo Paci ${ }^{3}$

${ }^{1}$ Private Practice, Prato, Italy; ${ }^{2}$ Centro di Riabilitazione Terranuova

Bracciolini, Arezzo, Italy; ${ }^{3}$ Unit of Functional Rehabilitation, Department

of Continuing Care, Azienda USL 4, Prato, Italy

Correspondence: Lorenzo Guidotti (lorenzo.guidotti3@gmail.com) -

Private Practice, Prato, Italy

Archives of Physiotherapy 2016, 6(Suppl 1):P22

\section{Introduction}

Previous studies show that neuromotor physiotherapy is not able to elicit adequate cardiovascular stress to induce a training effect [1-3]. One of the purposes of physiotherapy is to improve patient independence and a large number of patients can improve their walking function following physiotherapy [4]. Therefore, the aim of the present study is to investigate if neuromotor physiotherapy without specific aerobic training is able to improve walking capacity, including fitness and gait performance, in a sample of patients following stroke.

Method

Patients in this study were assessed when they were able to walk with minimal assistance (Functional Ambulation Category $>$ or $=4$ ) from less than one week (T0) and after 7 to 9 weeks (T1) by the $6 \mathrm{Mi}$ nute Walking Test. During the test, the distance covered, the mean gait speed and the Borg CR10 scale score were recorded. Through a portable metabolic measurement system (FITMATE Med ${ }^{\oplus}$ ) [5] the mean energy expenditure and the mean heart rate and mean gait speed ratio were also calculated. Comparisons between each assessment (between T0 and T1) were performed with the Wilcoxon Signed Ranks Test.

Results

Twenty patients were assessed (Table 6). Between T0 and T1 the distance covered (Fig. 18) and the mean gait speed increased $(p<.01)$, while the mean energy expenditure and the ratio between mean heart rate and mean gait speed decreased $(p<.05)$. The Borg CR10 Scale scores did not change between the two assessments.

\section{Conclusions}

The study suggests that neuromotor physiotherapy without specific aerobic training can improve walking capacity after stroke. The Borg CR10 scale scores did not decrease significantly between the two assessments probably because patients felt the same exertion, despite changes in the objective measurements. Since neuromotor physiotherapy without a specific aerobic training program is not able to induce a cardiorespiratory training effect, it is reasonable to think that this effect occurs indirectly both by recovery of motor impairment and by achievement of walking independence.

\section{References}

1. Mackay-Lyons MJ, Makrides L. Cardiovascular Stress During a Contemporary Stroke Rehabilitation Program: Is the Intensity Adequate to Induce a Training Effect? Arch Phys Med Rehabil. 2002; 83(10):1697-702.

2. Mackay-Lyons MJ, Makrides L. Longitudinal Changes in Exercise Capacity After Stroke. Arch Phys Med Rehabil. 2004; 85(10):1608-12.

3. Kuys S, Brauer S, Ada L. Routine physiotherapy does not induce a cardiorespiratory training effect post-stroke, regardless of walking ability. Physiother Res Int. 2006; 11:219-227.

4. Jørgensen, Henrik S. et al. Recovery of walking function in stroke patients: The Copenhagen stroke study. Arch Phys Med Rehabil. 1995; 76(1):27-32.

5. Nieman DC, Austin MD, Benezra L, Pearce S, Mclnnis T, Unick J, Gross SJ. Validation of Cosmed's FitMate in measuring oxygen consumption and estimating resting metabolic rate. Res Sports Med. 2006; 14(2):89-96.
Table 6 (abstract P22) Clinical and Demographic characteristics of patients $(n=20)$

\begin{tabular}{ll}
\hline Age [median (interquartile range) (range)] & $70(65.75-79.25)(36-87)$ \\
Gender (female/male) & $08 / 12$ \\
Type of stroke (ischemic/hemorrhagic) & $14 / 06$ \\
$\begin{array}{l}\text { Side (right/left) } \\
\text { Time from stroke (months) [median } \\
\text { (interquartile range) (range)] }\end{array}$ & $11 / 09$ \\
$\begin{array}{l}\text { Lower Limb Fugl-Meyer Score } \\
\text { [(median (interquartile range)] }\end{array}$ & $24(18.75-27.25)(4-33)$ \\
Anke Foot Orthosis $(n, \%)$ & $4(20 \%)$ \\
Walking aid (walking stick or quad cane) $(n, \%)$ & $20(100 \%)$ \\
\hline
\end{tabular}

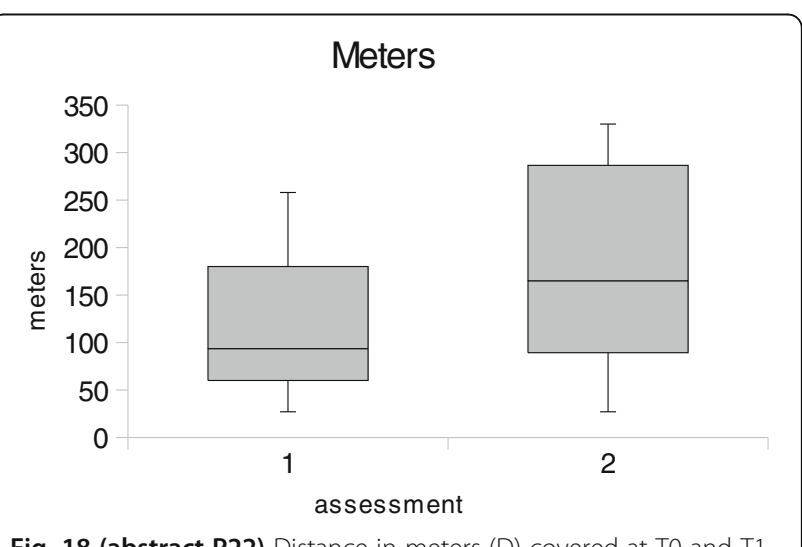

Fig. 18 (abstract P22) Distance in meters (D) covered at T0 and T1

P23

Intra and inter-session reliability of the angle between pain onset and submaximal pain during upper limb neurodynamics test $1:$ a study in healty individuals

Diego Leoni', Davide Storer ${ }^{2}$, Roberto Gatti ${ }^{2}$, Michele Egloff ${ }^{1}$, Marco Barbero $^{1}$

'Department of Business Economics, Health and Social Care,

University of Applied Sciences and Arts of Southern Switzerland, SUPSI, Manno, Switzerland; ${ }^{2}$ Rehabilitation Department, San Raffaele Hospital, Milan, Italy

Correspondence: Diego Leoni (diego.leoni@supsi.ch) - Department of Business Economics, Health and Social Care, University of Applied Sciences and Arts of Southern Switzerland, SUPSI, Manno, Switzerland

Archives of Physiotherapy 2016, 6(Suppl 1):P23

\section{Background and objective}

The Upper Limb Neurodynamics Test 1 (ULTN1) is a common procedure used to assess nerves' mechanosensitivity of the upper limb nerve trunks. Besides the clinical criteria to establish the positivity of the test, the measurement of pain onset (PO) and submaximal pain (SP) angles of occurrence during ULNT1 has been proposed to quantify the mechanosensitivity. The intrasession reliability of such measurement is considered high, while 
the inter-session reliability has not yet been extensively explored. Moreover a slight difference in patient positioning or in the ULNT1 execution during different sessions could affect the occurrence of PO and SP. We thought that the angle between PO and SP $(\Delta)$ could be a more reliable measurement between different sessions. Our aim was to investigate the intra- and inter-session reliability of $\Delta$ and test if it was higher compared to the reliability of PO and SP angles of occurrence.

\section{Materials and methods}

Twenty-nine healthy volunteers (10 female, 19 male) participated Each participant underwent three ULNT1 till PO and SP, twice in the first session and once in the second (Fig. 19). A splint, a positioning device and an electromagnetic goniometer were used to standardize the procedure and record the angles of PO and SP occurrence. The intra- and inter-session reliability of $\Delta$ was examined using Intraclass Correlation Coefficient (ICC [1,3]) and Bland-Altman plots. Similarly, the intra- and inter-session reliability of PO and SP angles of occurrence was explored.

Results

The intra- and inter-session ICC values for $\Delta$ were $0.71(95 \% \mathrm{Cl}$ : $0.47 ; 0.85)$, and $0.79(95 \% \mathrm{Cl}: 0.60 ; 0.89)$, respectively. The intra- and inter-session mean difference and $95 \%$ limits of agreement $( \pm 1.96$ $\mathrm{SD})$ in the Bland-Altman plots were $2.3^{\circ}\left(-18.3^{\circ} ; 23.1^{\circ}\right)$, and $2.8^{\circ}$ $\left(-14.7^{\circ} ; 20.4^{\circ}\right)$, respectively. ICC and Bland-Altman plots values are reported in Table 7.

\section{Discussion and conclusions}

The intra- and inter-session reliability of $\Delta$ during the ULNT1 in healthy individuals is high, and higher than the reliability of PO and $\mathrm{SP}$ angles of occurrence. Thus $\Delta$ could be a preferable variable in the assessment of neural mechanosensitivity. Further research should test the $\Delta$ reliability in the clinical setting.

\section{References}

1. Coppieters M, Stappaerts K, Janssens K, Jull G. Reliability of detecting 'onset of pain' and 'submaximal pain' during neural provocation testing of the upper quadrant. Physiother Res Int. 2002;7(3):146-56.

2. Elvey RL. Physical evaluation of the peripheral nervous system in disorders of pain and dysfunction. J Hand Ther. 1997;10(2):122-9.

3. Nee RJ, Jull GA, Vicenzino B, Coppieters MW. The validity of upper-limb neurodynamic tests for detecting peripheral neuropathic pain. J Orthop Sports Phys Ther. 2012;42(5):413-24.

4. Oliver GS, Rushton A. A study to explore the reliability and precision of intra and inter-rater measures of ULNT1 on an asymptomatic population. Man Ther. 2011;16(2):203-6.

5. Vanti C, Conteddu L, Guccione A, Morsillo F, Parazza S, Viti C et al. The Upper Limb Neurodynamic Test 1: intra- and intertester reliability and the effect of several repetitions on pain and resistance. J Manipulative Physiol Ther. 2010;33(4):292-9.

Table 7 (abstract P23) Intraclass Correlation Coefficients (ICC) and Bland-Altman Plots (B-A plots) values for the angle between PO and SP $(\triangle)$, and the angle of occurrence in range of $\mathrm{PO}$ and $\mathrm{SP}$

\begin{tabular}{|c|c|c|c|c|c|c|}
\hline & \multicolumn{3}{|c|}{ ICC (upper; lower bounds) } & \multicolumn{3}{|c|}{$\begin{array}{l}\text { B-A plots mean difference ( } 95 \% \\
\text { Limits of Agreement) }\end{array}$} \\
\hline & $\Delta$ & $\mathrm{PO}$ & SP & $\Delta\left(^{\circ}\right)$ & $\mathrm{PO}\left({ }^{\circ}\right)$ & $\mathrm{SP}\left({ }^{\circ}\right)$ \\
\hline $\begin{array}{l}\text { Intra- } \\
\text { session }\end{array}$ & $\begin{array}{l}0.71 \\
(0,47 ; 0.85)\end{array}$ & $\begin{array}{l}0.46 \\
(0,11 ; 0.70)\end{array}$ & $\begin{array}{l}0.55 \\
(0,23 ; 0.76)\end{array}$ & $\begin{array}{l}2.3 \\
(-18.3 ; 23.1)\end{array}$ & $\begin{array}{l}2.5 \\
(-33.9 ; 28.8)\end{array}$ & $\begin{array}{l}0.1 \\
(-26.8 ; 26.5)\end{array}$ \\
\hline $\begin{array}{l}\text { Inter- } \\
\text { session }\end{array}$ & $\begin{array}{l}0.79 \\
(0,60 ; 0.89)\end{array}$ & $\begin{array}{l}0.64 \\
(0,37 ; 0.81)\end{array}$ & $\begin{array}{l}0.48 \\
(0,15 ; 0.72)\end{array}$ & $\begin{array}{l}2.8 \\
(-14.7 ; 20.4)\end{array}$ & $\begin{array}{l}5.3 \\
(-30.7 ; 19.9)\end{array}$ & $\begin{array}{l}-2.5 \\
(-29.2 ; 24.1)\end{array}$ \\
\hline
\end{tabular}

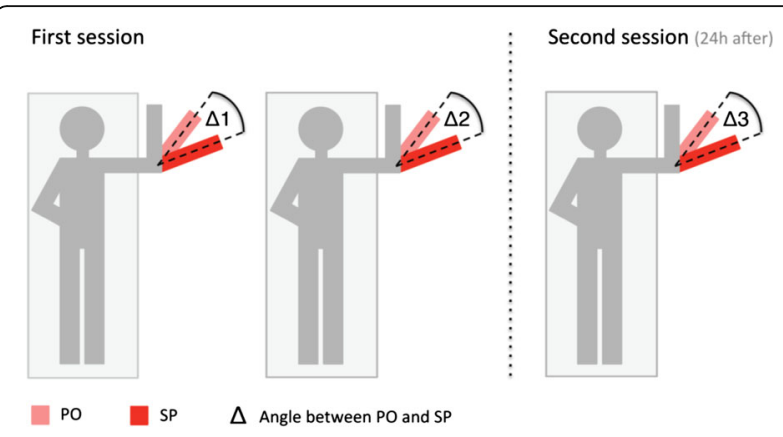

Fig. 19 (abstract 23) Representation of the experimental procedure. The angles of occurrence in range of pain onset (PO) and submaximal pain (SP) during elbow extension in ULNT1 were recorded; then the angle between PO and SP was calculated for each ULNT1 execution

P24

Effects of an AO-MI training on balance task in patients affected by multiple sclerosis

Magno Tiziano', Tettamanti Andrea²

${ }^{1}$ Vita-Salute San Raffaele University, Milan, Italy; ${ }^{2}$ Laboratory of Movement Analysis, Division of Neuroscience, San Raffaele Scientific Institute, Milan, Italy Correspondence: Magno Tiziano (t.magno@studenti.unisr.it) - Vita-Salute San Raffaele University, Milan, Italy

Archives of Physiotherapy 2016, 6(Suppl 1):P24

\section{Background and aim}

A facilitation in motor learning has been shown, in literature, when mirror neuron system is involved. Moreover, recent findings demonstrate that $\mathrm{AO}$, associated with $\mathrm{Ml}$, enhances the activation of some structures (SMA, putamen, cerebellum and motor e premotor cortex) $[1,2,3]$. The aim of this study is to find out if the increased central activation drove by observation and imagination reflects on better motor skills in patient with multiple sclerosis (MS). In particular, we evaluated patient's balance ability before and after a specific balance training combined with observation of experimental (EXP) or control (CNTR) videos.

Material and methods

Main inclusion criterion was a $\geq 3$ score in items number 6 and 7 of Berg Balance Scale (BBS). balance platform was used to record balance parameters (COP area, COP-A, and COP path length, COP-L) in the following tests [4]: 1) Bipedal stance with opened eyes, 2) Bipedal stance with closed eyes, 3) Bipedal stance with feet closed together, and 4) Bipedal stance on foam pad (Fig. 20). Then all the patients underwent the 25 Feet Walking Test (25FWT) and the Timed Up and Go (TUG). The tests were performed 2 times. After that, patients were randomly assigned to control (3 subjects) or experimental (4 subjects) group and they started a training of 12 days. This training was based on the observation of 5 videos (balance exercises videos for the EXP group, and control videos for the CNTR group), 4 minutes lasting. After each video the patient underwent an exercise of 4 minutes (the same exercise of the video watched by the EXP group). Once the training ended the patients repeated the assessment and data were compared with those of the first day.

Results

In Table 8 are reported the normalized variations (post-pre) obtained in the experimental and control group.

Discussion and conclusions

The results show that there are improvements in functional tasks and scale in both two groups, but only experimental group shows an increase on stabilometric balance when asked to keep feet closed together. 


\section{Consent}

The authors have written informed consent from the person in Fig. 20, and consent to publish the photograph. The relevant documents can be provided on request.

\section{References:}

1. Rizzolatti G. The mirror neuron system and its function in humans. Anat Embriol. 2005;210: 419-421.

2. Buccino G. Action observation treatment: a novel tool in neurorehabilitation Philos Trans R Soc Lond B Biol Sci. 2014;369 (1644): 20130185.

3. Taube W, Lorch M, Zeiter S, Martin Keller S. Non-physical practice improves task performance in an unstable, perturbed environment: motor imagery and observational balance training. Front Hum Neurosci. 2014;8:972.

4. Quagliarella L., Sasanelli N., Monaco V., Belgiovine G., Spinarelli A., Notarnicola A. Relevance of orthostatic posturography for clinical evaluation of hip and knee joint arthroplasty patients. Gait Posture. 2011; 34: 49-54.

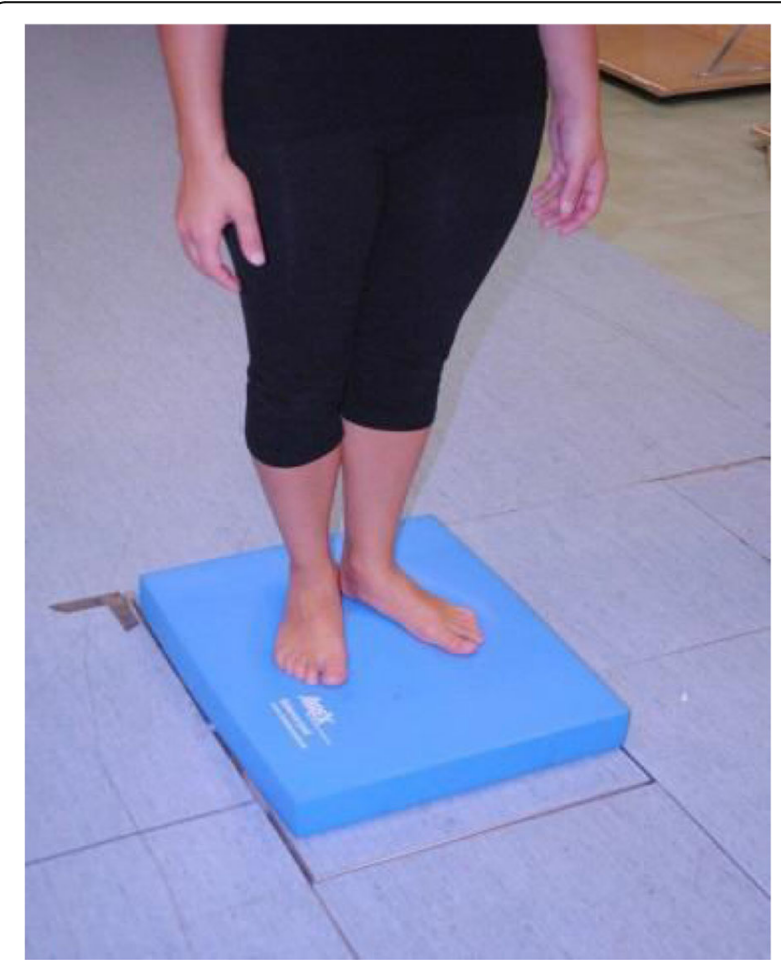

Fig. 20 (abstract P24) Subject performing the bipodalic test on foam pad

Table 8 (abstract P24) Post-pre changes observed in the two groups (data expressed as mean \pm SD)

\begin{tabular}{lll}
\hline & Experimental Group & Control Group \\
\hline TUG $^{\text {a }}$ & $-0,85 \pm 1,35$ & $-1,28 \pm 1,82$ \\
25FWT $^{a}$ & $-0,52 \pm 0,94$ & $-0,37 \pm 0,65$ \\
COP-A $^{a}$, feet together & $-23,35 \pm 28,31$ & $35,41 \pm 20,60$ \\
COP-L $^{\text {a }}$, feet together & $-8,95 \pm 18,20$ & $26,49 \pm 6,75$ \\
BBS $^{b}$ & $1,05 \pm 0,42$ & $2,77 \pm 1,34$ \\
FIM $^{\text {b }}$ & $1,76 \pm 2,76$ & $0,39 \pm 0,68$ \\
\hline
\end{tabular}

TUG Timed Up and Go, 25FWT 25 Feet Walking Test, COP-A area of Center of Pressure sway, COP-L path length of Center of Pressure sway, BBS Berg Balance Scale, FIM Functional Independence Measure

${ }^{a}$ Negative values indicate improvement. ${ }^{b}$ Positive values indicate improvement
P25

Outcomes of treatment with neuromuscular stimulator for chronic anterior knee pain: a clinical case

Daniele Maremmani ${ }^{1}$, Sebastiano Cencini ${ }^{2}$, Giuseppe Plebani ${ }^{1}$

${ }^{1}$ Department of Medicine, Surgery and Neurosciences, Siena University, Siena, Italy; ${ }^{2}$ Private practice, Siena, Italy

Correspondence: Giuseppe Plebani (plebani@unisi.it) - Department of Medicine, Surgery and Neurosciences, Siena University, Siena, Italy Archives of Physiotherapy 2016, 6(Suppl 1):P25

\section{Type of study}

Case report.

Background

Treatment with neuro-muscle stimulator (RSQ1) is the subject of numerous studies regarding the improvement of athletic performance. There is currently limited scientific knowledge for the treatment of neuro-musculoskeletal disorders. This case report shows the use of neuro-stimulation for the treatment of pain and the restoration of the normal joint function.

\section{Objective}

To describe the results obtained with the use of a neuro-stimulator (RSQ1) in one subject with chronic anterior knee pain.

Materials and Methods

Female patient with chronic anterior knee pain for 3 years. Treatment was performed with neuro-stimulator (RSQ1), 2 applications/week, for 4 weeks. Outcomes evaluated before treatment (D0), 1 month after treatment $\left(D_{1}\right)$ and 3 months after treatment $\left(D_{2}\right)$ were: VAS pain, IKDC questionnaire, Time walk on treadmill and ROM in Squat test.

Results

Initial assessment: VAS 8/10, IKDC 21.8, walk on treadmill 30 seconds, $20^{\circ}$ ROM Squat Test; post-treatment assessment: VAS 2/10, IKDC 37.9, walk on treadmill $15 \mathrm{~min}, 100^{\circ}$ ROM Squat Test (Table 9).

Discussion and conclusions

Although in literature articles can be found about the effectiveness of the neuromuscular stimulator for changes on muscle performance in healthy subjects, this case study shows that it might be effective in patients with joint disease for pain control and recovery of motor function. The effect might be due to the ability of instrument to rehabilitate the patient through functional movement. High-quality studies are needed to verify the effectiveness of this method in patients with chronic pain.

\section{Consent for publication}

The authors have written informed consent from the patient, and consent to publish. The relevant documents can be provided on request.

\section{Authors' information}

DM and GP: Adjunct Professor Master in Sports Physiotherapy, Department of Medicine, Surgery and Neurosciences, Siena University

\section{References}

1. Melzak R, Wall PD. Pain Mechanisms: A New Theory. Science. 19 Nov 1965;150(3699): 971-79.

2. Zizic TM, Hoffman KC, Holt PA, Hungerford DS, O'Dell JR, Jacobs MA Lewis CG, Deal CL, Caldwell JR, Cholewczynski JG, et al. The treatment of osteoarthritis of the knee with pulsed electrical stimulation. J Rheumatol. 1995 Sep;22(9):1757-61.

3. Cheing GLY and Hui-Chan CWY. Analgesic effects of transcutaneous electrical nerve stimulation and interferential currents on heat pain in healthy subjects. J Rehabil Med. 2003;35:15-19.

4. Monaghan B, Caulfield B, O'Mathúna DP. Surface neuromuscular electrical stimulation for quadriceps strengthening pre and post total knee replacement. Cochrane Database Syst Rev. 2010 Jan 20;(1):CD007177.

5. Dos Santos RL, Souza ML, Dos Santos FA. Neuromuscular electric stimulation in patellofemoral dysfunction: literature review. Acta Ortop Bras. 2013;21(1):52-8. 
Table 9 (abstract 25) Values of the various outcomes measured at D0 (pre- treatment), D1 (1 month after treatment) and D2 (3 months after the last treatment)

\begin{tabular}{llll}
\hline & D0 & D1 & D2 \\
\hline VAS pain & 8 & 4 & 2 \\
IKDC & 21,8 & 37,9 & 58,6 \\
Time Treadmill Walk (minutes) & $30^{\prime \prime}$ & $10^{\prime}$ & $15^{\prime}$ \\
Squat-Test (degrees) & $20^{\circ}$ & $80^{\circ}$ & $100^{\circ}$ \\
\hline
\end{tabular}

P26

Consistency in locating pressure stimuli over the lumbar spine on a digital body chart: a comparison between chronic low back pain patients and healthy subjects

Federica Moresi $1^{1}$, Marco Barbero ${ }^{2}$, Matteo Isnardi ${ }^{3}$, Alberto Gallace ${ }^{4,5}$, Corrado Cescon², Roberto Gatti

${ }^{1}$ Rehabilitation Department, San Raffaele Hospital, Milan, Italy;

${ }^{2}$ Rehabilitation Research Laboratory, Department of Business Economics, Health and Social Care, University of Applied Sciences and Arts of Southern Switzerland, SUPSI, Manno, Switzerland; ${ }^{3}$ San Raffaele University, Milan, Italy; ${ }^{4}$ Department of Psychology, University of MilanoBicocca, Milan, Italy; ${ }^{5}$ Milan Center for Neuroscience, Milan, Italy

Correspondence: Federica Moresi (federicamoresi@libero.it) Rehabilitation Department, San Raffaele Hospital, Milan, Italy Archives of Physiotherapy 2016, 6(Suppl 1):P26

\section{Background}

Body charts are a useful tool to assess pain in clinical practice. Reporting symptoms on a body chart involves subjective body spatial cognition and recognition over a standard two-dimensional template that does not take into account human morphological variations. Patients with chronic low back pain (CLBP) have altered cortical representation of the painful body part and mislocalization of sensory information. However, subjects' consistency in reporting symptoms on a body chart has never been investigated. The aim of the present study was to investigate the consistency in locating pressure stimuli over the lumbar spine on a digital body chart with CLBP and healthy participants.

Methods

Eleven patients with CLBP and nine healthy participants took part in the study. All subjects received, in standardized body sites, 135 pressure stimulations in a randomized order. For each subjects 15 out of 45 locations were randomly selected as follows: three for the left upper-back region, three for the right upper-back region, three for the left lower-back region, three for the right lower-back region and three for the forearm (Fig. 21a). For each selected site three pressure stimulations were performed using an algometer. During each stimulation, participants were requested to locate the perceived stimulus as a point drawn over a digital whole body chart (body chart dimensions: $768 \times 1024$ pixels) (Fig. 21b). A custom software was used to compared each group of three drawings representing the stimulation points on the body chart, in order to investigate spatial and temporal consistency in reporting the perceived stimuli; the barycenter of three points reported for the same location was identified, and the mean distance between the three reported points and the barycenter was calculated for each of 15 locations.

Results

The mean distances between the three sites and their barycenters located on the body chart was $10.68( \pm 3.7 \mathrm{SD})$ pixels in subject with CLBP, 10.22 ( $\pm 2.5 \mathrm{SD}$ ) pixels in healthy subjects. No significant difference between the two groups was observed. Consistency doesn't seem to change significantly among different body regions in both groups. Conclusions

The consistency in locating the pressure stimuli is not significantly different in patients with CLBP compared to healthy subjects. Further investigation involving a larger sample is needed to confirm these results.

\section{References}

1. Barbero M, Moresi F, Leoni D, Gatti R, Egloff M, Falla D. Test-retest reliability of pain extent and pain location using a novel method for pain drawing analysis. Eur J Pain. 2015 Sep;19(8):1129-38.

2. Bowering KJ, Butler DS, Fulton IJ, Moseley GL. Motor imagery in people with a history of back pain, current back pain, both, or neither. Clin J Pain. 2014 Dec; 30(12): 1070-75

3. Wand BM, Keeves J, Bourgoin C, George P, Smith AJ, O'Connell NE, Moseley GL. Mislocalization of sensory information in people with chronic low back pain. A preliminary investigation. Clin J Pain. 2013 Aug; 29(8): 737-43.
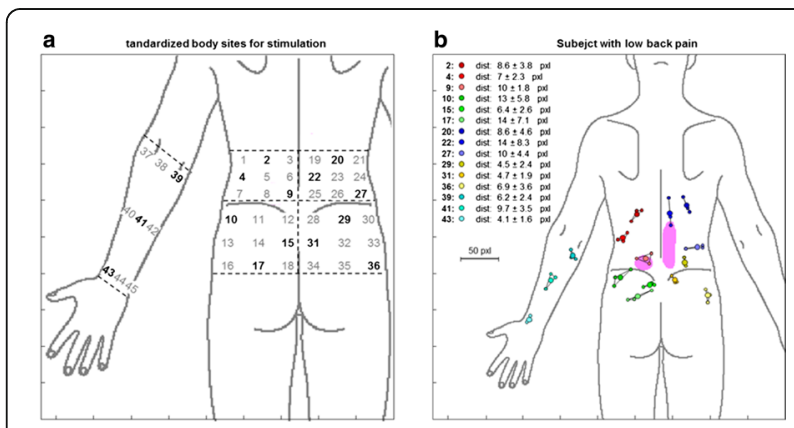

Fig. 21 (abstract P26) a Representation of the 45 locations for pressure stimuli over the body chart. $\mathbf{b}$ Example of pressure location on the body chart of a CLBP subject. Pink areas represent the pain locations of the subject. Small circles represent the pressure locations while the larger circles represent their barycenters

\section{P27}

Malignant Cord Compression in the thoraco-lumbar spine. Early signs and symptoms in the differential diagnosis of low back pain Moretti N, Maselli, Testa M.

Università degli Studi di Genova, Campus di Savona, Savona, Italy

Correspondence: Moretti N (nayara.moretti90@gmail.com) - Università degli Studi di Genova, Campus di Savona, Savona, Italy

Archives of Physiotherapy 2016, 6(Suppl 1):P27

\section{Background and objective}

Malignant Spinal Cord Compression (MSCC) is one of the most important and critical medical emergency, especially in oncologic patients. It is defined as a compression that involves the dural sac and its contents, due to primary tumor or to secondary causes as pathological fractures. The aim of this study is to define early symptoms of MSCC and to provide physical therapists the necessary indications in differential diagnosis of Low Back Pain.

Methods

We searched electronic databases, MEDLINE, PEDro and Google Scholar. Two reviewers independently reviewed the list of potentially eligible studies in literature from 2000 until 2015. We included studies regarding cord compression in an adult population, due to a primary tumor or a secondary cause, localized in the thoracic spine.

Results

The research in the databases identified 142 articles. 67 were excluded because duplicated and 32 because of the title and the abstract, yielding a total of 43 articles, of which 25 with full text availability. 14 cross references were added for a total number of 39 articles finally included.

Discussion

Oncologic patients are more incline to develop MSCC but it can appear also as first presentation in asymptomatic subjects. The primary 
tumors that are more incline to develop MSCC are breast, prostatic and pulmonary cancers. Clinical manifestations of MSCC are characterized by pain localized in the lumbar spine, with VAS 8/10, aggravating by laying down supine, coughing, sneezing, bending and often identified by the patient as worsening, more frequently defined as sharp and shooting. The presentation of motor, sensitive and neurological deficits represents malignancy in evolution.

\section{Conclusions}

Early presentations of MSCC has been identifying and reported as clinical manifestations that provide the elements to conduct a clinical reasoning that leads to a differential diagnosis of low back pain; for these reasons it is necessary to recognize early signs and symptoms and refer the patient to a clinician that can treat this medical emergency as soon as possible.

\section{References}

1. Viets-Upchurch J, Silvestre J, Rice TW, Brock PA, Todd K, Flomenbaum N, et al. Metastatic Spinal Cord Compression: A Review. Emergen Med. 2014;46(1):10-18

2. Lowey SE. Spinal cord compression. An oncologic emergency associated with metastatic cancer: Evaluation and Management for the Home Health Clinicians. Home Healthc Nurse. 2006;24(7): 439-46.

3. Savage P, Sharkey R, Kua T, Schofield L, Richardson D, Panchmatia N, et al. Malignant spinal cord compression: NICE guidance, improvements and challenges. QJM. 2014;107(4): 277-82.

4. Crnalic S, Hildingsson C, Bergh A, Widmark A, Svensson O, Löfvenberg R. Early diagnosis and treatment is crucial for neurological recovery after surgery for metastatic spinal cord compression in prostate cancer. Acta Oncol. (Madr) 2012;(March 2012): 1-7.

\section{P28}

End growth results of exercise treatment to avoid bracing in adolescents with idiopathic scoliosis: a prospective cohort controlled study

Stefano Negrini ${ }^{1,2}$, Sabrina Donzelli ${ }^{2}$, Francesco Saveri ${ }^{2}$, Alessandra Negrini ${ }^{2}$, Silvana Parzini ${ }^{2}$, Michele Romano ${ }^{2}$, Fabio Zaina ${ }^{2}$

${ }^{1}$ University of Brescia, IRCCS Don Gnocchi, Brescia, Italy; ${ }^{2} \mathrm{SICO}$, Istituto Scientifico Italiano Colonna Vertebrale, Milan, Italy

Correspondence: Francesco Saveri (francesco.saveri@isico.it) - ISICO, Istituto Scientifico Italiano Colonna Vertebrale, Milan, Italy Archives of Physiotherapy 2016, 6(Suppl 1):P28

\section{Background}

Doubts on the efficacy of exercise treatment for adolescents with Idiopathic Scoliosis (IS) still exist.

Design

Prospective observational controlled cohort study nested in a prospective database started in March 2003.

Methods

Setting: outpatient tertiary referral clinics. Participants: consecutive patients from start of the database to 31/12/2010. Inclusion criteria: IS; Risser $0-2 ; 11^{\circ}$ to $20^{\circ} \mathrm{Cobb}$; age 10 years or more; first evaluation. Exclusion criteria: consultations only; immediate prescription of a brace. Groups: 1) Physiotherapic Specific Scoliosis Exercises - SEAS school (PSSE: at least $45 \mathrm{~min} /$ week, 3 cognitive behavioral sessions/year); 2) Controls (CON: less than $15 \mathrm{~min} /$ week); 3) Usual Physiotherapy (UP: other institutes/protocols). End-Of-Treatment (EOT): medical prescription, bracing, Risser 3. Failures: bracing for scoliosis; EOT above $30^{\circ}$. Statistical analysis: intent-to-treat (ITT: drop-outs included as failures) and efficacy (EA: only EOT patients). Relative Risk of failure (RR), 95\% Confidence Interval (Cl), and clinical and radiographic changes have been calculated.

Results

Out of 327 patients, 34 (10\%) were excluded due to bracing at first evaluation. We included 293 adolescents: 145 PSSE, 95 UP, 53 CON, with no differences at baseline. Physicians prescribed bracing (failure) without differences among groups. Failures and drop-outs were $84(28.7 \%)$ and $47(16.0 \%)$, respectively: $21.4 \%$ and $18.6 \%$ in PSSE; $33.7 \%$ and $9.5 \%$ in UP; $39.6 \%$ and $20.8 \%$ in CON. Efficacy analysis (RR): CON vs PSSE, 1.90 (IC 1.48-2.33); UP vs PSSE, 1.42 (1.01-1.82); CON vs UP, not significant. Intent-totreat (RR): CON vs PSSE, 1.51 (1.21-1.80); CON vs UP, 1.40 (1.081.72); UP VS PSSE, not significant. At the end of exercises, aesthetics (TRACE) improved statistically in PSSE (1.8 points out of 12) and UP (1.5), not in CON; only PSSE improvement was statistically better than CON.

Discussion and conclusion

Based on result of this study, the PSSE effectiveness for the treatment of scoliosis patients is evident. Patients performing UP or nothing (CON), compared to those treated with PSSE (SEAS), increase the risk of failure (bracing and/or $30^{\circ}$ at EOT) 1.9 and 1.4 times respectively (EA).

\section{P29}

Reliability of the Ashworth scale and its modified versions: systematic review and meta-analysis

Leonardo Nesi ${ }^{1}$, Francesco Ferrarello ${ }^{2}$, Valeria Anna Maria Bianchi ${ }^{2}$, Matteo Paci ${ }^{2}$

${ }^{1}$ Private Practice, Prato, Italy; ${ }^{2}$ Unit of Functional Rehabilitation,

Department of Continuing Care, Azienda USL 4, Prato, Italy

Correspondence: Leonardo Nesi (leonardo91nesi@gmail.com) - Private Practice, Prato, Italy

Archives of Physiotherapy 2016, 6(Suppl 1):P29

\section{Introduction}

The Ashworth scale (AS) [1] and the Modified Ashworth scale (MAS) [2] are the most commonly used clinical measures of muscle spasticity. The aim of this review is to summarize findings on psychometric properties of the Ashworth Scale and its modified versions for the evaluation of spasticity in subjects with central nervous system diseases, according to different clinical conditions and muscle groups.

Methods

Two independent investigators conducted an extensive search in electronic databases (last search in July 2015), for complete original studies, published in English, reporting on Ashworth Scale or its modified versions. The indices extracted from studies were combined in the meta-analysis when the weighed k or the Intraclass Correlation Coefficient (ICC) were used. The analyses were performed for each version of the scale and for each muscle group, whenever available at least two comparable studies. An ICC $\geq .70$ were considered acceptable for studies on groups of subjects and an ICC $\geq .90$ for measurements used in individuals [3]. Quality assessment and risk of bias was assessed using a modified version of the QUADAS list [4] and the COSMIN checklist.

Results

Of 321 potentially relevant articles screened, 33 papers met all inclusion criteria and 19 were included in meta-analysis. Combined correlation coefficients of $>.70$ were found for intra- and inter- rater reliability for the MAS when assessing elbow flexors and for the MMAS as a whole. Similar results were evident when MMAS was used to assess elbow and wrist flexors (only inter- rater) (Tables 10 and 11). The selected studies had a quality score ranging from $63 \%$ to $100 \%$ (mean $84 \%$ ). Rating for methodology according to the COSMIN checklist are reported in tables. Discussion

The use of MMAS as a whole and MAS to measure elbow flexors, as well as MMAS for elbow and wrist flexors (only inter-rater) can be considered suitable for studies on groups of subjects. The lacking of acceptable reliability for the great part of versions of the scale for several muscle groups may be explained both by the scales characteristics and by the specific characteristics of the muscle tone.

\section{References}

1. Ashworth B. Preliminary trial of carisoprodol in Multiple Sclerosis. Practitioner. 1964; 192: 540-542.

2. Bohannon RW, Smith MB. Inter-rater reliability of a Modified Ashworth Scale of muscle spasticity. Physiotherapy. 1987; 67: 206-207.

3. Fitzpatrick R, Davey C, Buxton MJ, et al. Evaluating patient based outcome measures for use in clinical trials. Health Technol Assess. 1998; 2: $1-74$.

4. Ferrarello F, Bianchi VAM, Baccini M, et al. Tools for observational gait analysis in patients with stroke: a systematic review. Phys Ther. 2013; 93: 1673-1685. 
Table 10 (abstract P29) Reliability (scales as a whole)

\begin{tabular}{llllll}
\hline & Reliability & $\begin{array}{l}\text { Correlation } \\
\text { coefficient }(95 \% \text { Cl) }\end{array}$ & $\begin{array}{l}\text { No. of } \\
\text { studies }\end{array}$ & $\begin{array}{l}\text { No. of } \\
\text { participants }\end{array}$ & COSMIN \\
\hline AS & Inter-rater & $0.66(0.59$ to 0.73$)$ & 2 & 68 & $1 \mathrm{P} / 1 \mathrm{~F}$ \\
MAS & Inter-rater & $0.66(0.55$ to 0.78$)$ & 10 & 321 & $6 \mathrm{P} / 4 \mathrm{~F}$ \\
MMAS & Inter-rater & $0.85(0.79 \text { to } 0.91)^{\text {a }}$ & 5 & 152 & $1 \mathrm{P} / 4 \mathrm{~F}$ \\
AS & Intra-rater & $0.57(0.49$ to 0.66$)$ & 2 & 47 & $1 \mathrm{P} / 1 \mathrm{~F}$ \\
MAS & Intra-rater & $0.67(0.61$ to 0.74$)$ & 9 & 277 & $3 \mathrm{P} / 6 \mathrm{~F}$ \\
MMAS & Intra-rater & $0.75(0.62 \text { to } 0.88)^{\text {a }}$ & 2 & 53 & OP/2F \\
\hline
\end{tabular}

AS Asworth Scale, MAS Modified Ashworth Scale, MMAS Modified Modified Ashworth Scale, $P$ poor, $F$ fair

${ }^{a}$ correlation coefficient $>0.70$

Table 11 (abstract P29) Intra-rater reliability (muscle groups)

\begin{tabular}{|c|c|c|c|c|c|c|}
\hline & $\begin{array}{l}\text { Muscle } \\
\text { group }\end{array}$ & Reliability & $\begin{array}{l}\text { Correlation } \\
\text { coefficient } \\
(95 \% \text { Cl) }\end{array}$ & $\begin{array}{l}\text { No. of } \\
\text { studies }\end{array}$ & $\begin{array}{l}\text { No. of } \\
\text { participants }\end{array}$ & COSMIN \\
\hline MAS & $\begin{array}{l}\text { elbow } \\
\text { flexors }\end{array}$ & $\begin{array}{l}\text { Intra- } \\
\text { rater }\end{array}$ & $\begin{array}{l}0.75(0.68 \text { to } \\
0.82)^{a}\end{array}$ & 6 & 201 & $4 \mathrm{P} / 2 \mathrm{~F}$ \\
\hline MAS & wrist flexors & $\begin{array}{l}\text { Intra- } \\
\text { rater }\end{array}$ & $\begin{array}{l}0.68 \text { (0.56 to } \\
0.80)\end{array}$ & 4 & 152 & $2 \mathrm{P} / 2 \mathrm{~F}$ \\
\hline MAS & $\begin{array}{l}\text { hip } \\
\text { adductors }\end{array}$ & $\begin{array}{l}\text { Intra- } \\
\text { rater }\end{array}$ & $\begin{array}{l}0.66(0.61 \text { to } \\
0.71)\end{array}$ & 5 & 130 & $3 \mathrm{P} / 2 \mathrm{~F}$ \\
\hline MAS & knee flexors & $\begin{array}{l}\text { Intra- } \\
\text { rater }\end{array}$ & $\begin{array}{l}0.62 \text { ( } 0.48 \text { to } \\
0.76 \text { ) }\end{array}$ & 7 & 215 & $4 \mathrm{P} / 3 \mathrm{~F}$ \\
\hline MAS & $\begin{array}{l}\text { knee } \\
\text { extensors }\end{array}$ & $\begin{array}{l}\text { Intra- } \\
\text { rater }\end{array}$ & $\begin{array}{l}0.53 \text { (0.36 to } \\
0.71)\end{array}$ & 2 & 37 & $2 \mathrm{P} / \mathrm{OF}$ \\
\hline MAS & $\begin{array}{l}\text { ankle } \\
\text { plantaflexors }\end{array}$ & $\begin{array}{l}\text { Intra- } \\
\text { rater }\end{array}$ & $\begin{array}{l}0.60(0.52 \text { to } \\
0.68)\end{array}$ & 7 & 215 & $4 \mathrm{P} / 3 \mathrm{~F}$ \\
\hline MAS & $\begin{array}{l}\text { elbow } \\
\text { flexors }\end{array}$ & $\begin{array}{l}\text { Inter- } \\
\text { rater }\end{array}$ & $\begin{array}{l}0.77(0.62 \text { to } \\
0.91)^{a}\end{array}$ & 5 & 211 & $3 \mathrm{P} / 2 \mathrm{~F}$ \\
\hline MAS & wrist flexors & $\begin{array}{l}\text { Inter- } \\
\text { rater }\end{array}$ & $\begin{array}{l}0.68 \text { (0.49 to } \\
0.87)\end{array}$ & 4 & 132 & $3 P / 1 F$ \\
\hline MMAS & $\begin{array}{l}\text { elbow } \\
\text { flexors }\end{array}$ & $\begin{array}{l}\text { Inter- } \\
\text { rater }\end{array}$ & $\begin{array}{l}0.83(0.72 \text { to } \\
0.94)^{a}\end{array}$ & 3 & 100 & $\mathrm{OP} / 3 \mathrm{~F}$ \\
\hline MMAS & wrist flexors & $\begin{array}{l}\text { Inter- } \\
\text { rater }\end{array}$ & $\begin{array}{l}0.87(0.78 \text { to } \\
0.96)^{a}\end{array}$ & 2 & 45 & $\mathrm{OP} / 2 \mathrm{~F}$ \\
\hline MAS & $\begin{array}{l}\text { hip } \\
\text { adductors }\end{array}$ & $\begin{array}{l}\text { Inter- } \\
\text { rater }\end{array}$ & $\begin{array}{l}0.60 \text { ( } 0.41 \text { to } \\
0.80)\end{array}$ & 5 & 110 & $3 \mathrm{P} / 2 \mathrm{~F}$ \\
\hline MAS & $\begin{array}{l}\text { hip internal } \\
\text { rotators }\end{array}$ & $\begin{array}{l}\text { Inter- } \\
\text { rater }\end{array}$ & $\begin{array}{l}0.63 \text { ( } 0.43 \text { to } \\
0.83)\end{array}$ & 2 & 55 & $\mathrm{OP} / 2 \mathrm{~F}$ \\
\hline MAS & $\begin{array}{l}\text { elbow } \\
\text { flexors }\end{array}$ & $\begin{array}{l}\text { Inter- } \\
\text { rater }\end{array}$ & $\begin{array}{l}0.60 \text { ( } 0.46 \text { to } \\
0.74)\end{array}$ & 6 & 178 & $4 \mathrm{P} / 2 \mathrm{~F}$ \\
\hline MAS & $\begin{array}{l}\text { knee } \\
\text { extensors }\end{array}$ & $\begin{array}{l}\text { Inter- } \\
\text { rater }\end{array}$ & $\begin{array}{l}0.37 \text { (0.34 to } \\
0.41)\end{array}$ & 2 & 37 & $2 \mathrm{P} / \mathrm{OF}$ \\
\hline MAS & $\begin{array}{l}\text { ankle } \\
\text { plantaflexors }\end{array}$ & $\begin{array}{l}\text { Inter- } \\
\text { rater }\end{array}$ & $\begin{array}{l}0.45 \text { (0.36 to } \\
0.54)\end{array}$ & 7 & 195 & $4 \mathrm{P} / 3 \mathrm{~F}$ \\
\hline
\end{tabular}

\section{P30}

Differences in motor recovery between upper and lower limbs in stroke subtypes

Matteo Paci, Luca Nannetti, Bruna Lombardi

Unit of Functional Rehabilitation, Department of Continuing Care,

Azienda USL 4, Prato, Italy

Correspondence: Matteo Paci (matteo.paci@applicazione.it) - Unit of Functional Rehabilitation, Department of Continuing Care, Azienda USL 4, Prato, Italy

Archives of Physiotherapy 2016, 6(Suppl 1):P30

\section{Introduction}

A number of studies reported similar patterns of motor recovery of extremities [1-3]. Anyway, different stroke subtypes can have distinct motor outcomes [4]. The aim of this study was to compare the time course of upper limb (UL) and lower limb (LL) in a sample of patients who have had distinct subtypes of ischaemic stroke.

Methods

Consecutive patients following ischaemic stroke were recruited in a rehabilitation ward and evaluated at admission, discharge and 1 month after discharge with the UL and LL motor parts of the FuglMeyer scale (FM). To place the UL and LL data in the same scale, the FM motor scores were divided by the total possible score for that extremity ( 66 for $\mathrm{UL}, 34$ for $\mathrm{LL}$ ), obtaining a percentage of the FM motor score. Separate analyses of variance (ANOVA) for repeated measures were performed for the whole sample and for samples of each stroke subtype classified according to the Oxfordshire Community Stroke Project (OCSP).

Results

Four hundred fortythree patients were included in the study (Tables 12 and 13). All groups significantly improved motor function in both limbs $(p<.001)$. Only within the TACl group LL improved motor recovery more than UL $(p<.001)$. No significant difference between time course of UL and LL motor recovery was found in the whole sample and in the other groups.

Conclusion

This study confirms a similar motor recovery in $U L$ and $L L$ in the whole sample, but also shows that LL motricity recovers more completely than the UL motricity in the TACl group. Functional prognosis should take into account the distinct stroke subtypes.

\section{References}

1. Duncan PW, Goldstein LB, Horner RD, Landsman PB, Samsa GP, Matchar DB. Similar motor recovery of upper and lower extremities after stroke. Stroke. 1994;25:1181-8

2. Desrosiers J, Maouin F, Richards C, Bourbonnais D, Rochette A, Bravo G. Comparison of changes in upper and lower extremity impairments and disabilities after stroke. Int J Rehabil Res. 2003;26:109-16.

3. Verheyden G, Nieuwboer A, De Wit L, Thijs V, Dobbelaere J, Devos H, et al. Time course of trunk, arm, leg, and functional recovery after ischemic stroke. Neurorehabil Neural Repair. 2008;22:173-9.

4. Paci $M$, Nannetti $L$, D'Ippolito $P$, Lombardi B. Outcomes from ischemic stroke subtypes classified by the Oxfordshire Community Stroke Project: a systematic review. Eur J Phys Rehabil Med. 2011;47:19-23.

Table 12 (abstract P30) Sample characteristics ( $N=443)$

\begin{tabular}{lllllll}
\hline & $\begin{array}{l}\text { All } \\
\text { patients } \\
\end{array}$ & TACl & LACl & PACl & POCl & $p$ \\
& $(\mathrm{~N}=443)$ & $(\mathrm{N}=86)$ & $(\mathrm{n}=116)$ & $(\mathrm{n}=185)$ & $(\mathrm{n}=56)$ & \\
\hline Gender (males) & 164 & 30 & 41 & 67 & 26 & .461 \\
Age & $72.5 \pm 11.0$ & 70.9 & 73.1 & 73.2 & 71.0 & .313 \\
& & \pm 12.2 & \pm 12.4 & \pm 10.1 & \pm 10.1 & \\
Side of & 189 & 38 & 51 & 92 & 23 & .080 \\
hemiplegia (right) & & & & & & \\
$\begin{array}{l}\text { Time since } \\
\text { stroke (days) }\end{array}$ & $18.0 \pm 14.0$ & 21.0 & 16.0 & $16.0 \pm 8.0$ & 26.0 & .217 \\
\hline
\end{tabular}

Table 13 (abstract P30) Outcome measures scores between limbs at $\mathrm{T} 1, \mathrm{~T} 2$, and $\mathrm{T} 3$

\begin{tabular}{lllllll}
\hline & Limb & $\begin{array}{l}\text { All patients } \\
(\mathrm{N}=443)\end{array}$ & $\begin{array}{l}\mathrm{TACl} \\
(\mathrm{N}=86)\end{array}$ & $\begin{array}{l}\mathrm{LACl} \\
(\mathrm{n}=116)\end{array}$ & $\begin{array}{l}\mathrm{PACl} \\
(\mathrm{n}=185)\end{array}$ & $\begin{array}{l}\mathrm{POCl} \\
(\mathrm{n}=56)\end{array}$ \\
\hline Admission & Upper & $37.5 \pm 34.2$ & $11.8 \pm 21.9$ & $55.2 \pm 31.2$ & $30.2 \pm 29.6$ & $64.7 \pm 32.4$ \\
& Lower & $47.1 \pm 28.4$ & $28.4 \pm 24.7$ & $60.6 \pm 27.8$ & $42.7 \pm 24.5$ & $62.1 \pm 26.6$ \\
\multirow{2}{*}{ Discharge } & Upper & $52.6 \pm 35.4$ & $19.2 \pm 26.0$ & $70.5 \pm 29.5$ & $48.7 \pm 31.6$ & $79.8 \pm 25.6$ \\
& Lower & $61.3 \pm 25.1$ & $45.2 \pm 22.4$ & $70.9 \pm 26.1$ & $59.0 \pm 21.6$ & $73.7 \pm 22.8$ \\
\multirow{2}{*}{ Follow-up } & Upper & $62.2 \pm 31.0$ & $22.2 \pm 28.1$ & $76.2 \pm 27.9$ & $55.2 \pm 32.6$ & $83.8 \pm 23.2$ \\
& Lower & $66.5 \pm 24.5$ & $54.1 \pm 24.4$ & $74.1 \pm 25.3$ & $64.5 \pm 22.3$ & $76.3 \pm 21.2$ \\
\hline
\end{tabular}


P31 Influence of clinical experience on the reliability of the Salford Gait Tool

Giuditta Mini ${ }^{1}$, Mariangela Marchettini ${ }^{2}$, Francesco Ferrarello ${ }^{2}$, Matteo Paci ${ }^{2}$

${ }^{1}$ Private practice, Florence, Italy; ${ }^{2}$ Unit of Functional Rehabilitation, Azienda USL 4 Prato, Italy

Correspondence: Mariangela Marchettini (ma.marchettini@tiscali.it) -

Unit of Functional Rehabilitation, Azienda USL 4 Prato, Italy

Archives of Physiotherapy 2016, 6(Suppl 1):P31

\section{Introduction}

The Salford Gait Tool (SF-GT) is an observational tool developed to assess the gait of children with cerebral palsy. SF-GT evaluates in a sagittal plane the position of the lower limb joints during six specific events of the gait cycle. A good reproducibility is reported for the tool, the mean percentage agreement was found to be $77 \%$ and $75 \%$ for inter- and intra- rater reliability, respectively (Toro et al., 2007). Some studies (Ong et al., 2008, Viehweger et al., 2010, Brunnekreef et al., 2005) showed that the reliability of observational gait analysis may be influenced by the clinical experience of the raters. The purpose of this study was to verify if the experience of the raters may influence inter-rater reliability of the SF-GT.

\section{Methods}

Standardized videos of gait of eight children (seven with cerebral palsy and one with muscular dystrophy) were recorded. Three physiotherapists with experience in pediatrics (FP), three physiotherapists with experience with adult individuals (FA) and three students of physiotherapy completed the video-based SF-GT. The inter-rater reliability were estimated for each joint and for each phase of the gait cycle, with the Intraclass Correlation Coefficient (ICC) and the Standard Error of Measurement (SEM). As reported by Fitzpatrick (1998) ICC values $\geq .70$ were considered acceptable.

Results

The inter-rater reliability for joints were acceptable for both FA (ICC=.745; SEM=1.34) and for FP (ICC=.743; SEM=1.05) while for students the ICC was .644 (SEM=1.54). The inter-rater reliability for the gait phase was acceptable for both $\mathrm{FA}(\mathrm{ICC}=.774$; $\mathrm{SEM}=0.55)$ and $\mathrm{FP}$ (ICC=.765; SEM=0.60), while it was under the threshold of .70 for students $(\mathrm{ICC}=.438$; $\mathrm{SEM}=1.02$ ).

\section{Conclusions}

FA and FP showed higher reliability, whereas students did not achieve acceptable reliability. We can therefore assume that the reliability of the SF-GT can be influenced by the experience of the raters. There were no differences between FA and FP, suggesting that clinical experience more than the specific field can influence the reliability of SF-GT.

\section{References}

1. Toro B, Nester CJ, Farren PC. Inter- and intraobserver repeatability of the Salford Gait Tool: an observational-based clinical gait assessment tool. Arch Phys Med Rehabil. 2007;88:328-32.

2. Ong AM, Hillman SJ, Robb JE. Reliability and validity of the Edinburgh Visual Gait Score for cerebral palsy when used by inexperienced observers. Gait Posture. 2008;28(2):323-6.

3. Viehweger $\mathrm{E}$, Zurcher Pfund $\mathrm{L}$, Helix $\mathrm{M}$, et al. Influence of clinical and gait analysis experience on reliability of observational gait analysis (Edinburgh Gait Score Reliability). Ann Phys Rehabil Med. 2010; 53: 535-546.

4. Brunnekreef JJ, van Uden CJ, van Moorsel S, Kooloos JG. Reliability of videotaped observational gait analysis in patients with orthopedic impairments. BMC Musculoskelet Disord. 2005;6:17.

5. Fitzpatrick R, Davey C, Buxton MJ, et al. Evaluating patientbased outcome measures for use in clinical trials. Health Technol Assess. 1998:2:1-74.
P32

A somatosensory discrimination training induces brain functional changes in healthy young subjects

Fabio Piccolo ${ }^{1,4}$, Federica Agosta ${ }^{1}$, Elisabetta Sarasso ${ }^{1,4}$, Paola Adamo ${ }^{4}$, Federico Temporiti ${ }^{4}$, Andrea Falini ${ }^{3}$, Roberto Gatti ${ }^{4}$, Massimo Filippi ${ }^{1,2}$

${ }^{1}$ Neuroimaging Research Unit, San Raffaele Scientific Institute and VitaSalute San Raffaele University, Milan, Italy; ${ }^{2}$ Department of Neurology, Institute of Experimental Neurology, San Raffaele Scientific Institute and Vita-Salute San Raffaele University, Milan, Italy; ${ }^{3}$ Department of

Neuroradiology and CERMAC, San Raffaele Scientific Institute and VitaSalute San Raffaele University, Milan, Italy; ${ }^{4}$ Laboratory of Movement Analysis, Division of Neuroscience, San Raffaele Scientific Institute and Vita-Salute San Raffaele University, Milan, Italy

Correspondence: Fabio Piccolo (zonca.lucia@hsr.it) - Neuroimaging Research Unit, San Raffaele Scientific Institute and Vita-Salute San

Raffaele University, Milan, Italy

Archives of Physiotherapy 2016, 6(Suppl 1):P32

\section{Background and objectives}

Several studies showed that a motor training enhances neuroplasticity in healthy people. Preliminary studies suggested that a somatosensory discrimination training may stimulate the use of cognitive processes, such as movement planning and monitoring, which can be useful during the execution of active motor tasks [1-3]. The aims of this study were to assess the effect of a somatosensory discrimination training on brain functional activity during different tasks and on motor and sensory abilities. Preliminary data found in a small sample of participants were presented at the 1st Congress of the European Academy of Neurology. ${ }^{4}$ Materials and methods

Thirty-eight young healthy subjects were enrolled from a convenience sample and randomized into 2 groups. The experimental group underwent ten 30 minutes daily sessions of shape, surface and two-point distance discrimination training ( 5 times/week for 2 weeks); during the same period the control group performed 10 minutes sessions of simple objects manipulation. Right hand sensory (Two Point Discrimination test), motor (9 Hole Peg test, Minnesota Manual Dexterity test and Finger Tapping test) and fMRI with three different tasks (1. tactile stimulation; 2. manipulation of a simple object; and 3. a complex active motor task) evaluations were performed at baseline and after the training.

Results

After the training, all participants performed better at dexterity tests but the improvement was higher in experimental group. Moreover, in the experimental group an increased activation of the contralateral post-central gyrus was observed during the tactile stimulation and manipulation tasks, whereas during the complex motor task the activation was increased in the contralateral striatum and pallidum and reduced in the ipsilateral pre/post-central gyri. Conversely, in the control group the recruitment of the contralateral cerebellum was increased during the active motor task.

Discussion

These findings confirm in a larger sample of participants that a somatosensory discrimination training enhance the activity of the contralateral primary sensory cortex during tactile stimulation and object manipulation tasks. Furthermore, it influences the strategies of cortical areas activation during hand movement.

Conclusion

Based on the data presented, a somatosensory discrimination training might be useful in the rehabilitation of specific neurological impairments.

\section{References}

1. Aman JE, Elangovan N, Yeh IL, Konczak J. The effectiveness of proprioceptive training for improving motor function: a systematic review. Front Hum Neurosci. 2015 Jan 28;8:1075. 
2. Vahdat S, Darainy M, Ostry DJ. Structure of plasticity in human sensory and motor networks due to perceptual learning. J Neurosci. 2014 Feb 12;34(7):2451-63

3. Savini $N$, Babiloni $C$, Brunetti $M$, et al. Passive tactile recognition of geometrical shape in humans: An fMRI study. Brain Res Bull. 2010 Oct 30;83(5):223-31.

4. Sarasso E, Agosta F, Adamo P, et al. Brain functional changes after a somatosensory discrimination training in healthy young subjects. Eur J Neurol. 2015; 22 (Suppl. S1):01123.

P33

Effects of dynamic tilt-table with integrated robotic stepping associated with functional electrical stimulation: a cross-over study Daniele Piscitelli, ${ }^{1,2}$, Roberto Meroni ${ }^{1}$, Leonardo Pellicciari ${ }^{3}$, Marco A. Mondelli ${ }^{1}$, Thomas Favaron ${ }^{1}$, Cesare G. Cerri ${ }^{1}$, Enrico A. Tallarita ${ }^{2}$ ${ }^{1}$ Department of Translational medicine and Surgery, Program in Physical Therapy, University of Bicocca, Milan, Italy; ${ }^{2}$ Rehabilitation Department, S. Anna Hospital, Como, Italy; ${ }^{3} \mathrm{PhD}$ Program in Advanced Sciences and Technologies in Rehabilitation Medicine and Sports, Tor Vergata University, Rome, Italy

Correspondence: Daniele Piscitelli (danypisci@yahoo.it) - Rehabilitation Department, S. Anna Hospital, Como, Italy

Archives of Physiotherapy 2016, 6(Suppl 1):P33

\section{Background and objective}

Stroke is a leading cause of long-term disability in the world, resulting in physical and cognitive impairments and reduced quality of life [1]. Recently, robotic systems have been proposed in the rehabilitative treatment and several studies proved their effectiveness [2, 3]. Therefore, the purpose of this study was to investigate the short-term effects of an orthostatic training on a robotic system in patients with severe acquired brain injury (ABI).

Materials and methods

Two subjects with $\mathrm{ABI}$ were undergone to an orthostatic training using Erigo $^{\oplus}$ (Hocoma AG, Switzerland), a dynamic tilt-table with integrated robotic stepping, used with step-synchronized functional electrical stimulation (FES) to the legs. Each subject performed 11 treatments with Erigo ${ }^{\circledR}$ lasting 30 minutes, carried out with and without FES, administered on alternate days. The treatment involved a tilting to $30^{\circ}$ in the first 5 minutes, increasing to a maximum of $80^{\circ}$ according to the clinical condition of the patient and tolerance towards orthostatic training. The treatment was in addition to conventional physiotherapy. Blood pressure (BP), heart rate (HR) and oximetry were recorded at the baseline and every 5 minutes during the treatment. The Modified Ashworth scale (MAS) was administered before and after each session. Results

Two subjects were recruited (Table 14), which carried out 11 treatments among three weeks; the incomplete sessions were seven. The results showed an improvement of clinical measures and a muscle tone decreased in the lower limbs in both subjects. There was no significant difference in the improvement of orthostatic tolerance (BP, HR, oximetry) comparing treatment with or without FES (Fig. 22).

\section{Discussion}

The training with Erigo ${ }^{\oplus}$ has shown an improvement of vital parameters; however, no difference was detected between treatment with and without FES; the values of the $95 \%$ confidence intervals were similar between the two types of intervention. The number of incomplete sessions was consistent with literature [4].

Conclusion

Subjects showed a global improvement in orthostatic tolerance and a decrease of muscle tone in the short term. Further studies are needed to determine if the results are stable over time, and which patients could benefit from this training.

\section{References}

1. Mozaffarian D, Benjamin EJ, Go AS, Arnett DK, Blaha MJ, Cushman M, et al. Heart disease and stroke statistics-2015 update: a report from the American Heart Association. Circulation. 2015;131(4):e29-322.

2. Chang WH, Kim YH. Robot-assisted Therapy in Stroke Rehabilitation. J Stroke. 2013;15(3):174-81.
3. Wieser M, Gisler S, Sarabadani A, Ruest RM, Buetler L, Vallery $H$, et al Cardiovascular control and stabilization via inclination and mobilization during bed rest. Med Biol Eng Comput. 2014;52(1):53-64.

4. Luther MS, Krewer C, Muller F, Koenig E. Comparison of orthostatic reactions of patients still unconscious within the first three months of brain injury on a tilt table with and without integrated stepping. A prospective, randomized crossover pilot trial. Clin Rehabil. 2008;22(12):1034-41

Table 14 (abstract P33) Clinical and demographic characteristics of the sample

\begin{tabular}{lll}
\hline & Subject 1 & Subject 2 \\
\hline Age (years) & 66 & 75 \\
GCS & 15 & 15 \\
LCF & 5 & 5 \\
DRS & 13 & 10 \\
MAS & $1+$ & $1+$ \\
Time since stroke (days) & 35 & 42 \\
\hline
\end{tabular}

GCS Glasgow Coma Scale, LCF Levels of Cognitive Functioning, DRA Disability Rating Scale, MAS Modified Ashworth Scale

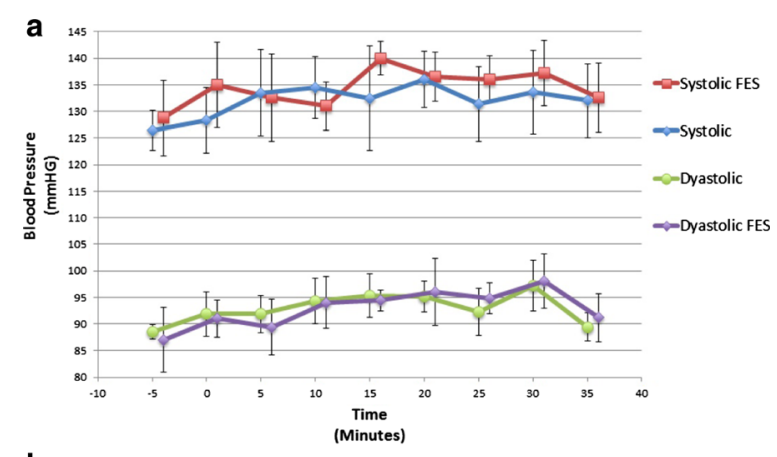

b

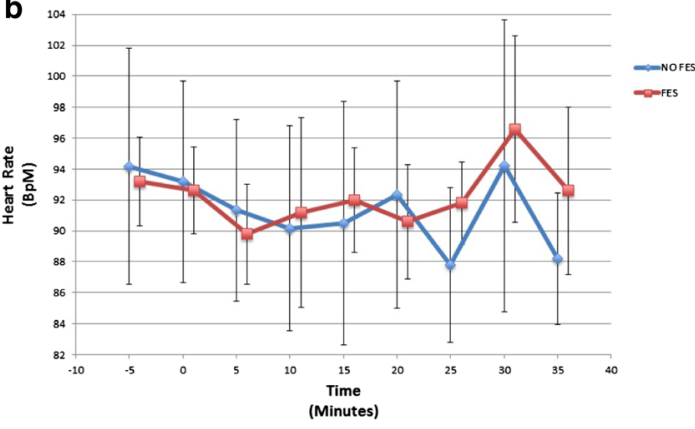

C

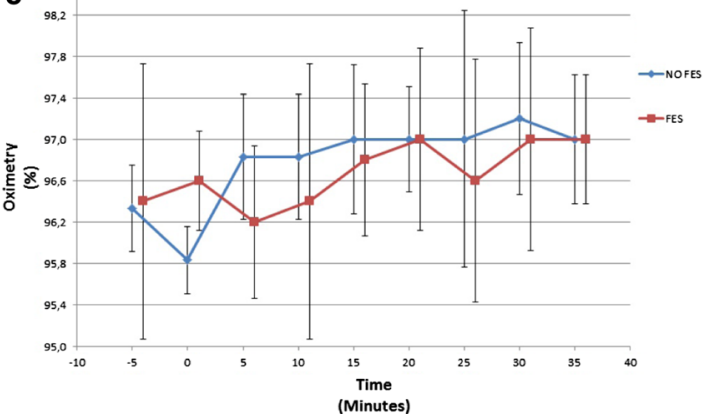

Fig. 22 (abstract P33) Blood pressure $\mathbf{a}$, heart rate $\mathbf{b}$, oximetry $\mathbf{c}$ during tilt-table training, with and without FES. Data are mean, error bars indicate $95 \%$ confidence interval 
P34

Manual therapy techniques in the treatment of whiplash and its associated disorders: a systematic review Ravizzotti Elisa', Vercelli Stefano ${ }^{2}$

${ }^{1}$ University of Genova, Genova, Italy; ${ }^{2}$ Unit of Occupational Rehabilitation and Ergonomics, Salvatore Maugeri Foundation, IRCCS, Veruno (NO),

Italy

Correspondence: Ravizzotti Elisa (elaisa21@hotmail.it) - University of Genova, Genova, Italy

Archives of Physiotherapy 2016, 6(Suppl 1):P34

\section{Background and Objective}

There are many therapeutic approaches aimed at treating whiplash and its associated disorders (WAD). Manual therapy (MT) is commonly used in the management of WAD. However, no comprehensive reviews have been published on the effectiveness of spinal manipulation/mobilization and soft tissue mobilization techniques in these patients. Aim of this study was to identify and synthesize literature on MT for patients suffering from WAD.

Material and Methods

A systematic literature review of randomized clinical trial studies was conducted searching in Pubmed, PEDro, and Embase. The search was performed by combining the terms "whiplash injuries" and "musculoskeletal manipulations" or "spinal manipulation". Only studies with a Pedro Scale $\geq 5$, addressed to humans, and written in English were considered. Any limitation about publication period was set. The search strategy is shown in Fig. 23.

Results

Three studies were identified ${ }^{1-3}$ and synthetized in Table 16. MT techniques included were: spinal mobilization (C5-C6 lateral glide), fascial manipulation technique (localized frictions), ${ }^{2}$ and sub-occipital muscle inhibition (constant and painless pressure). ${ }^{3}$ Outcomes were expressed in at least one of the following: neck pain (VAS) ${ }^{1-3}$ disability related to neck pain (Neck Disability Index), ${ }^{2}$ active cervical range of movement (ROM), ${ }^{2}$ elbow ROM performing Upper Limb Neurodynamic Test of the median nerve, ${ }^{3}$ pressure pain threshold, ${ }^{1,2}$ thermal pain thereshold, ${ }^{1}$ nociceptive flexion reflex, ${ }^{1}$ and free-pain grip strength. ${ }^{3}$ Only limited effectiveness of manual techniques was found (detailed results are reported in Table 15).

\section{Discussion}

This review highlighted the paucity of high-quality studies conducted to analyze effectiveness of MT techniques in patient suffering from WAD. The three studies identified had a limited sample size, no longterm follow-up, and two ${ }^{1,3}$ of them did not use a common cervical treatment as a contrast. The heterogeneity of manual approaches confirms the little agreement between therapists as to the ideal treatment for these patients. Nevertheless, results seem to be promising and further studies based on MT in WAD are strongly needed.

\section{Conclusion}

The evidence to support the use of MT is poor due to a lack of primary studies to investigate the effects of these treatments in WAD.

\section{References}

1. Sterling M, Pedler A, Chan C, Puglisi M, Vuvan V, Vicenzino B. Cervical lateral glide increases nociceptive flexion reflex threshold but not pressure or thermal pain thresholds in chronic whiplash associated disorders: A pilot randomised controlled trial. Man Ther. 2010 Apr;15(2):149-53.

2. Picelli A, Ledro G, Turrina A, Stecco C, Santilli V, Smania N. Effects of myofascial technique in patients with subacute whiplash associated disorders: a pilot study. Eur J Phys Rehabil Med. 2011 Dec;47(4):561-8.

3. Antolinos-Campillo PJ, Oliva-Pascual-Vaca A, Rodríquez-Blanco C, HerediaRizo AM, Espí- López GV, Ricard F. Short-term changes in median nerve neural tension after a suboccipital muscle inhibition technique in subjects with cervical whiplash: a randomised controlled trial.

4. Physiotherapy. 2014 Sep;100(3):249-55.

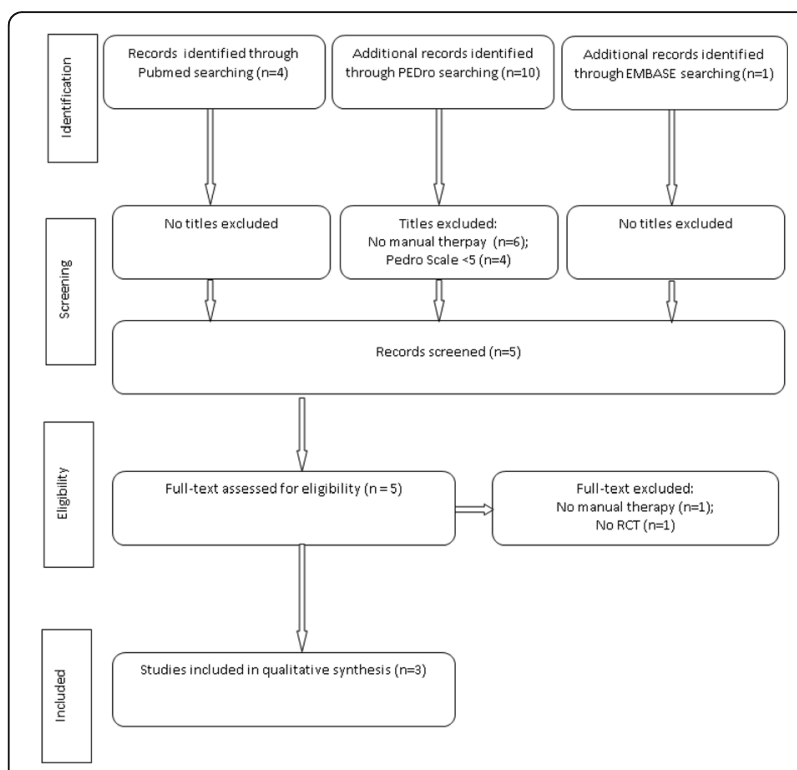

Fig. 23 (abstract P34) Flow of studies through the review

Table 15 (abstract P34) Synthesis of studies reviewed

\begin{tabular}{|c|c|c|c|c|c|c|c|c|}
\hline Authors & $\begin{array}{l}\text { PEDro } \\
\text { value }\end{array}$ & $\mathrm{N}$ & QTFS & $\begin{array}{l}\text { Intervention } \\
\text { group }\end{array}$ & $\begin{array}{l}\text { Control } \\
\text { group }\end{array}$ & $\begin{array}{l}\text { Outcome } \\
\text { measures }\end{array}$ & Results & $\begin{array}{l}\text { Follow- } \\
\text { up }\end{array}$ \\
\hline $\begin{array}{l}\text { Sterling } \\
\text { et al. } \\
\text { (2009) }\end{array}$ & $5 / 10$ & 39 & $\begin{array}{l}\text { Grade } \\
\|\end{array}$ & $\begin{array}{l}\text { Spine manual } \\
\text { therapy at } \\
\text { C5- C6 spinal } \\
\text { level: } 3 \text { sets } \\
\text { of } 1^{\prime} \text { cervical } \\
\text { lateral glide } \\
\text { with } 1^{\prime} \text { rest } \\
\text { between sets }\end{array}$ & $\begin{array}{l}\text { Manual } \\
\text { contact } \\
\text { at C5-C6 } \\
\text { spinal } \\
\text { level } \\
\text { without } \\
\text { movement }\end{array}$ & $\begin{array}{l}\text { Pressure } \\
\text { Pain } \\
\text { Threshold } \\
\text { Thermal } \\
\text { Pain } \\
\text { Threshold } \\
\text { NFR } \\
\text { (threshold } \\
\text { and VAS) }\end{array}$ & $\begin{array}{l}\text { Only NFR } \\
\text { increased } \\
\text { significantly }\end{array}$ & $\begin{array}{l}\text { Short } \\
\text { term }\end{array}$ \\
\hline $\begin{array}{l}\text { Picelli } \\
\text { et al. } \\
\text { (2011) }\end{array}$ & $7 / 10$ & 18 & $\begin{array}{l}\text { Grade } \\
1-\|\end{array}$ & $\begin{array}{l}\text { Fascial } \\
\text { Manipulation } \\
\text { technique: } 3- \\
\text { sessions } \\
\text { (each } 30^{\prime} \text { ) } \\
\text { every } 5 \text { days }\end{array}$ & $\begin{array}{l}\text { Daily } \\
\text { training } \\
\text { program } \\
\text { including } \\
20^{\prime} \text { of neck } \\
\text { mobilization } \\
\text { exercises + } \\
10^{\prime} \text { of neck } \\
\text { muscle } \\
\text { stretching: } \\
10 \text { sessions } \\
\text { in } 2 \text { weeks }\end{array}$ & $\begin{array}{l}\text { Active } \\
\text { cervical } \\
\text { ROM } \\
\text { Neck } \\
\text { pain (VAS) } \\
\text { Disability } \\
\text { problems } \\
\text { related to } \\
\text { neck pain } \\
\text { (NDI) } \\
\text { Pression } \\
\text { pain } \\
\text { threshold } \\
\text { (algometer) }\end{array}$ & $\begin{array}{l}\text { Only } \\
\text { cervical } \\
\text { ROM } \\
\text { increased } \\
\text { significantly }\end{array}$ & $\begin{array}{l}2 \\
\text { weeks }\end{array}$ \\
\hline $\begin{array}{l}\text { Antolinos- } \\
\text { Campillo } \\
\text { et al. } \\
\text { (2013) }\end{array}$ & $7 / 10$ & 40 & $\begin{array}{l}\text { Grade } \\
\text { I-II }\end{array}$ & $\begin{array}{l}\text { Suboccipital } \\
\text { muscle } \\
\text { inhibition for } \\
4^{\prime}\end{array}$ & $\begin{array}{l}\text { Active } \\
\text { movement } \\
\text { of the hip } \\
\text { and knee } \\
\text { joints on } \\
\text { the } \\
\text { opposite } \\
\text { side for } 4^{\prime}\end{array}$ & $\begin{array}{l}\text { Elbow } \\
\text { ROM } \\
\text { during } \\
\text { ULNT-1 } \\
\text { Neck } \\
\text { pain } \\
\text { (VAS) } \\
\text { Free- } \\
\text { pain grip } \\
\text { strenght } \\
\text { (dynamometer) }\end{array}$ & $\begin{array}{l}\text { Only } \\
\text { elbow } \\
\text { ROM } \\
\text { increased } \\
\text { significantly }\end{array}$ & $\begin{array}{l}\text { Short } \\
\text { term }\end{array}$ \\
\hline
\end{tabular}

Table 16: QTFS Quebeck Task Force scale (Grade I: neck pain, stiffness or tenderness without physical signs; Grade II: neck complaint and musculoskeletal signs), NDI Neck Disability Index, VAS Visual Analog Scale, ULNT-1 Upper Limb Neurodynamic Test of the median nerve, NFR Nociceptive flexion reflex 
P35

The Patient and Observer Scar Assessment Scale (POSAS) as a screening tool for early detection of pathologic post-surgical scars in physiotherapy

Rossetti Sara', Ciceri Matteo ${ }^{2}$, Vercelli Stefano ${ }^{3}$

${ }^{1}$ School of Physiotherapy, University of Piemonte Orientale, Novara, Italy:

${ }^{2}$ School of Physiotherapy, University of Insubria, Varese, Italy; ${ }^{3}$ Unit of

Occupational Rehabilitation and Ergonomics, Salvatore Maugeri

Foundation, IRCCS, Veruno (NO), Italy

Correspondence: Rossetti Sara (saraross18@hotmail.it) - School of

Physiotherapy, University of Piemonte Orientale, Novara, Italy

Archives of Physiotherapy 2016, 6(Suppl 1):P35

\section{Background and Objective}

Early assessment and treatment of pathologic scars can have a high impact on the final outcome [1, 2]. The main difficulty remains the ability to determine whether a scar will become a source of pathologic problems, and thus require an adequate treatment by the physiotherapist [2]. Our goal was to identify a clinical screening tool to be used for early detection of what can be considered a pathologic post-surgical scar, i.e. a scar which requires treatment in a rehabilitation setting.

\section{Material and methods}

This study used a cross-sectional design. The screening tool was represented by the Patient and Observer Scar Assessment Scale (POSAS) [3], a recommended instrument for clinical evaluation of post-surgical scars that is composed by two subscales: one reflecting the patient's (PSAS) and one the observer's (OSAS) point of view [3]. The POSAS was administered to a sample of 23 patients with post-surgical scars at a mean time of 63 days from surgery (range: 14 to 90 days). At the same time, a team of experts (two physiotherapists and a physiatrist) judged independently whether the scar had to be treated (pathologic scar group) or not (nonpathologic scar group). Conflicts were resolved by consensus. A ROC analysis was used to identify the threshold value of the POSAS subscales (total score and overall opinion) that better discriminates the two groups of patients.

Results

The scale that best discriminated patients with a problematic scar from those that did not undergo a treatment was the OSAS total score, with a cut-off threshold of $\leq 17$ points (AUC $81.7 \%$; sensitivity: $87.5 \%$; specificity: $64.3 \%$ ) (Fig. 24). The cut-off values for all scales are showed in Table 16.

Discussion

The POSAS was originally intended to be used as an outcome measure. Our study showed that the OSAS subscale had also a good ability to discriminate two groups of patients with and without problematic scars after surgery. This will help physiotherapists undertaking surgical procedures that are not aware of scar management.

Conclusions

The POSAS, and in particular the OSAS subscale score, can be used as an early screening tool to prevent any pathologic scar and undertaking appropriate therapeutic measures.

\section{References}

1. Vercelli S, Ferriero G, Sartorio F, Stissi V, Franchignoni F. How to assess postsurgical scars: a review of outcome measures. Disabil Rehabil. 2009;31(25):2055-63.

2. Téot L. Clinical evaluation of scars. Wound Repair and Regeneration 2002:10:93-7.

3. Draaijsers JL, Tempelman FR, Botman YAM, et al. The Patient and Observer Scar Assessment Scale: a reliable and feasible tool for scar evaluation. Plast Reconstr Surg. 2014;113:1960-1965.

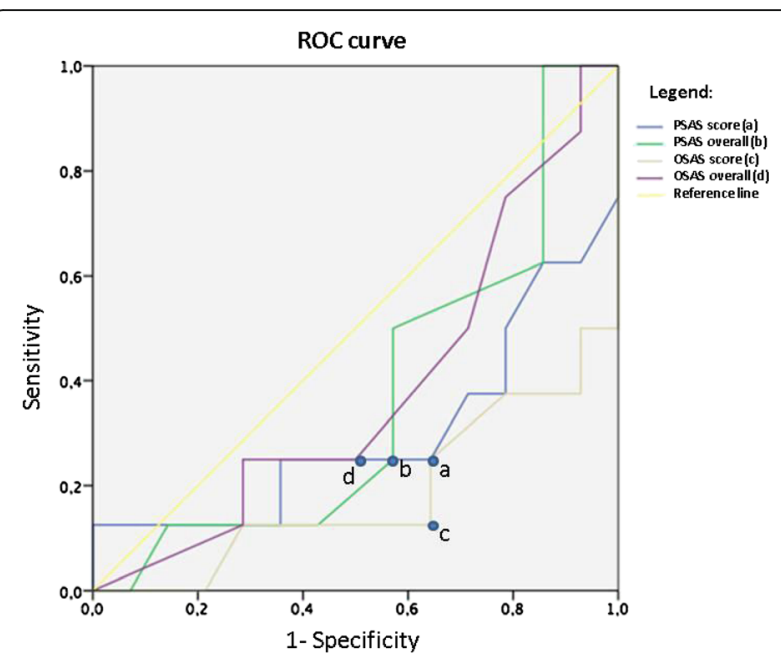

Fig. 24 (abstract P35) The ROC curve evaluates diagnostic ability of tests to discriminate the true state of subjects, finding the optimal cut off values. To determine the optimal cut-off point, we maximized sensitivity and specificity incorporating ethical issues for correct and false diagnosis. Thus, priority was given to higher sensitivity level to avoid the risk of not correctly diagnosing (and including to treatment) patients who had pathological scars.Total and overall scores of the PSAS and OSAS were plotted; solid dots $-a, b, c$, and d- represent the optimal cut-off point for each score, respectively

Table 16 (abstract P35) Results of ROC analysis

\begin{tabular}{lllll}
\hline & PSAS score & PSAS overall & OSAS score & OSAS overall \\
\hline Range score & $0-60$ points & $0-10$ points & $0-60$ points & $0-10$ points \\
Cut-off point & $<28$ points & $<6$ points & $\leq 17$ points & $<5$ points \\
Area Under Curve & 0.701 & 0.629 & 0.817 & 0.616 \\
Sensitivity & $75 \%$ & $75 \%$ & $87.5 \%$ & $75 \%$ \\
Specificity & $64.3 \%$ & $57.1 \%$ & $64.3 \%$ & $50 \%$ \\
\hline
\end{tabular}

P36

The anatomical basis of genetic dystonia: a multimodal MRI study Elisabetta Sarasso ${ }^{1}$, Federica Agosta1, Aleksandra Tomić ${ }^{3}$, Silvia Basaia1, Nataša Dragašević ${ }^{3}$, Marina Svetel ${ }^{3}$, Massimiliano Copetti ${ }^{4}$, Vladimir S. Kostic $^{3}$, Massimo Filippi ${ }^{1,2}$

${ }^{1}$ Neuroimaging Research Unit, San Raffaele Scientific Institute, Vita-Salute San Raffaele University, Milan, Italy; ${ }^{2}$ Department of Neurology, Institute of Experimental Neurology, Division of Neuroscience, San Raffaele Scientific Institute, Vita-Salute San Raffaele University, Milan, Italy; ${ }^{3}$ Clinic of Neurology, Faculty of Medicine, University of Belgrade, Belgrade, Serbia; ${ }^{4}$ Biostatistics Unit, IRCCS-Ospedale Casa Sollievo della Sofferenza, San Giovanni Rotondo, Foggia, Italy

Correspondence: Elisabetta Sarasso (elisabetta.sarasso@hotmail.it) Neuroimaging Research Unit, San Raffaele Scientific Institute, Vita-Salute San Raffaele University, Milan, Italy

Archives of Physiotherapy 2016, 6(Suppl 1):P36

\section{Background and objective}

Primary dystonia has been associated with over 14 different genotypes, most of which follow an autosomal dominant inheritance pattern with 
reduced penetrance [1]. This study investigated cortical thickness and white matter (WM) tract alterations in a large cohort of asymptomatic and symptomatic subjects carrying different DYT mutations.

Materials and methods

This study included 9 asymptomatic mutation carriers (4 DYT1, 4 DYT6, 1 DYT10) and 26 symptomatic mutation carriers (7 DYT1, 7 DYT6, 9 DYT5 or dopa-responsive dystonia, 1 DYT18, 1 DYT10, and 1 DYT25). 37 age- and sex-matched healthy controls were also studied. Subjects underwent 3D T1 weighted and diffusion tensor (DT) MRI [2, 3]. Cortical thickness measures were analyzed using surface-based morphometry. Tract-based spatial statistics (TBSS) was applied to compare DT MRI metrics between groups on a voxel-by-voxel basis.

Results

No cortical thickness abnormalities were found in asymptomatic mutation carriers relative to controls. When compared to healthy subjects and asymptomatic carriers, symptomatic DYT mutation carriers showed cortical thinning of motor and frontal areas bilaterally. Compared to controls, asymptomatic carriers showed a pattern of increased mean (MD) and radial (radD) diffusivities and decreased fractional anisotropy (FA) of the right internal capsule, corona radiate and WM underneath motor areas. The pattern of WM abnormalities in symptomatic patients relative to controls showed only a small region of decreased FA in the WM close to the right premotor cortex and a more widespread increase of $\mathrm{MD}$, radD and axial diffusivity involving both motor and extramotor pathways. No DT MRI differences were observed between asymptomatic and symptomatic mutation carriers.

Discussion

This study revealed that specific WM alterations can be identified in asymptomatic DYT mutation carriers, supporting the hypothesis that these changes are causative rather than an effect of the disorder. In addition, the analysis of the DT MRI eigenvalues revealing a different pattern of abnormalities in clinically manifesting (increased axD and $\mathrm{radD}$ ) and non-manifesting (increased radD, unchanged axD) mutation carriers may allow to gain insight into the possible determinants of penetrance.

\section{Conclusions}

Whether different DYT mutations are associated with specific structural changes remains to be tested in larger groups of DYT mutation carriers.

\section{References}

1. Albanese A et al. Mov Disord. 2013.

2. Hess CW et al. Curr Neurol Neurosci Rep. 2013.

3. Zoons E. Neuroimage. 2011.

P37

The relative inclination of the end vertebrae of a scoliotic single curve can influence the results of the conservative treatment? A pilot study

Francesco Saveri, Michele Romano, Matteo Mastrantonio, Alessandra Negrini, Fabio Zaina, Negrini Stefano

ISICO, Istituto Scientifico Italiano Colonna Vertebrale, Milan, Italy

Correspondence: Francesco Saveri (francesco.saveri@isico.it) - ISICO,

Istituto Scientifico Italiano Colonna Vertebrale, Milan, Italy

Archives of Physiotherapy 2016, 6(Suppl 1):P37

\section{Introduction}

The relative difference of the inclination of the upper and lower limit of scoliosis curves and its possible effects on final results of a conservative treatment is unknown. Aim of the study: to evaluate if the final results of scoliosis specific exercises (SEAS) is correlated to the difference between the upper and lower slope of the end vertebrae.

Materials and methods

Study design: retrospective cohort study. Population: 29 scoliosis consecutive subjects ( 26 female), mean age $12.10 \pm 1.04$, mean initial Cobb angle $13,95^{\circ} \pm 4,39^{\circ}$, from ISICO clinics. Among these patients 23 finished therapy whit curves below $30^{\circ}$, thus avoiding brace treatment, while 6 had to wear a brace to stop the curve progression. Inclusion criteria: Idiopathic scoliosis (IS) at start, final results availability; single curve; treated with exercises only. Exclusion criteria: all secondary scoliosis, unavailability final data; start of treatment with brace. All patients have been treated with the SEAS approach. Statistical analysis: correlation analysis was done between the delta of inclination of the end vertebrae (DI), the delta of Cobb degrees (DC), the TRACE (Trunk Aesthetic Clinical Evaluation -DT), the ATR (trunk rotation -DA), pre-post treatment; and the localization of the vertebra with major inclination and results.

Results

The data analysis did not reveal any statistically significant correlation between DI and DC, DT and DA. The localization of the end vertebra with major inclination did not influence the results of the treatment (see Table 17).

Discussion

According to the present results we can reject the null hypothesis: the inclination of upper and lower limit of the curves, does not influence the final result of SEAS treatment. The small convenience sample size can bias results, hence it's necessary to enlarge the population, with wider inclusion criteria, in order to have more powerful and generalizable results.

Conclusion

The relative inclination of the apical vertebrae does not affect the final result of the treatment, nevertheless, the limit of the present research as the clinical experience guides us to take into consideration also the upper and lower slopes of the curve and their relations, during the preparation of the corrective movement, combining it with ATR, Cobb degrees and frontal unbalance of the spine.

Table 17 (abstract P37)

\begin{tabular}{lll}
\hline & Correlation coefficient & $p$ value \\
\hline Delta inclination $(X)$ vs Delta Cobb $(Y)$ & 0.1453 & 0.1435 \\
Delta inclination $(X)$ vs Delta ATR $(Y)$ & -0.1203 & 0.9257 \\
Delta inclination $(X)$ vs Delta TRACE $(Y)$ & -0.087 & 0.8443 \\
Group 1 Main upper slope & \\
Delta inclination $(X)$ vs Delta Cobb $(Y)$ & 0.2578 & 0.5030 \\
Delta inclination $(X)$ vs Delta ATR $(Y)$ & -0.1915 & 0.5484 \\
Delta inclination $(X)$ vs Delta TRACE $(Y)$ & -0.1824 & 0.5989 \\
Group 2 Main lower slope a & & \\
Delta inclination $(X)$ vs Delta Cobb $(Y)$ & -0.1314 & 0.5807 \\
Delta inclination $(X)$ vs Delta ATR $(Y)$ & 0.0873 & 0.9330 \\
Delta inclination $(X)$ vs Delta TRACE $(Y)$ & 0.0458 & 0.9041 \\
\hline
\end{tabular}

${ }^{a}$ The main slope is defined as the most frontally flexed segment of the spine

P38

Physiotherapy for myofascial pain syndromes: reported methodological quality of randomized controlled trials indexed in the PEDro database

Alessandro Schneebeli ${ }^{1}$, Greta Castellini ${ }^{2}$, Valentina Redaelli ${ }^{2}$, Emiliano Soldini ${ }^{3}$, Marco Barbero

${ }^{1}$ Rehabilitation Research Laboratory, Department of Business Economics, Health and Social Care, University of Applied Sciences and Arts of Southern Switzerland, SUPSI, Manno, Switzerland; ${ }^{2}$ Private practitioner, Como, Italy; ${ }^{3}$ Department of Business Economics, Health and Social Care, University of Applied Sciences and Arts of Southern Switzerland, SUPSI, Manno, Switzerland

Correspondence: Alessandro Schneebeli

(alessandro.schneebeli@supsi.ch) - Rehabilitation Research Laboratory, Department of Business Economics, Health and Social Care, University of Applied Sciences and Arts of Southern Switzerland, SUPSI, Manno, Switzerland

Archives of Physiotherapy 2016, 6(Suppl 1):P38

\section{Background and aim}

Myofascial pain syndrome (MPS) is defined as a regional pain characterized by the presence of one or more myofascial trigger point. Different 
treatments are currently available for MPS but there is no consensus in the literature on the best therapy approach. RCT are considered the gold standard for determining the cause and effect relationship between interventions and outcomes and allow to assess the effectiveness of different treatments. The present study aims to describe the reported quality of RCTs indexed in PEDro for MPS.

Materials and methods

A literature search was performed using PEDro database in December 2014. Pre-defined search strategies were designed to identify published RCTs aimed to investigate the efficacy of at least one physiotherapy intervention for MPS. PEDro scale was used to assess the methodological quality. Two reviewers extracted year of publication and PEDro score for the selected RCTs. The relationship between trial quality and time was evaluated using regression analyses for the PEDro total score.

Results

A total of 557 records were retrieved from search strategies and data from 170 RCTs for MPS published between 1978 and 2014 were analysed. The mean $( \pm S D)$ total PEDro score was $5.5 \pm 1.6$, with half of the included RCTs ranging from 5 to 6 . The number of RCTs for MPS and the average PEDro score increased over time. The total PEDro score was related to time, with the total PEDro score increasing by an average of 0.315 points every five years between 1978 and 2014 (Fig. 25). Discussion and conclusion

The number of RCTs for MPS increased considerably in the last decade. The overall reported methodological quality of RCTs for MPS is moderate although a trend toward an improvement of methodological quality can be noticed. Further improvement is necessary to both improve the validity of systematic reviews and to inform clinical practice.

\section{References}

1. Simons DG, Travell JG, Simons LS. Travell and Simons' Myofascial Pain and Dysfunction: The Trigger Point Manual. Volume 1 Upper Half of Body. 2nd ed. Baltimore, MD: Williams \& Wilkins; 1999.

2. Simons DG. New views of myofascial trigger points: etiology and diagnosis. Arch Phys Med Rehabil. 2008 Jan;89(1):157-9

3. Gerwin RD. Diagnosis of myofascial pain syndrome. Phys Med Rehabil Clin N Am. 2014; 25(2):341-55.

\section{Acknowledgements}

This study was supported by the Thim van der Laan Foundation, Landquart, Switzerland.

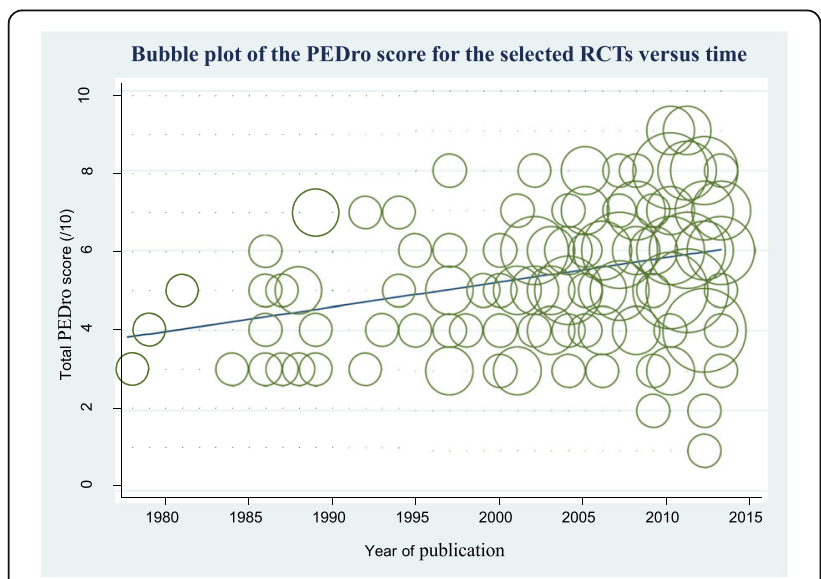

Fig. 25 (abstract P38) Bubble plot of the total PEDro score for the selected RCTs vs. time.
P39

Is the patellar pubic percussion test useful to diagnose only femur fractures or something else? Two case reports

Segat $\mathrm{M}^{1}$, Casonato $\mathrm{O}^{2,3,4}$, Margelli $\mathrm{M}^{5,6,7}$, Pillon $\mathrm{S}^{8}$

${ }^{1}$ Private practitioner in Vittorio Veneto, Treviso, Italy; ${ }^{2}$ Private practitioner in Oderzo, Treviso, Italy; ${ }^{3}$ Department of Molecular Medicine, Padua University, Padua, Italy; ${ }^{4}$ Department of Medicine, Surgery and Neurosciences, Siena University, Siena, Italy; ${ }^{5}$ Private Practitioner in San Martino, Ferrara, Italy; ${ }^{6}$ Department of Molecular Medicine, Padua University, Padua, Italy; ${ }^{7}$ Department of Clinical and Translational Medicine, Tor Vergata University, Rome, Italy; ${ }^{8}$ Ulss7, Vittorio Veneto, Treviso, Italy

Correspondence: Segat M (segat.marco@gmail.com) - Private practitioner in Vittorio Veneto, Treviso, Italy Archives of Physiotherapy 2016, 6(Suppl 1):P39

In this abstract the authors describe the utility of the Patellar Pubic Percussion Test (PPPT) to diagnose a pelvis fracture in two patients who had a negative pelvis and femur x-ray after a fall. This study has been published as a full-text article after the 5th S.I.F. Congress [1]. Authors' information

OC: Adjunct Professor Master in Manual Therapy and Musculoskeletal Rehabilitation, Department of Molecular Medicine, Padua University, Padua, Italy. Adjunct Professor Master in Sports Physiotherapy, Department of Medicine, Surgery and Neurosciences, Siena University, Siena, Italy.

MM: Clinical Tutor Master in Manual Therapy and Musculoskeletal Rehabilitation, Department of Molecular Medicine, Padua University, Padua, Italy. Adjunct Professor Master Manual Therapy applied to Physiotherapy, Department of Clinical and Translational Medicine, Tor Vergata University, Rome, Italy.

References

1. Segat M, Casonato O, Margelli M, Pillon S. Is the patellar pubic percussion test useful to diagnose only femur fractures or something else? Two case reports. Man Ther. 2016 Feb;21:292-6.

\section{P40}

Effectiveness of new rehab method for MDI

Spunton V, Fenini R, Garofalo R, Conti M

Private practice, Milan, Italy

Correspondence: Spunton V (valentina.spunton@gmail.com) - Private practice, Milan, Italy

Archives of Physiotherapy 2016, 6(Suppl 1):P40

\section{Background}

MDI Rehabilitation is generally considered a difficult task with great relevance for the proprioception recovery, but no clear methods are recognized to approach this crucial aspect. Increased understanding of the cortical changes observed with functional MRI analysis potentially offers opportunities for novel treatment methods to re-stabilize the shoulder. Suggestions to integrate cognitive aspects come from studies on "action observation treatment" and "graded motor imagery".

Target

This study report preliminary results from a pilot study on the use of a new standardized rehab method focused on enhancing proprioceptive GH and ST proprioceptive control, to be added to the strength recovery: the so called Ha-t-Ha (Hand to Hand) method.

Method

A preliminary group of 6 patients (22 28 years old) suffering of MDI were assessed with DASH, WOSI and SPADI questionnaires before and 8 months $( \pm 2.5)$ after a strength recovery, integrated by home based daily $\mathrm{Ha}-\mathrm{t}-\mathrm{Ha}$ exercises. The $\mathrm{Ha}-\mathrm{t}-\mathrm{Ha}$ method is based on standardized sequences of exercises with every 3 wks increasing difficulty scale (hand to hand closed chain open eyes, hand to hand 
closed chain closed eyes, hand front to hand open chain slow and then fast motion)

Results

Post rehab results shows a decrease of $63 \%$ (from 46,7 to 17,2 ) and $65,6 \%$ (from 61,5 to 21,2 ) of DASH and SPADI functional limitation score respectively and the increase of $154 \%$ (from 29,7 to 75,3 ) of the WOSI index score. VAS of patients appreciation was 9,2 (scale $0-10)$. Patients evaluation of relevance of video recording for home implementation was 9/10.

Conclusion

Ha-t-Ha method seems to be effective in the MDI rehab. A second phase comparing larger number of patients rehabilitated with or without the Ha-t-Ha method is needed to assess the plus value of the system.

P41

Toe walking and autism: cross-sectional study on clinical presentation patterns and correlation with language delay Valagussa G, Balatti V, Trentin L, Melli S, Norsi M, and Grossi E Autism Research Unit, Villa Santa Maria Institute, Tavernerio, Italy Correspondence: Valagussa G (giulio.valagussa@gmail.com) - Autism Research Unit, Villa Santa Maria Institute, Tavernerio, Italy Archives of Physiotherapy 2016, 6(Suppl 1):P41

\section{Background and objectives}

Till now there is no standardized clinical method of assessment of Toe walking (TW) in autism. Moreover, it seems that the persistence of toe walking can be related to language impairment ${ }^{1}$ even if systematic observations in the literature are poor. The aims of this cross-sectional study are: 1) to assess the prevalence of toe walking in an ASD cohort; 2 ) to describe the clinical patterns of presentation of TW; 3) to evaluate the relationship between TW presentation patterns and the severity of autism with particular regard to language delay.

\section{Materials and methods}

The study includes 73 consecutive children $(60$ males, 13 females; mean age $=14,7$ years) diagnosed with autism according to the DSM V criteria and under observation at our institute. A therapist assessed the presence of Tiptoe behavior (TTB) during standing, walking and running using direct observation and interview of the main caregiver living with the children. The severity of autism and the language delay severity was established using the ADOS (2nd version) assessment test.

Results

Overall: 23 children $(31,51 \%)$ presented TTB. Ten children $(13,70 \%)$ exhibited it while standing, walking and running (class 1 ), six $(8,22 \%)$ only during walking and running (class 2$)$ and seven children $(9,59 \%)$ only during running (class 3$)$. The ADOS mean scores of non TTB children (20.32 (5.39 SD)) and of TTB children (23.39 (5.35)) were not significantly different. Otherwise there were no significant differences in the mean overall ADOS score of the TTB children according to the three TTB classes. Instead we found that language delay severity was correlated with the presence of TTB ( $p<0.05$ ).

\section{Discussion}

At our knowledge, this is the first study that shows the presence of three different pattern of presentation of TW in ASD patients and that analyzes and finds a relationship between TTB and severity of language delay.

Conclusions

TTB frequently manifests itself in individuals with Autism. It may occur in three mutually exclusive modalities, which include what is commonly defined toe walking. The presence of TTB is correlated to language delay severity.

\section{References}

1. Accardo PJ, Barrow W. Toe walking in autism: further observations. J Child Neurol. 2015; 30(5): 606-609.
Table 18 (abstract P41) Language levels according to the ADOS system

\begin{tabular}{lllll}
\hline & $\begin{array}{lll}\text { Class 1 } \\
\left(\mathrm{N}^{\circ} 10\right)\end{array}$ & $\begin{array}{l}\text { Class 2 } \\
\left(\mathrm{N}^{\circ} 6\right)\end{array}$ & $\begin{array}{l}\text { Class 3 } \\
\left(\mathrm{N}^{\circ} 7\right)\end{array}$ & $\begin{array}{l}\text { No TTB } \\
\left(\mathrm{N}^{\circ} 50\right)\end{array}$ \\
\hline Absence of language & $70 \%$ & $66,6 \%$ & $71,4 \%$ & $46 \%$ \\
Single words & $30 \%$ & $44,4 \%$ & $14,3 \%$ & $36 \%$ \\
Simple sentences & $0 \%$ & $0 \%$ & $14,3 \%$ & $12 \%$ \\
Fluent & $0 \%$ & $0 \%$ & $0 \%$ & $6 \%$ \\
\hline
\end{tabular}

P42

Active Kyphosis Value (AKV): a new test for the evaluation of the kyphotisation mobility of the thoracic spine

Massimiliano Vanossi, Francesco Saveri, Michele Romano

ISICO, Istituto Scientifico Italiano Colonna Vertebrale, Milan, Italy

Correspondence: Francesco Saveri (francesco.saveri@isico.it) - ISICO,

Istituto Scientifico Italiano Colonna Vertebrale, Milan, Italy

Archives of Physiotherapy 2016, 6(Suppl 1):P42

\section{Introduction}

Given the natural tendency of the scoliotic thoracic spine to change its orientation towards the flattening, the reliability of assessment of sagittal plan mobility is more and more important. The plumb line distances and the inclinometer angles represent a set of important information but does not allow to obtain objective data about the dynamics of this portion of the spine. The aim of the study is to verify the repeatability and reproducibility of a new test for sagittal plane measure

Design

Test retest study.

Methods

A specific test has been developed to measure the mobility of the thoracic spine in the sagittal plan. The AKV (Active Kyphosis Value) is performed with the patient in all fours. Using a statometer it is possible to measure the height of a reference point of the spine parallel to the floor and in an aligned position. We can compare this value with the same point of the spine in a maximum kyphotisation position, calculating the difference by subtraction. Population: 50 subjects (39 females and 11 males), age 11.4-13.7 years (mean 12.1). The measurements are performed twice by two different blinded physiotherapists. Statistical analysis is performed by an independent operator. The statistical analysis was performed with the Bland and Altman method, a test used to assess agreement with repeated measures.

Results

Repeatability assessment: mean value of the first series of measurements $=8.134$; mean value of the second series of measurements $=8.126$; mean of differences $=0.04$ (SD 0.96); confidence interval $=1.83 /-1.93$. Reproducibility assessment: mean of differences $=0.20$ (SD 1.91); confidence interval $=3.55 /-3.99$.

Discussion

The low reliability of the results in the reproducibility assessment indicates that an adequate training is necessary for the operators performing the test. Also for this reason, in the follow in time we will evaluate another more valid methods for the data collection.

\section{Conclusion}

The results of the study allow the clinical use of the test even if further research is needed to assess the sensitivity.

\section{P43}

Pain Drawing and psychological distress in low back pain systematic review and meta-analysis

Carla Vanti ${ }^{1}$, Sara Taioli ${ }^{1}$, Ivan Gardenghi ${ }^{1}$, Lucia Bertozzi ${ }^{1}$, Anna Rosso ${ }^{2}$, Antonio Romeo ${ }^{2}$, Paolo Pillastrini ${ }^{1}$

${ }^{1}$ Department of Biomedical and Neuromotor Sciences, University of Bologna, Bologna, Italy; ${ }^{2}$ Department of Molecular Medicine, University of Padova, Padova, Italy

Correspondence: Carla Vanti (carla.vanti@unibo.it) - Department of Biomedical and Neuromotor Sciences, University of Bologna, Bologna, Italy Archives of Physiotherapy 2016, 6(Suppl 1):P43 
In this oral communication the authors describe the results of a systematic review aimed at estimating the accuracy of pain drawing (PD) in identifying psychological distress in people with subacuyte or chronic low back pain. The study has been published as a full-text article after the 5th S.I.F. Congress [1]. Based on the 7 studies included in the review, the authors concluded that the current evidence does not support the accuracy of PD in detecting psychological distress in this population.

\section{References}

1. Bertozzi L, Rosso A, Romeo A, Villafañe $\mathrm{JH}$, Guccione AA, Pillastrini P, Vanti C. The accuracy of pain drawing in identifying psychological distress in low back pain - systematic review and meta-analysis of diagnostic studies. J Phys Ther Sci. 2015;27:3319-24.

P44

Responsiveness of the Oswestry Disability Index in symptomatic lumbar spondylolisthesis

Carla Vanti ${ }^{1}$, Silvano Ferrari ${ }^{2}$, Martina Ruggeri ${ }^{1}$, Marco Monticone ${ }^{3}$

${ }^{1}$ School of Physiotherapy, Department of Biomedical and Neuromotor

Sciences, University of Bologna, Bologna, Italy; ${ }^{2}$ Master of Manual

Therapy and Musculoskeletal Rehabilitation, Molecular Medicine,

Department of Human Anatomy, University of Padova, Padova, Italy;

${ }^{3}$ Physical Medicine and Rehabilitation Unit, Salvatore Maugeri

Foundation, IRCCS, Lissone (Monza Brianza), Italy

Correspondence: Carla Vanti (carla.vanti@unibo.it) - School of

Physiotherapy, Department of Biomedical and Neuromotor Sciences,

University of Bologna, Bologna, Italy

Archives of Physiotherapy 2016, 6(Suppl 1):P44

\section{Background and objective}

The Oswestry Disability Index (ODI) is one of the most widely used questionnaires measuring Low Back Pain-related disability. The responsiveness of the ODI Italian version (ODI-I) was investigated in subjects complaining of non-specific LBP, however to date no study was made on other clinical conditions. This study aimed to investigate the responsiveness and the minimum important change of the ODI-I in subjects with lumbar spondylolisthesis (SPL).

Materials and methods

151 patients with symptomatic SPL completed the ODI-I, the 0-100 Numerical Rating Scale (NRS), and performed the Prone and the Supine Bridge Tests to measure lumbar muscles endurance, pre- and posttreatment. The global perception of effectiveness was measured with a 7-point Likert scale. Responsiveness was assessed by distribution methods [Minimum Detectable Change (MDC); Effect Size (ES); Standardized Response Mean (SRM)] and anchor-based methods (ROC curves).

Results

The mean number of sessions was $8 \pm 2$ and the mean duration of the treatment was $2 \pm 1$ months. The main ODI score pre-treatment was $22.8 \pm 12.9$ and the main post-treatment change was $-10.7 \pm 0.9$. All other outcome measures (NRS, PBT, and SBT) showed statistically significant improvements after the period of treatment. The MDC was 4.23; the ES was 0.95 and the SRM was 1.25 ; ROC analysis revealed an area under the curve of 0.76 thus indicating moderate discriminating capacity; the best cut-off point for the dichotomous outcome was 7.5 (sensitivity $90.3 \%$ and specificity $56.7 \%$ ).

Discussion

The main ODI-I score and the main post-treatment changes were similar with those calculated in another study on SPL subjects; the changes in ODI-I scores are in line with the minimum important change proposed in literature (a reduction of 10 points, or a decrease of $30 \%$ compared to baseline). The changes in ODI-I score appeared also significantly related to the amount of perceived improvement and were coherent with the changes in the other outcome measures, concerning lumbar pain and muscular endurance.

Conclusions

Our results showed a relevant and comparable effect of the treatment on the ODI-I score. The ODI-I proved to be responsive in detecting changes after physical therapy treatment in subjects with lumbar SPL.

\section{References}

1. Fairbank JCT, Pynsent PB. The Oswestry Disability Index. Spine 2000; 25(22): 2940-2953
2. Ostelo RW, Deyo RA, Stratford P, Waddell G, Croft P, Von Korff M et al Interpreting Change Scores for Pain and Functional Status in Low Back Pain. Towards International Consensus Regarding Minimum important change. Spine. 2008;33(1): 90-94

3. Monticone $M$, Baiardi $P$, Ferrari S, Foti $C$, Mugnai $R$, Pillastrini $P$ et al. Development of the Italian version of the Oswestry Disability Index (ODI-I): A cross-cultural adaptation, reliability, and validity study. Spine. 2009; 34(19): 2090-5.

4. Monticone M., Baiardi P., Vanti C., Ferrari S., Pillastrini P., Mugnai R et al. Responsiveness of the Oswestry Disability Index and the Roland Morris Disability Questionnaire in Italian subjects with sub-acute and chronic low back pain. Eur Spine J. 2012;21(1):122-9.

5. Schellenberg KL, Lang JM, Chan KM, Burnham RS. A clinical tool for office assessment of lumbar spine stabilization endurance. Am J Phys Med Rehabil. 2007;86 (5):380-386.

Table 19 (abstract P44) Responsiveness of NRS (Numerical Rating Scale) and ODI-I (Oswestry Disability Index, Italian version)

\begin{tabular}{llll}
\hline & Total & Improved & $\begin{array}{l}\text { Not } \\
\text { improved }\end{array}$ \\
\hline NRS & & & \\
Minimum Detectable Change (MDC) & 9.77 & 7.98 & 9.75 \\
Effect Size (ES) & 1.15 & 1.29 & 0.65 \\
Effect Size (Guyatt) & 1.25 & 1.41 & 0.65 \\
Standardised Response Mean (SRM) & 1.21 & 1.38 & 0.65 \\
Optimal cut-off point (AUC; sensitivity; & 17.5 & & \\
specificity) & $(0.85 ; 90.3 ; 37.5)$ & & \\
ODl-I & & & \\
Minimum Detectable Change (MDC) & 5.72 & 4.23 & 8.14 \\
Effect Size (ES) & 1.0 & 0.95 & 0.15 \\
Effect Size (Guyatt) & 0.87 & 0.86 & 0.15 \\
Standardised Response Mean (SRM) & 1.0 & 1.25 & 0.17 \\
Optimal cut-off point (AUC; sensitivity; & 7.5 & & \\
specificity) & $(0.76 ; 90.3 ; 56.7)$ & & \\
\hline AUC Area Under (ROC) Curve & & &
\end{tabular}

AUC Area Under (ROC) Curve

168 subjects with symptomatic lumbar Spondylolisthesis were assessed

15 subjects were excluded:

-5 had inflammatory spinal disease

- 3 had peripheral neuropathy

-5 had previous spinal surgery

- 2 had lumbar stenosis

153 subjects with symptomatic lumbar Spondylolisthesis remained

2 subjects did not sign the informed consent

151 subjects participated to the study

Fig. 26 (abstract P44) Flow-chart 
P45

The relationship between instability tests, pain and disability in non-specific low back pain

Carla Vanti ${ }^{1}$, Bellini Filippo ${ }^{1}$, Cristina Conti ${ }^{1}$, Federica Faresin ${ }^{1}$, Martina Ruggeri ${ }^{1}$, Raffaella Piccarreta ${ }^{3}$ Silvano Ferrari ${ }^{2}$

${ }^{1}$ School of Physiotherapy, Department of Biomedical and Neuromotor

Sciences, University of Bologna, Bologna, Italy; ${ }^{2}$ Master of Manual

Therapy and Musculoskeletal Rehabilitation, Molecular Medicine,

Department of Human Anatomy, University of Padova, Padova Italy;

${ }^{3}$ Department of Decision Sciences, L. Bocconi University, Milan, Italy

Correspondence: Carla Vanti (carla.vanti@unibo.it) - School of

Physiotherapy, Department of Biomedical and Neuromotor Sciences,

University of Bologna, Bologna, Italy

Archives of Physiotherapy 2016, 6(Suppl 1):P45

\section{Background and objective}

Clinical instability is considered one of low back pain (LBP) subgroups and can be recognized using tests evaluating lumbar stabilization during active or passive movements or measuring muscle endurance. Despite a recent systematic review confirmed that these tests may be recommended, at the current state of knowledge a complete investigation of their diagnostic accuracy is still needed. The aims of this study were: (1) to investigate the relationship between the clinical tests detecting spinal instability and the perceived pain and disability in non-specific low back pain (LBP); (2) to investigate the relationship between endurance and instability tests.

Materials and methods

101 subjects (57.4\% females, mean age 45.4 years) with nonspecific LBP were included in this study from June to December 2014. Four instability tests [aberrant movements, active straight leg raising (ASLR), prone instability test (PIT), and passive lumbar extension test (PLE)], and two endurance tests [prone bridge test (PBT) and supine bridge test (SBT)] were performed by three physical therapists with expertise in orthopaedic manual therapy. Their results were compared with the Numerical Rating Scale and the Oswestry Disability Index, evaluating pain and disability, respectively.

Results

AMs resulted positive in 55 subjects (54.7\%), ASLR in 61 (60.4\%), PIT in 35 (34.6\%), and PLE in 39 (38.6\%). The means (SD's) for the PBT and for the SBT were 24.32 (25.92) and 81.46 (65.36), respectively. A low to moderate significant relationship between pain, disability and all tests but PBT was observed. A low to moderate significant relationship between instability tests and endurance tests was shown. The results of PBT and SBT were significantly related to the duration of symptoms ( $p$-value $=0.0014 ; p$-value $=0.0203$, respectively).

Discussion

Our data evidenced the existence of a significant relationship between disability and all clinical tests. A similar relationship was found with the amount of pain for all tests, with the exception of PBT.

Conclusion

From a clinical point of view, more positive results on clinical instability tests may be expected in LBP subjects with higher level of disability or pain. The persistence of pain may significantly reduce anterior and posterior core muscles endurance.

\section{References}

1. Delitto A, George SZ, Van Dillen L, Whitman JM, Sowa G, Shekelle P, et al. Low back pain. Clinical Practice Guidelines linked to the International Classification of Functioning, Disability, and Health from Orthopaedic Section of the American Physical Therapy Association. J Orthop Sports Phys Ther. 2012;42:A1-A57.

2. Ferrari S, Manni T, Bonetti F, Villafane J, Vanti C. Clinical tests for lumbar instability in low back pain: validity and applicability in clinical practice. A literature review. Chiropr Man Therap. 2015 Apr 8;23:14.

3. Ferrari S, Vanti C, Piccarreta R, Monticone M. Pain, disability, and diagnostic accuracy of clinical instability and endurance tests in subjects with lumbar spondylolisthesis. J Manipulative Physiol Ther. 2014;37(9):647-659.

4. Rabin A, Shashua A, Pizem K, Dickstein R, Dar G. A Clinical Prediction Rule to Identify Patients With Low Back Pain Who Are Likely to Experience Short-Term Success Following Lumbar Stabilization Exercises: A
Randomized Controlled Validation Study. J Orthop Sports Phys Ther 2014;44(1):6-B13

5. Schellenberg KL, Lang JM, Chan KM, Burnham RS. A clinical tool for office assessment of lumbar spine stabilization endurance: prone and supine bridge maneuvers. Am J Phys Med Rehabil. 2007;86:380-6.

Table 20 (abstract P45) Relations Between Clinical Tests, Pain and Disability

\begin{tabular}{|c|c|c|c|c|c|c|c|}
\hline & \multicolumn{2}{|c|}{ Spearman Correlations } & \multicolumn{4}{|c|}{ Rank-biserial correlations } \\
\hline & & PBT & SBT & ASLR & PIT & PLE & AM \\
\hline \multirow[t]{2}{*}{ NRS } & coefficients & -0.168 & -0.296 & -0.241 & -0.501 & -0.348 & -0.306 \\
\hline & $p$-values & 0.0939 & 0.0026 & 0.0152 & $<.0001$ & 0.0004 & 0.0018 \\
\hline \multirow[t]{2}{*}{ ODI-I } & coefficients & -0.304 & -0.377 & -0.281 & -0.398 & -0.421 & -0.365 \\
\hline & $p$-values & 0.002 & 0.0001 & 0.0045 & $<.0001$ & $<.0001$ & 0.0002 \\
\hline
\end{tabular}

AM Aberrant Movements, ASLR Active Straight Leg Raise, NRS Numerical Rating Scale, ODI-I Oswestry Disability Index- Italian Version, PBT Prone Bridge Test, PIT Prone Instability Test, PLE Passive Lumbar Extension Test, SBT Supine Bridge Test

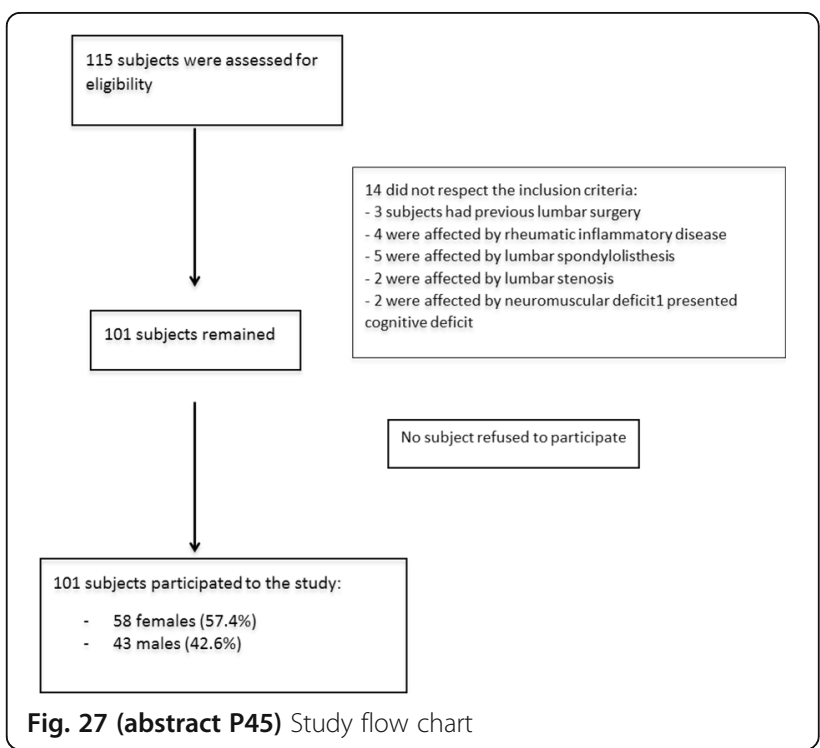

P46

Smartphone applications (apps) for physical therapists: a review Villanova Luca', Vercelli Stefano ${ }^{2}$

${ }^{1}$ School of Physiotherapy, University of Piemonte Orientale, Novara, Italy; ${ }^{2}$ Unit of Occupational Rehabilitation and Ergonomics, Salvatore Maugeri Foundation,IRCCS, Veruno (NO), Italy.

Correspondence: Villanova Luca (luca.villanova@nabhi.it) - School of Physiotherapy, University of Piemonte Orientale, Novara, Italy Archives of Physiotherapy 2016, 6(Suppl 1):P46

\section{Background and objectives}

The use of downloadable mobile applications (apps) in clinical practice is increasing, thanks to the widespread use of smartphones [1]. Usually, these apps are user-friendly, low expensive, and potentially they can bring important benefits to healthcare providers and patients. The aim of this study was to provide a review of clinician-oriented apps available for physical therapists, namely the apps intended for clinical use by healthcare providers, both for patient assessment and treatment [2]. Material and methods

A literature search was conducted on Medline database up to August, 2015. Only articles published in English were selected, without 
restriction of publication period. The search strategy is shown in Fig. 28. The bibliographies of the selected articles were then examined for additional relevant articles with the same characteristics. Papers dealing with apps not addressed to physical therapists, intended to provide reference or educational information, or apps that require the use of external devices, were excluded. For each app we synthetized the following characteristics: operating platform system, smartphone sensor used by the app, cost, description and intended use.

Results

The literature search produced initially 1365 articles, 57 of which were included in this review. Thirty-nine apps were classified into 6 different categories: balance (assessment or treatment; 5 apps), clinical tests (2 apps), gait analysis (9 apps), goniometric tools (18 apps), assessment of pain intensity ( $1 \mathrm{app})$, tremor assessment (4 apps). The characteristics of each app are reported in Table 21.

\section{Discussions}

To our knowledge, this is the first study that reviewed apps for a physical therapy intended use. Most of the apps have been proposed to be used as a measuring instrument -especially for range of motion measurement (ROM)- more than for the treatment. Quality (and quantity) of information available for each app is very heterogeneous: some of them have been subjected to a rigorous validation process from different research groups, while other lack of basic information such as name, cost, or sensor used.

\section{Conclusions}

This review synthesized the validated apps that physical therapists can use with confidence in clinical practice, both for patient assessment or treatment.

\section{References}

1. Milani P, Coccetta CA, Rabini A, Sciarra T, Massazza G, Ferriero G. Mobile smartphone applications for body position measurement in rehabilitation: a review of goniometric tools. PMR. 2014 Nov;6(11):1038-43.

2. Dicianno BE, Parmanto B, Fairman AD, Crytzer TM, Yu DX, Pramana G, et al. Perspectives on the evolution of mobile (mHealth) technologies and application to rehabilitation. Phys Ther. 2015;95(3):397-405.

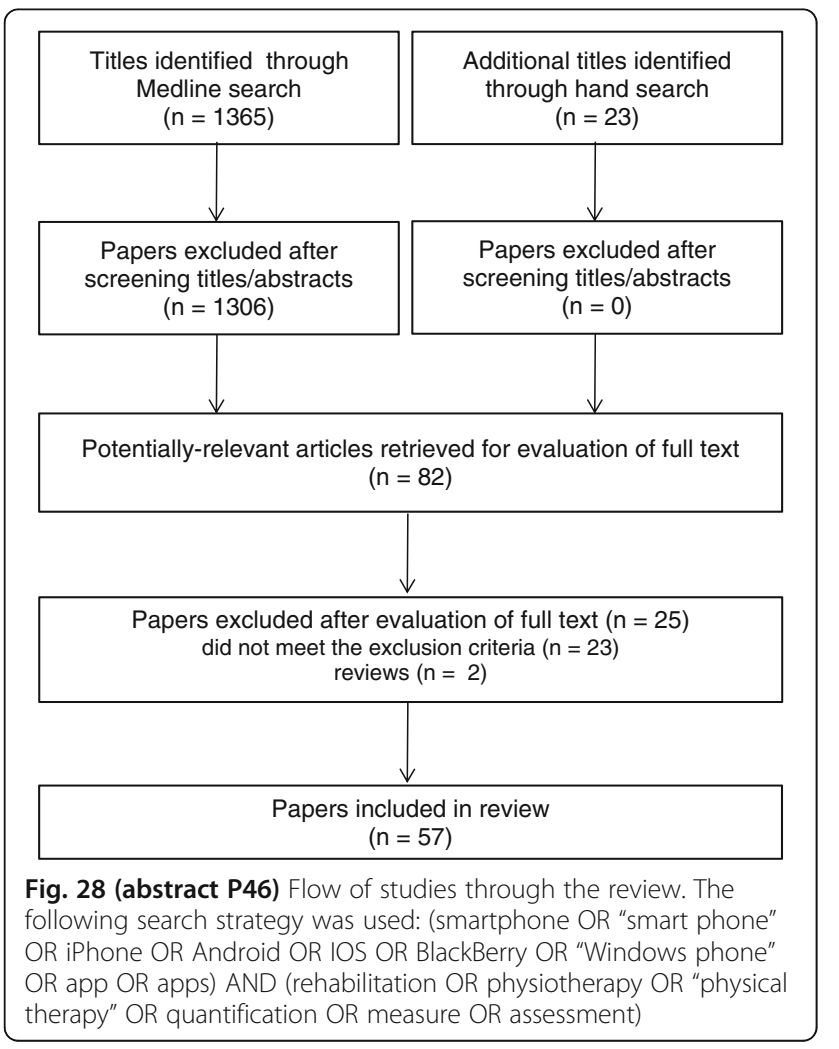

Table 21 (abstract P46) Characteristics of apps for physical therapists

\begin{tabular}{|c|c|c|c|c|c|}
\hline Authors & App & Platform & Sensor & Cost & Description \\
\hline \multicolumn{6}{|l|}{$\begin{array}{l}\text { Category: } \\
\text { Balance }\end{array}$} \\
\hline $\begin{array}{l}\text { Cerrito et al. } \\
\text { (2015) }\end{array}$ & - & Android & $\begin{array}{l}\text { Accelerometer } \\
\text { \& } \\
\text { magnetometer }\end{array}$ & - & $\begin{array}{l}\text { Measure the sit-to- } \\
\text { stand }\end{array}$ \\
\hline $\begin{array}{l}\text { Franco et al. } \\
\text { (2013) }\end{array}$ & iBalance-ABF & iOS & $\begin{array}{l}\text { Accelerometer, } \\
\text { gyroscope \& } \\
\text { magnetometer }\end{array}$ & - & $\begin{array}{l}\text { Balance training } \\
\text { through an integratec } \\
\text { and configurable } \\
\text { auditory-biofeedback } \\
\text { loop }\end{array}$ \\
\hline $\begin{array}{l}\text { Gefen et al. } \\
(2015)\end{array}$ & $\begin{array}{l}\text { iPhone } \\
\text { Balance } \\
\text { Application }\end{array}$ & iOS & Gyroscope & - & $\begin{array}{l}\text { Balance training by } \\
\text { interfering with the } \\
\text { anticipatory } \\
\text { processing of visual } \\
\text { information }\end{array}$ \\
\hline $\begin{array}{l}\text { Patterson et al. } \\
\text { (2014) }\end{array}$ & SWAY Balance & iOS & Accelerometer & Free & $\begin{array}{l}\text { Assessment of } \\
\text { balance }\end{array}$ \\
\hline $\begin{array}{l}\text { Galán-Mercant } \\
\text { et al. (2014) }\end{array}$ & xSensor Pro & iOS & Accelerometer & - & $\begin{array}{l}\text { Measure trunk } \\
\text { accelerations in the } \\
\text { Romberg Test }\end{array}$ \\
\hline
\end{tabular}

Category:

Clinical test

(2014)

Android

\& IOS

Accelerometer

\& gyroscope

Measure anterior tibial translation (Lachman

Williams et al. TiltMeter iOs

(2013); Yoon

OS

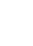

$$
\text { Free }
$$

App to perform the Weight Bearing unge Test and Trochanteric Prominence Angle Test.

Category: Gait

Capela et al.

(2015)

BlackBerry

Acceleromete gyroscope \& magnetometer

Measure the Six Minute Walk Test.

Isho et al. (2015)

Android

Accelerometer

Measure trunk accelerations during

Nishiguchi et al.

Android

Accelerometer

Gait analysis

Yamada et al.

(2012)

Android

Accelerometer

Gait analysis

Yang et al.

(2012)

Cheng et al.

(2013)

GaitTrack

Android

Accelerometer

Gait analysis

Measure the Six Minute Walk Test

Juen et al.

(2014)

Yamada et al.

(2011)

Mellone et al. UTUG

(2012)

Galán-Mercant

et al. (2013;

2014)

Category: Goniometrics

Johnson et al.

(2015)

Yan et al. (2013) -

Android

Quek et al. (2014) -

Jenny (2013) Angle

Shin et al. (2012); Clinometer

Shin et al. (2012

Laflamme et al.

(2013); Werner

et al. (2013; 2014)
Magnetometer

Magnetometer

Android

Accelerometer \& magnetometer

iOS

Accelerometer

Android

Assess dual-tasking ability as prediction tool for risk of falls

Measure the Timed Up and Go Test

Ten Meters Extended Timed Get-Up-and-Go Test

Measure shoulder abduction

Measure shoulder ROM

Measure cervical ROM

Measure knee flexion

\& iOS

Android Measure cervica free, iOS shoulder ROM 
Table 21 (abstract P46) Characteristics of apps for physical therapists (Continued)

\begin{tabular}{|c|c|c|c|c|c|}
\hline $\begin{array}{l}\text { Jacquot et al. } \\
\text { (2012); Qiao } \\
\text { et al. (2012) }\end{array}$ & CobbMeter & iOS & Accelerometer & $8,99 €$ & $\begin{array}{l}\text { Measure the Cobb } \\
\text { angle on radiographs }\end{array}$ \\
\hline $\begin{array}{l}\text { Tousignant- } \\
\text { Laflamme et al. } \\
\text { (2013) }\end{array}$ & Compass & iOS & Magnetometer & Free & $\begin{array}{l}\text { Measure the cervical } \\
\text { ROM }\end{array}$ \\
\hline $\begin{array}{l}\text { Ferriero et al. } \\
\text { (2011; 2013); } \\
\text { Jeon et al. } \\
\text { (2013); Otter } \\
\text { et al. (2015) }\end{array}$ & DrGoniometer & iOS & Camera & $11,99 €$ & $\begin{array}{l}\text { Measure elbow, knee } \\
\text { and first } \\
\text { metatarsophalangeal } \\
\text { joint ROM }\end{array}$ \\
\hline $\begin{array}{l}\text { Mitchell et al. } \\
\text { (2014) }\end{array}$ & GetMyROM & iOS & Accelerometer & $2,99 €$ & $\begin{array}{l}\text { Measure active } \\
\text { shoulder external } \\
\text { rotation }\end{array}$ \\
\hline $\begin{array}{l}\text { Wellmon et al. } \\
\text { (2015) }\end{array}$ & $\begin{array}{l}\text { Goniometer } \\
\text { Pro }\end{array}$ & $\begin{array}{l}\text { Android } \\
\text { \& iOS }\end{array}$ & Accelerometer & $14,99 €$ & Measure ROM \\
\hline $\begin{array}{l}\text { Wellmon et al. } \\
\text { (2015) }\end{array}$ & $\begin{array}{l}\text { Goniometer } \\
\text { Records }\end{array}$ & $\begin{array}{l}\text { Android } \\
\& \text { iOS }\end{array}$ & Accelerometer & $\begin{array}{l}\text { Free } \\
\text { demo }\end{array}$ & Measure ROM \\
\hline $\begin{array}{l}\text { Ege et al. (2013); } \\
\text { Walter et al. } \\
\text { (2013) }\end{array}$ & Hallux Angles & iOS & $\begin{array}{l}\text { Accelerometer } \\
\& \text { camera }\end{array}$ & Free & $\begin{array}{l}\text { Radiographic } \\
\text { measurements of } \\
\text { hallux valgus angle, } \\
\text { intermetatarsal angle, } \\
\text { and distal metatarsal } \\
\text { articular angle }\end{array}$ \\
\hline $\begin{array}{l}\text { Kolber et al. } \\
\text { (2013); Salamh } \\
\text { et al. (2014); } \\
\text { Vohralik et al. } \\
\text { (2014) }\end{array}$ & iHandy Level & iOS & Accelerometer & Free & $\begin{array}{l}\text { Measure ankle } \\
\text { dorsiflexion, lumbar } \\
\text { ROM and lordosis }\end{array}$ \\
\hline $\begin{array}{l}\text { Oihénart et al. } \\
\text { (2012) }\end{array}$ & iShould & iOs & $\begin{array}{l}\text { Accelerometer } \\
\& \text { gyroscope }\end{array}$ & - & $\begin{array}{l}\text { Functional } \\
\text { assessment of } \\
\text { shoulder }\end{array}$ \\
\hline $\begin{array}{l}\text { Hambly et al. } \\
\text { (2012); } \\
\text { Ockendon et al. } \\
\text { (2012); Milanese } \\
\text { et al. (2014) }\end{array}$ & $\begin{array}{l}\text { Knee } \\
\text { Goniometer }\end{array}$ & iOs & Accelerometer & $4,99 €$ & Measure knee ROM \\
\hline $\begin{array}{l}\text { Franko et al. } \\
\text { (2012); zatt et al. } \\
\text { (2012); Balg et al. } \\
\text { (2014); Qiao et al. } \\
\text { (2014) }\end{array}$ & Scoliogauge & iOs & Accelerometer & - & $\begin{array}{l}\text { Measure trunk } \\
\text { rotation in patients } \\
\text { with idiopathic } \\
\text { scoliosis. }\end{array}$ \\
\hline $\begin{array}{l}\text { Jones et al. } \\
\text { (2014) }\end{array}$ & $\begin{array}{l}\text { Simple } \\
\text { Goniometer }\end{array}$ & iOS & Accelerometer & $0,99 €$ & Knee ROM \\
\hline $\begin{array}{l}\text { Shaw et al. } \\
\text { (2012) }\end{array}$ & TiltmeterPro & iOs & - & - & $\begin{array}{l}\text { Measure the Cobb } \\
\text { angle on radiographs }\end{array}$ \\
\hline \multicolumn{6}{|l|}{ Category: Pain } \\
\hline $\begin{array}{l}\text { De la Vega et al. } \\
\text { (2014) }\end{array}$ & Painometer & $\begin{array}{l}\text { Android } \\
\& \text { iOS }\end{array}$ & - & Free & $\begin{array}{l}\text { Assess pain intensity } \\
\text { (Faces Pain Scale-- } \\
\text { Revised, Numerical } \\
\text { Rating Scale, } \\
\text { Coloured Analogue } \\
\text { Scale, Visual Analog } \\
\text { Scale) }\end{array}$ \\
\hline \multicolumn{6}{|l|}{$\begin{array}{l}\text { Category: } \\
\text { Tremor }\end{array}$} \\
\hline $\begin{array}{l}\text { Arora et al. } \\
\text { (2015) }\end{array}$ & - & Android & $\begin{array}{l}\text { Accelerometer, } \\
\text { voice recorder, } \\
\text { touch screen }\end{array}$ & - & $\begin{array}{l}\text { Detection and } \\
\text { monitoring of } \\
\text { symptoms of } \\
\text { Parkinson's disease }\end{array}$ \\
\hline $\begin{array}{l}\text { Daneault et al. } \\
\text { (2013) }\end{array}$ & - & BlackBerry & Accelerometer & - & $\begin{array}{l}\text { Detection and } \\
\text { monitoring of tremors }\end{array}$ \\
\hline $\begin{array}{l}\text { Joundi et al. } \\
\text { (2011) }\end{array}$ & iSeismo & iOS & Accelerometer & Free & $\begin{array}{l}\text { Measure frequency of } \\
\text { lower limbs tremor }\end{array}$ \\
\hline $\begin{array}{l}\text { Kostikis et al. } \\
\text { (2014) }\end{array}$ & iTremorSense & $\begin{array}{l}\text { Android } \\
\& \text { iOS }\end{array}$ & $\begin{array}{l}\text { Accelerometer } \\
\& \text { gyroscope }\end{array}$ & Free & $\begin{array}{l}\text { Measure hands } \\
\text { tremor }\end{array}$ \\
\hline
\end{tabular}

P47

A randomized controlled pilot trial of hand robotic training compared with a sensory-motor training program in post stroke patients

Violini Claudia', Cenci Marco Joseph ${ }^{2}$, Delconte Carmen ${ }^{3}$, Pisano Fabrizio ${ }^{4}$ ${ }^{1}$ School of Physiotherapy, University of L.U.de.S., Lugano, Switzerland;

${ }^{2}$ School of Physiotherapy, University of Insubria, Varese, Italy;

${ }^{3}$ Neurological Rehabilitation Division, Fondazione Salvatore Maugeri,

IRCCS, Veruno (NO), Italy; ${ }^{4}$ Head of Neurological Rehabilitation- Fondazione

Salvatore Maugeri, IRCCS, Veruno (NO), Italy

Correspondence: Violini Claudia (Email: claudiacv@live.it) - School of

Physiotherapy, University of L.U.de.S. Lugano, Switzerland

Archives of Physiotherapy 2016, 6(Suppl 1):P47

\section{Background and objective}

In recent years the use of robotics developed in functional recovery of the paretic limbs resulted a valuable instrument in the world of rehabilitation medicine [1]. In patients with acquired brain injury the robotic devices perform their role through the application of graduated forces on segments of the upper or lower limbs. Our study aims to compare the effectiveness of robotic intervention on the functional recovery of the hand with respect to the rehabilitation program based on a sensory- motor training protocol.

Material and methods

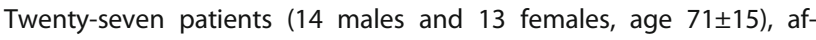
fected by ischemic or hemorrhagic stroke in a subacute phase, were recruited. Subjects were then randomly assigned to the two treatment groups. One group, Amadeo ${ }^{\oplus}$ Robotic System (ARS), underwent the treatment 1 hour/day, divided into two sessions, 5 days a week, with the robotic device (Tyromotion $\mathrm{GmbH}$ Graz, Austria); this robot determines flexion-extension movements of fingers with predetermined pattern. The other group, Sensory-Motor Training Protocol (SMTP), underwent for the same amount of time an intensive rehabilitation program articulated on 6 active and/or passive exercises, specifically designed for the hand. The total duration of treatment was three weeks. Evaluations have been performed on patients at the baseline (T0) and at the end of treatment (T1). Primary outcomes of the study were represented by the Fugl-Meyer (FM) and Motricity Index (MI) scores. Secondary outcomes were the Box and Block Test (BBT) [2], the Manual Muscle Test (MMT) [3] and the Modified Ashworth Scale (MAS) [4].

Results

Both groups presented statistical improvements in all scales scores without a statistically significant difference between the groups.

Discussion

Both groups showed a significant improvement at the $\mathrm{Ml}$, the FM and the BBT. These results demonstrate that the robotic rehabilitation with Amadeo $^{\circledR}$ was as effective as the sensory-motor protocol.

Conclusions

The most important advantage of robotic devices is the possibility to provide intensive, well tolerated, repetitive and interactive training without overburdening therapists.

\section{References}

1. Sale P, Mazzoleni S, Lombardi V, Galafate D, Massimiani MP, Posteraro F, Damiani C, Franceschini M. Recovery of hand function with robotassisted therapy in acute stroke patients: a randomized-controlled trial. Int J Rehabil Res. 2014 Sep;37(3):236-42

2. Mathiowetz V, Volland G, Kashman N, Weber K. Adult norms for the Box and Block Test of manual dexterity. Am J Occup Ther. 1985 Jun;39(6):386-91:

3. Daniels, K. and C. Worthingham, Muscle Testing Techniques of Manual Examination. 5 ed. 1986, Philadelphia: WB Saunders.

4. Bohannon, R. and Smith, M. Interrater reliability of a modified Ashworth scale of muscle spasticity. Phys Ther. 1987;67: 206. 
Table 22 (abstract P47) Baseline (T0) and post-treatment (T1) assessment and pre-post comparisons in the Sensory-Motor Training Protocol (SMTP) group and in the Amadeo ${ }^{\oplus}$ Robotic System (ARS) group

\begin{tabular}{|c|c|c|c|c|c|c|}
\hline & \multicolumn{3}{|c|}{ SMTP } & \multicolumn{3}{|l|}{ ARS } \\
\hline & TO & $\mathrm{T} 1$ & $p$ value & T0 & $\mathrm{T} 1$ & $p$ value \\
\hline $\mathrm{Ml}$ & 55.6 & 67.8 & 0.000110 & 53.4 & 65.0 & 0.000292 \\
\hline FMA & 31.3 & 44.3 & 0.000047 & 35.7 & 48.2 & 0.000009 \\
\hline MMT- upper limb & 21.4 & 28.8 & 0.000017 & 23.3 & 30.6 & 0.000034 \\
\hline MMT- hand & 3.8 & 6.8 & 0.000115 & 4.1 & 6.9 & 0.000003 \\
\hline BBT & 5.2 & 21.6 & 0.000015 & 6.1 & 15.1 & 0.001828 \\
\hline FIM & 58.4 & 83.1 & 0.000119 & 51.9 & 93.6 & 0.000005 \\
\hline MAS-shoulder & 0.0 & 0.0 & 1 & 0.2 & 0.3 & 0.334282 \\
\hline MAS-elbow & 0.2 & 0.7 & 0.007685 & $0-7$ & 0.7 & 1 \\
\hline MAS-wrist & 0.2 & 0.5 & 0.075304 & 0.5 & 0.6 & 0.472822 \\
\hline MAS-fingers & 0.0 & 0.2 & 0.172490 & 0.2 & 0.2 & 0.744309 \\
\hline
\end{tabular}

MI Motricity Index, FMA Fugl-Meyer Assessment, MMT Manual Muscle Test, BBT Box and Block Test, FIM Functional Independence Measure, MAS Modified Ashworth Scale

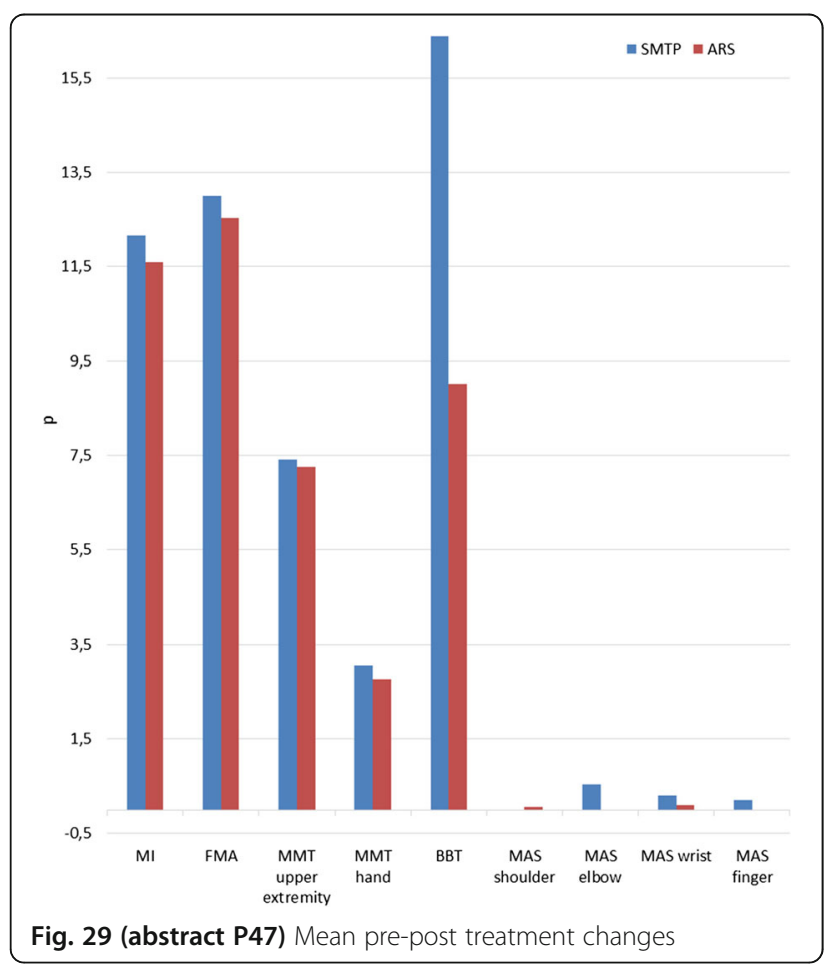

P48

Critical Illness PolyNeuroMyopathy (CIPNM): chance for a good prognosis

Youssef S, Montesano M, Picardi M, De Giampaulis P, Corbo M, Pisani L Department of Neurorehabilitation Sciences, Casa di Cura del Policlinico, Milano, Italy

Correspondence: Youssef S (saadyous@gmail.com) - Department of Neurorehabilitation Sciences, Casa di Cura del Policlinico, Milano, Italy Archives of Physiotherapy 2016, 6(Suppl 1):P48

\section{Background}

CIPNM is common complication of critical care and may cause severe weakness of limb and respiratory muscles $[1,3]$, impairing motor function and negatively affecting daily living and quality of life. When CIPNM is severe there may be little or no recovery $[2,4]$. In patients with CIPNM and mechanical ventilation for more than seven to ten days, the mortality increases from $19 \%$ up to $84 \%$. Moreover, at one-year follow-up only one out of four with CIP recovered [5]. Physical rehabilitation for patients with CIPNM may help recovery, improve activities of daily living, and prevent complications, although there are no published RCTs that confirm this assumption [2]. High quality evidence [2] seems to suggest early rehabilitation, but the most appropriate rehabilitation approach and its frequency and intensity are still undefined [4].

Patient and methods

We describe a 48 year old man, hospitalized in Intensive Care Unit for septic shock and multi-organ failure. During mechanical ventilation, he developed diffuse and marked weakness, and with electrophysiological support the diagnosis of severe CIPNM was made. One month from the onset of neuromyopathic symptoms, he started physical therapy in our rehabilitation Center. The rehabilitation treatment focused on strengthening of the lower limb and deep abdominal muscles with exercises of increasing difficulty (e.g. in supine and side positions, single leg bridge and standing position). Balance training, mobility training and activities to improve aerobic capacity were also included. Duration and frequency of exercise training were 45 minutes and twice a day for five times a week, respectively.

Results and conclusions

Despite his serious clinical and neurophysiologic conditions at onset, the studied patient with CIPNM showed a good and extraordinary functional recovery after a 3 months physical therapy program. The relation between the changes of electrophysiologic testing and the functional improvement exhibited by the patient as a result of the planned rehabilitation treatment for the severe polyneuromyopathy will be also presented and discussed. Our clinical description confirms the need for more evidence to guide the best practice in this neuromuscular disorder.

Consent for publication

The authors have written informed consent from the patient, and consent to publish. The relevant documents can be provided on request.

\section{References}

1. Fan E. Critical illness neuromyopathy and the role of physical therapy and rehabilitation in critically ill patients. Respir Care. 2012;57(6):933-44; discussion 944-6.

2. Mehrholz J, Pohl M, Kugler J, Burridge J, Mückel S. Physical rehabilitation for critical illness myopathy and neuropathy. Cochrane Database Syst Rev. 2014, Issue 1.

3. Latronico N, Bolton CF. Critical illness polyneuropathy and myopathy: a major cause of muscle weakness and paralysis. Lancet Neurol. 2011;10(10):931-41.

4. Hermans G, De Jonghe B, Bruyninckx F, Van den Berghe G. Clinical review: critical illness polyneuropathy and myopathy. Crit Care. 2008;12(6):238

5. Burtin C, Clerckx B, Robbeets C, Ferdinande P, Langer D, Troosters T, et al. Early exercise in critically ill patients enhances short-term functional recovery. Crit Care Med. 2009;37(9):2499-505.

P49

The EdUReP approach plus manual therapy for the management of insertional Achilles tendinopathy: a case study

Zanetta Anna ${ }^{1}$; Garzonio Fabiola ${ }^{2}$; Ruella Carolina ${ }^{3}$; Sartorio Francesco ${ }^{4}$

${ }^{1}$ Physiotherapist, private practice, Nebbiuno, Novara, Italy;

${ }^{2}$ Physiotherapist, private practice, Somma Lombarda, Varese, Italy;

${ }^{3}$ Physiotherapist, private practice, Vigevano, Pavia, Italy; ${ }^{4}$ Unit of Occupational Rehabilitation and Ergonomics, Salvatore Maugeri Foundation, IRCCS, Veruno (NO), Italy

Correspondence: Zanetta Anna (anna.zanetta1@gmail.com) -

Physiotherapist, private practice, Nebbiuno, Novara, Italy Archives of Physiotherapy 2016, 6(Suppl 1):P49

\section{Background \& objective}

Achilles tendinopathy is a common soft-tissue disorder that affects both athletes and active non-athletes, causing functional limitation 
and pain [1]. Depending on the exact site of the pain, Achilles tendinopathies can be subdivided into mid-portion and insertional (IAT). IAT accounts for about $20-25 \%$ of Achilles tendinopathies. ${ }^{2}$ Conservative approaches for treating IAT have proven poorly effective [2]. The Education, Unloading, Reloading, and Prevention (EdUReP) is an evidence-based theoretical model [3] that aims to reduce functional limitations and disability of patients with tendon disorders, but it has never been applied in a clinical setting. The aim of this study is to describe the application of EdUReP combined with InstrumentAugmented Soft Tissue Mobilization (I-ASTM) - a manual therapy that is believed to produce analgesic, vascular, and structural remodeling effects on soft tissues [4] - in the treatment of IAT.

Material and methods

A 51-year-old active man with left IAT for about 9 months reported severe pain that forced him to discontinue sports activities. The patient was previously unsuccessfully treated with a high-load eccentric training program. He then decided to undergo a comprehensive 2month rehabilitation program according to EdUReP (Table 23), including 8 sessions of I-ASTM (Fig. 30). Outcome measures were: Visual Analogue Scale (rating pain during Achilles tendon palpation test), Passive Straight Leg Raise test, Single Leg hop test, PatientSpecific Functional Scale, and Foot and Ankle Ability Measure.

Results

The patient achieved clinically significant results that persisted over a 6-month- long follow-up, in all outcomes, and resumed his usual sports activities without pain or limitations. An ultrasound scan showed the improvement in the tendon structure.

\section{Discussion}

The EdUReP incorporates a composite approach to IAT [5], treating the patient from a more global perspective; it treats not only the symptoms, but also addresses to causal factors of symptoms, including technical errors, poor biomechanics, and the impaired tendon structure.

\section{Conclusions}

This is the first study applying the EdUReP approach plus I-ASTM in a patient with IAT, and the results suggest that the comprehensive proposed approach might be effective in the treatment of patients with IAT. Further studies are warranted.

\section{Consent for publication}

The authors have written informed consent from the patient, and consent to publish. The authors also have consent to publish the photographs in Fig. 30. The relevant documents can be provided on request.

\section{References}

1. Alfredson $\mathrm{H}$, Lorentzon R. Chronic Achilles tendinosis: recommendations for treatment and prevention. Sports Med. 2000;29(2):135-146.

2. Roche AJ, Calder JD. Achilles tendinopathy: a review of the current concepts of treatment. Bone Joint J. 2013;95-B(10):1299-307.

3. Davenport TE, Kulig K, Matharu Y, Blanco CE. The EdUReP model for nonsurgical management of tendinopathy. Phys Ther. 2005;85(10):1093-103.
4. Hammer W. The effect of mechanical load on degenerated soft tissue. J Bodyw Mov Ther. 2008;12:246-56.

5. Reinking M. Tendinopathy in athletes. Phys Ther Sport. 2012;13:3-10.

Table 23 (abstract 49) Progression of training in EdUReP

\begin{tabular}{|c|c|c|c|c|c|}
\hline & $\begin{array}{l}\text { 1st- } 4 \text { th week } \\
\text { (Education and } \\
\text { Unloading } \\
\text { phase) }\end{array}$ & $\begin{array}{l}\text { 5th week } \\
\text { (Reloading } \\
\text { phase) }\end{array}$ & 6th week & 7th week & 8th week \\
\hline $\begin{array}{l}\text { Manual } \\
\text { Therapy }\end{array}$ & $30 \mathrm{~min}$ I-ASTM & $30 \mathrm{~min}$ I-ASTM & $30 \mathrm{~min}$ I-ASTM & $30 \mathrm{~min}$ I-ASTM & $30 \mathrm{~min}$ I-ASTM \\
\hline Stretching & $\begin{array}{l}4 \times 30 \mathrm{sec} \\
\text { bilateral static } \\
\text { stretching of } \\
\text { hamstrings, } \\
\text { triceps surae } \\
\text { and ileo-tibial } \\
\text { band }\end{array}$ & $\begin{array}{l}4 \times 30 \mathrm{sec} \\
\text { bilateral static } \\
\text { stretching of } \\
\text { hamstrings, } \\
\text { triceps surae } \\
\text { and ileo-tibial } \\
\text { band }\end{array}$ & $\begin{array}{l}4 \times 30 \mathrm{sec} \\
\text { bilateral static } \\
\text { stretching of } \\
\text { hamstrings, } \\
\text { triceps surae } \\
\text { and ileo-tibial } \\
\text { band }\end{array}$ & $\begin{array}{l}4 \times 30 \mathrm{sec} \\
\text { bilateral static } \\
\text { stretching of } \\
\text { hamstrings, } \\
\text { triceps surae } \\
\text { and ileo-tibial } \\
\text { band }\end{array}$ & $\begin{array}{l}4 \times 30 \mathrm{sec} \\
\text { bilateral static } \\
\text { stretching of } \\
\text { hamstrings, } \\
\text { triceps surae } \\
\text { and ileo-tibial } \\
\text { band }\end{array}$ \\
\hline $\begin{array}{l}\text { Stationary } \\
\text { bike }\end{array}$ & $\begin{array}{l}20 \min (100 \\
\text { watts, } 90-100 \\
\mathrm{rpm}, 120-140 \\
\mathrm{bpm})\end{array}$ & $\begin{array}{l}40 \text { min cross } \\
\text { training }^{a}\end{array}$ & $\begin{array}{l}40 \text { min cross } \\
\text { training }^{\text {a }}\end{array}$ & $\begin{array}{l}40 \text { min cross } \\
\text { training }^{\mathrm{a}}\end{array}$ & $\begin{array}{l}40 \text { min cross } \\
\text { training }^{\text {a }}\end{array}$ \\
\hline $\begin{array}{l}\text { Swimming } \\
\text { pool }(50 \mathrm{~m})\end{array}$ & - & $\begin{array}{l}10 \text { pools twice } \\
\text { a week }\end{array}$ & $\begin{array}{l}16 \text { pools twice } \\
\text { a week }\end{array}$ & $\begin{array}{l}20 \text { pools twice } \\
\text { a week }\end{array}$ & $\begin{array}{l}30 \text { pools twice } \\
\text { a week }\end{array}$ \\
\hline Treadmill & - & $20 \mathrm{~min}, 9 \mathrm{~km} / \mathrm{h}$ & $30 \mathrm{~min}, 11 \mathrm{~km} / \mathrm{h}$ & $30 \mathrm{~min}, 12 \mathrm{~km} / \mathrm{h}$ & $40 \mathrm{~min}, 14 \mathrm{~km} / \mathrm{h}$ \\
\hline
\end{tabular}

${ }^{a} 10^{\prime}$ at 100 Watts, $100-110 \mathrm{rpm}$ (revolution per minute) $+5^{\prime}$ at 150 Watts, 70 $\mathrm{rpm}+3^{\prime}$ at 200 Watts, $80 \mathrm{rpm}+2^{\prime}$ at 250 Watts, $90 \mathrm{rpm}$ (sequence repeated twice; heart rate training target: $120-140$ heart beats per minute)

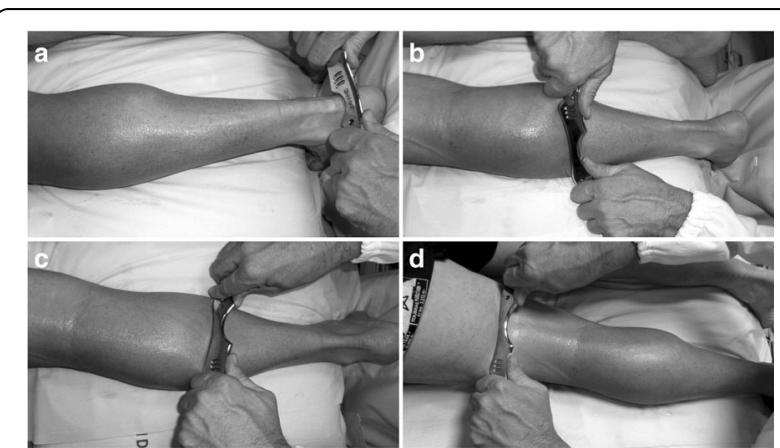

Fig. 30 (abstract P49) Instrument-assisted augmented soft-tissue mobilization technique applied to Achilles tendon (a), gastrocnemius (b), soleus (c) and hamstrings muscles (d)
Submit your next manuscript to BioMed Central and we will help you at every step:

- We accept pre-submission inquiries

- Our selector tool helps you to find the most relevant journal

- We provide round the clock customer support

- Convenient online submission

- Thorough peer review

- Inclusion in PubMed and all major indexing services

- Maximum visibility for your research

Submit your manuscript at www.biomedcentral.com/submit
Biomed Central 